\title{
A Rising Tide: Climate Change Programming for Teens in Aquariums and Zoos
}

A Thesis submitted to the faculty of

San Francisco State University

In partial fulfillment of

the requirements for

the Degree

Master of Arts

In

Museum Studies

by

Kathryn Joanne Papoulias

San Francisco, California

January 2022 


\section{Copyright by}

Kathryn Joanne Papoulias

2022 


\section{Certification of Approval}

I certify that I have read A Rising Tide: Climate Change Programming for Teens in Aquariums and Zoos by Kathryn Joanne Papoulias, and that in my opinion this work meets the criteria for approving a thesis submitted in partial fulfillment of the requirement for the degree Master of Arts in Museum Studies at San Francisco State University.

Edward M. Luby, Ph.D.

Professor,

Thesis Committee Chair

Lissette Jiménez, Ph.D.

Assistant Professor 


\title{
A Rising Tide: Climate Change Programming for Teens in Aquariums and Zoos
}

\author{
Kathryn Joanne Papoulias \\ San Francisco, California \\ 2022
}

Climate change is the most significant threat the world faces today, and museums, aquariums, and zoos are uniquely poised to educate the public about this threat using their collections. As the next generation of changemakers, teens are an ideal audience for climate change programs. This thesis examines climate change-specific programming and practices employed by museum educators in engaging teens. A literature review that studies how climate change is communicated, best practices in interpretation, learning theories, and conservation programming in museums, aquariums, and zoos, with a focus on teen learning, is first conducted. This is followed by three case studies of institutions with distinctive youth climate change programs; educators at each institution were interviewed as content experts. Several conclusions and recommendations are then presented. A major conclusion is that successful youth climate change programs are interactive, adaptable, empowering, and perhaps most importantly, solutions-based. 


\section{Acknowledgements}

These past several months I learned that writing a thesis about climate change during a pandemic while working full time and trying to maintain some level of sanity... well, it turns out it isn't easy.

My endless thanks go to the entire Museum Studies department, and especially to Dr. Edward Luby and Dr. Lissette Jiménez for their immense support, guidance, and words of encouragement.

Thank you to my friends and loved ones who read my rough drafts, forced me outside for fresh air and walks on the beach, gave me chocolate and coffee, and supported me throughout this journey.

Thank you to my momma, who sat me down as a little kid in front of the Outer Bay exhibit at the Monterey Bay Aquarium and helped me learn my first scientific name (Mola mola, the ocean sunfish, objectively the most wonderful fish in the world). Thank you for teaching me to always be kind, creative, and loving.

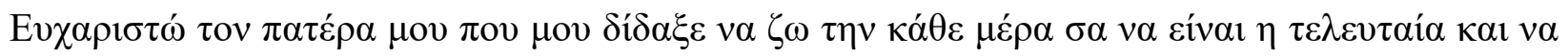

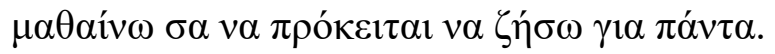

And thank you to the Earth. From the smallest Osedax worm at the bottom of the ocean to the towering redwood trees above, this is a pretty amazing place we call home.

At summer camp growing up, we learned to leave the park a better place when we go than it was when we got there. Whether that means picking up litter while on a hike, teaching a group of kids about local wildlife, or advocating for robust climate change legislation, I'll always keep trying to make the world a better place.

I hope you'll keep trying too. 


\section{Table of Contents}

List of Appendices.....................................................................................................................iii

CHAPTER 1: INTRODUCTION................................................................................................. 1

CHAPTER 2: CLIMATE CHANGE COMMUNICATION ................................................... 6

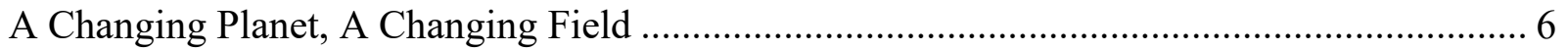

The Challenges of Communicating Climate Change........................................................... 9

Considerations in Interpretation and Framing Models ........................................................ 13

CHAPTER 3: EDUCATION IN MUSEUMS, AQUARIUMS, AND ZOOS .......................... 18

Development of Museum Education .............................................................................. 18

Conservation Education in Museums, Aquariums, and Zoos............................................. 24

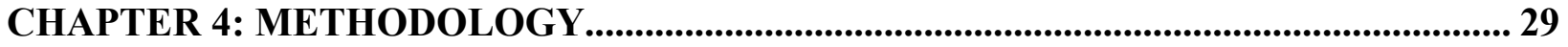

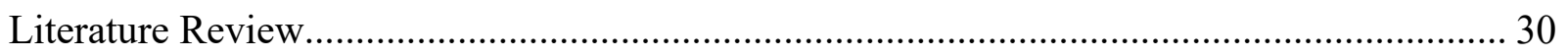

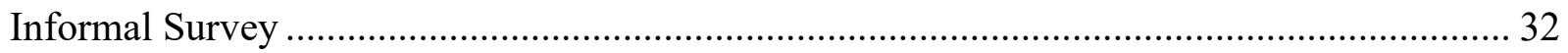

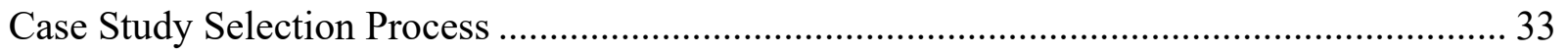

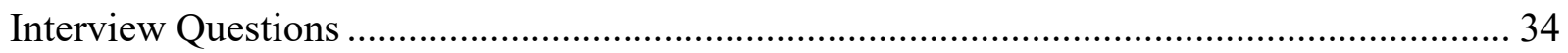

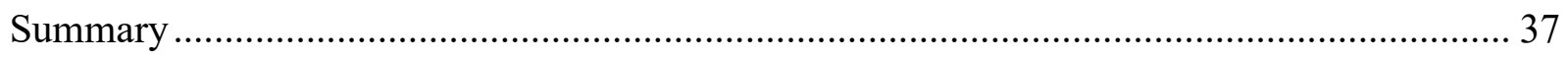

CHAPTER 5: SAN DIEGO ZOO WILDLIFE ALLIANCE ................................................. 38

Organization Background and Mission ...................................................................... 38

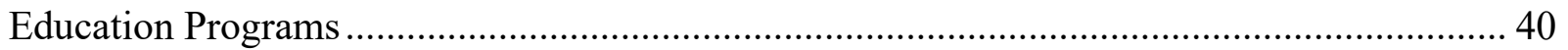

Climate Change Programming: "Polar Bear Bioacoustics and Energetics"........................... 43

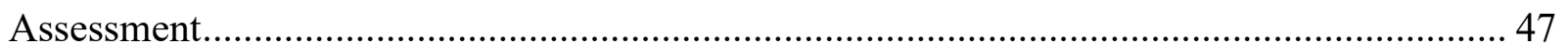

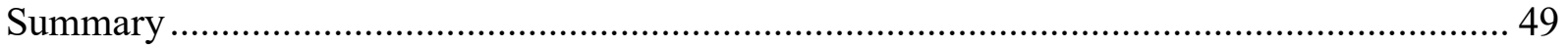

CHAPTER 6: NEW ENGLAND AQUARIUM ................................................................51

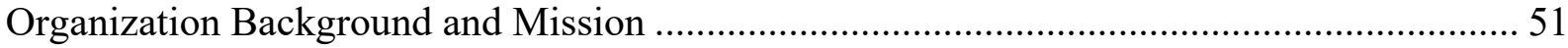

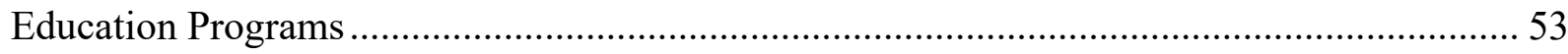

Climate Change Programming: "Blue Impact" ............................................................... 55

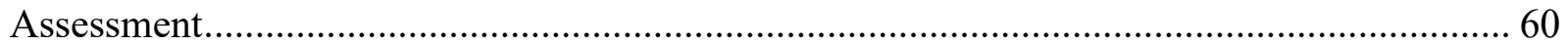

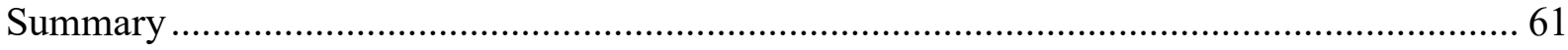

CHAPTER 7: MONTEREY BAY AQUARIUM............................................................ 63

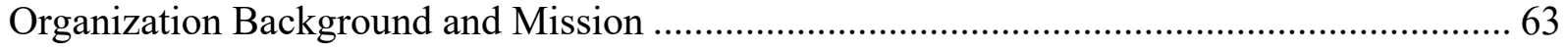

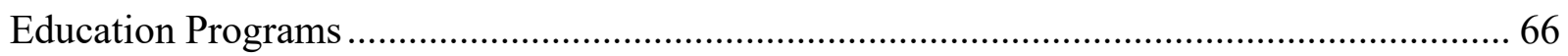

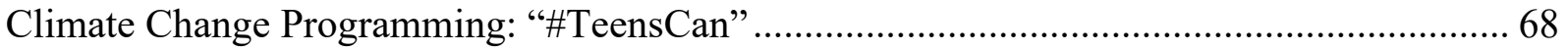




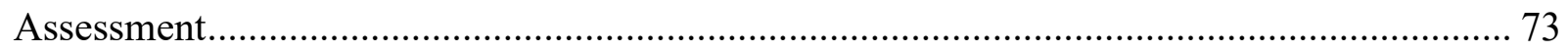

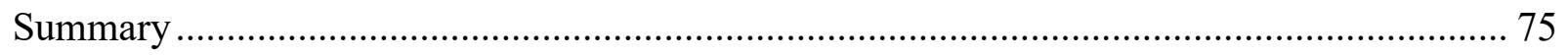

CHAPTER 8: DISCUSSION AND CONCLUSIONS .................................................. 76

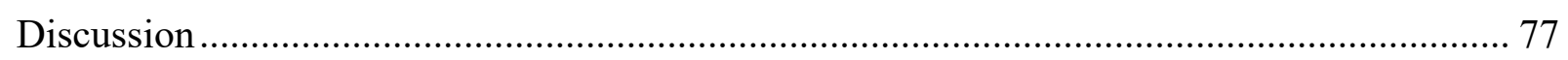

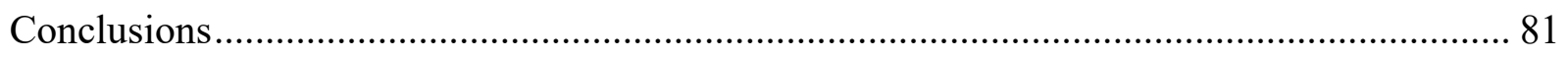

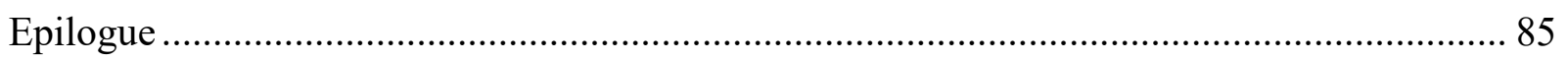

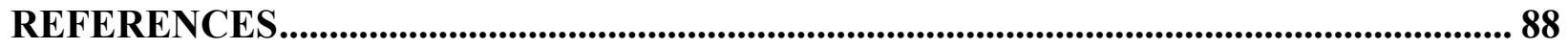




\section{List of Appendices}

Appendix A: San Diego Zoo Wildlife Alliance Website Sources............................................... 97

Appendix B: New England Aquarium Website Sources ................................................... 121

Appendix C: Monterey Bay Aquarium Website Sources .................................................. 143 


\section{CHAPTER 1: INTRODUCTION}

\section{In the end, we will conserve only what we love, we will love only what we understand, and we will understand only what we are taught.}

- Baba Dioum, Address to the IUCN (1968)

The world is facing many interconnected crises, thrown into stark relief more now than ever before. We are grappling with social unrest, reckoning with centuries of misogyny, racism, and homophobia, living through a global pandemic and an ongoing biodiversity crisis - all while the effects of climate change cause raging wildfires, intense hurricanes, soaring temperatures, and sudden cold snaps. Facing these entangled crises of social inequality and climate change, it is apparent that we are not doing enough as cultural institutions to build and support climate movements and foster community partnerships that tackle these deeply intertwined issues.

But why cultural institutions? Museums, aquariums, and zoos are places of education and are routinely rated as the most trusted institutions in the country, and are therefore positioned to use their reputations and collections to educate the public about the most urgent issue of our time - climate change. These institutions have "unique communicative, affective social qualities and promote intergenerational learning outside the classroom" and can use objects (including, but not limited to, natural history specimens and living collections) and immersive exhibitions to "facilitate an active role on the part of audiences in cocreating narratives around climate change"

(Cameron, Hodge, and Salazar 2013, 9). And these narratives cannot be reduced to simple graphs of the buildup of heat-trapping gases in the atmosphere over time or chemical equations that 
detail ocean acidification. It is essential that museums address the climate crisis as the intersectional issue that it is, and include community work and solutions in their conversations. In their 2013 article "Representing Climate Change in Museum Space and Places," Cameron, Hodge, and Salazar expounded on this issue:

Museums and science centers across the world are coming to terms with the idea that climate change should be presented as a story based on experiences worth listening to, not just as disembodied information without a storyteller. Ways of knowing about climate change cannot be disembodied as abstract information (as is often presented by the mainstream media), but must be rich in feeling, in intuition, and connected to larger social, historical, and ecological contexts. For this reason, community engagement is essential for museums. A politics of engagement must also include a serious concern for climate change education and literacy, a public pedagogy of climate change, which often does not take place through other cultural institutions (Cameron, Hodge, and Salazar 2013, 17).

Aquariums and zoos in particular are well-situated for climate change programming, as

visitors to these institutions are more likely to be attuned to and concerned about climate change than the general public (Kelly et al. 2014). Further, studies have shown that "feeling connected to animals at the zoo is significantly associated with cognitive and emotional responses to climate change" and that zoos present a "supportive social context for considering [climate change]" (Clayton et al. 2014, 460). And while these institutions excel at educational programming for young children, programming for teens is often limited to career-based internships or interpretive volunteering, with any conversations on climate change being tacked on the end as a "so what?" message rather than the main focus of the program. Museums, aquariums, and zoos are "leaders in conservation action" and have the opportunity to "foster the youngest animal advocates through training and experiences that may change their lives forever," and indeed the lives of 
others, by developing and engaging their youth in action-based climate change and conservation programming (Swanson and Joseph 2021, 6).

This thesis examines how museums, aquariums, and zoos can leverage their unique resources and collections to create effective, empowering climate change programming for teens. While research has been done, and is ongoing, on effective practices in interpreting challenging topics like climate change, museums lack a comprehensive toolkit and practical examples of how to successfully implement solutions-based climate change programming. To address this gap in knowledge, this thesis explores three central questions: 1) What climate change-specific programming exists for teens in museums, aquariums, and zoos?; 2) How prevalent is this programming?; and 3) What practices do these institutions employ that make this programming successful? In pursuit of answers to these questions, this study is supported by a literature review and case studies of three institutions that provide interactive, action-based climate change programs for teens.

A review of the literature is presented in Chapters 2 and 3. Chapter 2 reviews the challenges of communicating and interpreting climate change, followed by current best practices in interpretation and successful framing techniques. Teens were selected as a focus, because they are at a stage where they are gaining independence and more control over their lives and futures and have great potential to influence and impact their communities. Therefore, Chapter 3 discusses museum education and learning theories and conservation programming in museums, aquariums, and zoos, with a focus on teen learning. 
The methods used in this thesis are presented in Chapter 4. Key sources for the literature review, criteria for selecting the case study institutions and programs, and the interview questions asked and their purposes are outlined. Then, three case studies of institutions that offer climate change-specific programming for teens are presented: the San Diego Zoo Wildlife Alliance (SDZWA), the New England Aquarium (NEAq), and the Monterey Bay Aquarium (MBA). Each case study chapter consists of a background of the organization and their mission, a review of their education programs, followed by a focused study on their climate changespecific teen programming, and ending with a brief assessment and summary of the institution's efforts.

The thesis then closes with Chapter 8, which first analyzes the common features of the programs at all three case study institutions in relation to current best practices in climate change communication, museum education, and learning theories presented in the literature review. The chapter then ends with conclusions drawn from the analysis, and reflects upon the unique position museums, aquariums, and zoos hold as catalysts for conversations about climate change and as advocates for community-based solutions.

Climate change is the most significant threat the world faces today. Museums, aquariums, and zoos are uniquely poised to educate the public about this threat using their collections (including both living collections as well as natural history specimens). Unfortunately, there appears to be little programming focused on climate change in museums, and many institutions are unsure of best practices in creating these programs, particularly for youth. In examining three institutions with climate change-specific teen programming, this study analyzes what impacts 
these programs have and offers them as examples of a framework or inspiration for other organizations to follow.

Museums, aquariums, and zoos have the extraordinary ability to use their vast collections to tell stories — powerful stories. This capacity to weave stories from objects and construct new experiences through interpretation, exhibitions, and education programs gives museums a uniquely strong position from which to foster dialogue about climate change and join in community-oriented climate solutions. As examined in this thesis, how can museums, aquariums, and zoos rise to the most consequential challenge of our time and empower the next generation of changemakers? 


\section{CHAPTER 2: CLIMATE CHANGE COMMUNICATION}

While the scientific community has been discussing and investigating the effects of human-induced climate change since the late-1800s, communicating these facts to the general public is a more recent endeavor. Conversations on the causes and effects of climate change only entered mainstream public discourse in the 1990s, and in recent decades the focus has shifted from proving the impacts stem from human action to outlining strategies for mitigation and adaptation. Inherent in these strategies is the need to communicate the problems and possible solutions in a way that is engaging, accessible, and inspiring; here, the field of climate change communication and education is swiftly developing.

This chapter will explore the rapidly evolving field of climate change communication in three sections. First, a brief primer on climate change and a history of early communication methods will be outlined. Next, major challenges in communicating a field as complex and, at times, controversial as climate change will be introduced. This is followed by a list of considerations to have in mind when interpreting climate change, including audience make-up, and the chapter concludes with a review of framing models and primary resources in climate change communication today.

\section{A Changing Planet, A Changing Field}

Climate change has often been referred to simply as global warming, referencing the heat-trapping nature of our atmosphere and the ability of our oceans to act as heat sinks due to their high specific heat capacity; however, this oversimplification disregards the long-term impacts of temperature shifts. A better, broader definition of climate change is the "changes in 
[the] long-term pattern of temperature and precipitation" across the globe, with anthropogenic climate change generally being associated with the introduction of rampant levels of carbon dioxide in the atmosphere through the unrestrained use of coal, gas, and oil (Ennes 2020).

Scientists first began to ring the alarm bells on anthropogenic climate change in the late1900s, particularly with the establishment of the Intergovernmental Panel on Climate Change (IPCC). Founded in 1988 by the World Meteorological Organization (WMO) and the United Nations Environment Programme (UNEP), the IPCC is an intergovernmental body of the United Nations that produces regular reports on climate change. Their specific focus is in assessing and relaying scientific studies, technical research, and published papers to the world in order to inform policymakers on current and projected climate change impacts and possible adaptation responses or mitigation strategies (IPCC 2021).

Policymakers in the United States, however, have been dramatically divided on their responses to the climate crisis. Anthropogenic climate change became part of the national conversation in 1988 when Dr. James Hansen (then Director of the NASA Goddard Institute for Space Studies) declared in his testimony to Congress, “...the greenhouse effect has been detected, and it is changing our climate now" (Brulle 2018). Headlines splashed across major news outlets but behind closed doors, major misinformation campaigns funded by the fossil fuel industry had already begun. Climate models and projections were routinely dismissed as unreliable science, with current warming trends being downplayed and referred to as part of the Earth's normal warming and cooling trends. These campaigns permeated public consciousness despite the fact 
that fossil fuel executives were themselves actively researching the impacts of human-induced climate change on pipeline productivity and fueling operations (Jerving et al. 2015).

Things reached a head during the 2000 presidential election when climate change became firmly entrenched as a partisan issue, with Democrats being more likely to report being concerned about environmental issues and global warming and Republicans being more likely to dismiss concerns or assert that the climate crisis was being exaggerated (Worland 2017; Gilden and Peters 2017). However, climate change has recently become too obvious and dangerous to ignore; widespread wildfires, historic droughts, and extreme temperature fluctuations have demonstrated to most skeptics that the climate is not only changing, but changing rapidly. The latest report from the Yale Program on Climate Change Communication shows that most Americans now believe that climate change (referred to in the report as "global warming") is happening, with over $50 \%$ of people surveyed understanding that these changes are humancaused (Leiserowitz et al. 2021). Public discourse has shifted from denial to acceptance, and now most discussions are centered on what can and should be done. To that end, the communication and interpretation of climate change has emerged as a discipline in its own right, with an "almost exponential increase in the number of publications coming out every year on climate change communication" (Moser 2016). These publications often center on the challenges of communicating something as complex, alarming, emotional, and divisive as climate change, which will be outlined next. 


\section{The Challenges of Communicating Climate Change}

Although a majority of Americans (over 60\%) report being at least "somewhat worried" about climate change (and $25 \%$ reporting they are "very worried"), about $67 \%$ report that they "rarely" or "never" discuss it with friends and loved ones (Leiserowitz et al. 2021). Since conversations are happening less frequently when out with friends or around the dinner table, most Americans are left hearing about climate change from the media and news reports, which can be less than uplifting. A cursory glance at articles covering the latest IPCC report (the first part of the Sixth Assessment Report, Climate Change 2021: The Physical Science Basis, published August 9, 2021) reveals the key takeaway for most readers is overwhelming despair over unavoidable, disastrous impacts of anthropogenic climate change (e.g., Hirji 2021; Jericho 2021; Plumer and Fountain 2021). This feeling of existential dread is one of the many challenges

that make climate change uniquely difficult to interpret; in fact, an entire field of study has arisen based on the emotional labor and evidence of "climate anxiety" in both those who teach climate change and those who learn about it (Clayton 2020; Swim and Fraser 2013). Given this, it is important to be informed about the diverse challenges that come with communicating and interpreting climate change before developing effective communication strategies.

The major challenges that will be outlined in this section are the complexity of the issue, particularly given the low levels of scientific literacy and climate change understanding in the United States; climate change being seen as an "invisible" issue; the physically and temporally distant impacts of climate change; and the timescale between mitigation efforts and favorable results. 


\section{Complicated and Misunderstood}

Climate change is complex. There is inherent uncertainty when studying how interconnected systems will respond to changes in the environment, so while we do understand individual meteorological and oceanic patterns, it is not easy to predict the ways in which they will interact with fluctuating temperatures and atmospheric changes. In spite of these challenges, immense progress has been made in understanding changes in the climate thanks in part to more powerful computational software and modeling programs. This progress, however, is not always understood by the public.

Years of calculated misinformation campaigns have firmly entrenched the belief that there is "a lack of scientific consensus and greater uncertainty about the extent and causes of modern climate change, suggesting that a wait-and-see stance is the most responsible and scientifically justified course of action" (Moser 2010,35). This is especially alarming given the strikingly low levels of scientific literacy and climate understanding in the United States, especially among youth. A recent survey of 15 -year-old students in 54 countries found that the United States ranked near the bottom in a self-assessment of their awareness of environmental issues and their confidence in being able to explain those issues:

Even amongst 15 -year-olds, US students were significantly less likely to feel well informed about greenhouse gases than those in European countries. This is a stark finding. Compared with other countries, the US was identified in 2019 as 'one of the worst-performing countries' and worsening in 2020 in regard to both national and international policy. The policies and practices of different states and cities are not currently well aligned with the administration, which appears to promote skepticism towards anthropogenic causes of climate change and the withdrawal from the Paris agreement (Oliver and Adkins 2020, 6). 
Scientific literacy and critical thinking are of course crucial skills in general for a student, but especially so when it comes to work that must be done to address climate change at governmental, economic, and societal levels. As many educators have noted, "When citizens lack scientific literacy, they do not understand the links between their actions and potential impacts" (Tomovic, McKinney, and Berube 2017, 179). These high levels of scientific illiteracy, combined with the complicated, interconnected, and often unpredictable nature of climate change, make environmental issues uniquely difficult to interpret for the public in the United States.

An Invisible Crisis

The second challenge outlined in this section is that climate change is easily overshadowed by more immediate crises. Both the causes and effects of climate change are often not visible in our day-to-day lives. This is meant literally, since when fossil fuels such as coal, gas, and oil are used for energy, the carbon dioxide and other heat-trapping gases produced are invisible to the naked eye. Compounding this challenge is the fact that when those heat-trapping gases are produced, the impacts they have on the environment are not immediately seen. This leads to the third challenge: the physically and temporally distant impacts of climate change.

\section{Distant Impacts}

Perhaps the biggest roadblock in convincing the public that climate change is a real and present threat is that the impacts of it are spread disproportionately across the globe and are not immediately felt. Emissions take time to accumulate in the atmosphere, and it is often hard for individuals to differentiate short-term changes (e.g., daily weather) from long-term ones (e.g., 
climate patterns). It has taken decades of study for scientists to demonstrate conclusive evidence that human actions are driving changes in the climate above and beyond normal fluctuations; indeed, much of the data sets used in climate science come from studies over 30 years old (Rosenzweig et al. 2008). These studies show trends in physical data, e.g., warming ocean temperatures, sea level rise, and shrinking glaciers, as well as biological data, e.g., phenology studies that show plants blooming earlier in the spring and studies of museum collections that show changes in breeding patterns of birds in response to the climate change (Walther et al. 2002; Piao et al. 2019; Suarez and Tsutsui 2004; Dunn and Winkler 1999).

These trends, however, are often not felt in day-to-day life, leading many people to view climate change "as a real and current threat, but one that [affects] other people and places more than themselves" (Lee et al. 2020, 11). Polar bears are an example of this; used often as the poster child for climate change, the ubiquitous image of a polar bear on a melting ice floe has contributed to the view of climate change as a distant issue (O'Neill and Hulme 2009). Beyond the physical distance, even if individuals recognize that climate change is an issue, there is a commonly held belief that it will primarily affect people in the future, so there is less impetus to act on solutions today (Markowitz and Shariff 2012).

\section{Long-Term Solutions}

Paired with climate change as a long-term issue is the fact that it will require long-term solutions. As a species we tend to struggle with long timescales - there is always something more immediate that needs to be dealt with, like the current COVID-19 pandemic, and studies have suggested that we have a finite "worry budget" and experience "threat fatigue" (Bostrom et al. 
2020). Thus, there is little motivation to work on climate change solutions, especially when the results of those solutions are not immediately felt. As Moser (2010) notes,

The lags in the climate and social systems and the cumulative nature of emissions also make it difficult to see the link between taking mitigation action and seeing beneficial changes in the climate (such as a return to a more stable climate, fewer extreme events, etc.). It is virtually certain that no individual alive today will see the Earth's climate return to its state under current, much less pre-industrial, concentrations of greenhouse gases and temperatures...even if massive emission reduction efforts were undertaken.

This long timescale between mitigation efforts and favorable results has led many people to either ignore climate change or become easily disheartened or paralyzed when working towards solutions (Clayton 2020).

\section{Considerations in Interpretation and Framing Models}

Given that climate change communication poses such distinct and diverse challenges, careful consideration of interpretation methods, including framing models and strategies, is needed. This section will briefly outline best practices in the field of interpretation as a whole, then outline strategic framing techniques in climate change communication alongside key resources for climate change communicators and interpreters.

\section{Best Practices in Interpretation}

There is, of course, no one set of best practices in interpretation; effective interpretation varies depending on audience, institution, and message. The National Association for Interpretation defines it as "a purposeful approach to communication that facilitates meaningful, relevant, and inclusive experiences that deepen understanding, broaden perspectives, and inspire engagement with the world around us" (NAI 2021). Freeman Tilden was the first person in the 
United States to record and standardize this communication process, publishing his six principles of interpretation in 1957. In the decades since, interpretation has become a formalized field, incorporating research from communication studies, child and adult education, and human psychology. Effective communication and interpretation stimulates both the head and the heart of a person; it is especially important in science and climate change communication that educators avoid "fact-dumping" and remember to engage emotions. As actor, author, and experienced science communicator Alan Alda remarked in regard to communicating difficult subjects, "First, it's understanding what another person is feeling-what's usually called empathy — and second, an awareness of what another person is thinking — what scientists call Theory of Mind" (Alda 2017, 24).

Most critical in developing and implementing effective interpretive practices is to first define a focused "master plan" that outlines the mission, core messages, and objectives of an interpretive program (Tschaenn et al. 2014). Once a clear program theme is designated, other key components include: tailoring the program to a specific audience, including place-based messaging, utilizing a mix of tangible and intangible objects and concepts, relating the theme to a universal value, including multisensory and interactive elements, and when applicable, outlining post-program action steps (Skibins, Powell, and Stern 2012). These broadly defined best practices will be described in more detail next as they relate to climate change.

Talking to youth about climate change requires a fundamentally different approach than talking to adults. Learning theories will be outlined in further detail in the following chapter, but suffice it to say that tailoring a program about climate change to youth includes ensuring the 
content and details provided are age-appropriate, relevant to their lives, and provides sufficient background knowledge on the mechanisms of climate change. Creating a program that is relevant to an audience, especially a younger audience, often includes cultivating a sense of place. And because climate change is often a very intangible concept (refer to the challenges of it being an "invisible" crisis above), utilizing tangible (and preferably local) examples is crucial when interpreting the issues. These can include specimens in natural history collections as examples of changes over time, a tank in an aquarium used in a program on ocean acidification, or a polar bear pelt in a zoo when discussing ice melt due to the increase of heat-trapping gases in the atmosphere.

After establishing intangible and tangible examples, linking these to universal values is also considered best practice in interpretive studies today (Skibins, Powell, and Stern 2012). Universal values (morals and beliefs that are shared across cultures) found to be particularly useful in interpreting climate change are the concepts of protection and responsible management (Climate Interpreter 2017). Finally, interpretive programs tend to be most effective when they include multisensory and interactive engagements; in museum programs, this could include interactive public programming, worksheets that utilize exhibits, or video lectures that include a call to action (Stern et al. 2013).

\section{Strategic Framing}

Climate change communication has recently shifted from focusing on catastrophe, and the so-called "doom and gloom" stories in the news, to instead conveying messages of hope and sustained, productive engagement (Moser 2016). Key in this shift is the use of strategic framing 
techniques that promote understanding and avoid unproductive discussions. In partnership with the FrameWorks Institute, the National Science Foundation Climate Change Education Partnership, and the New England Aquarium, the National Network for Ocean and Climate Change Interpretation (NNOCCI) has emerged as a key resource in developing framing models in informal learning settings. Their combined research has identified three core techniques that lead to productive and effective programming on climate change:

1. When creating programs, focus on framing the messaging by appealing to universal values as outlined in the previous section, e.g., protection, interconnectedness, and human innovation. Focusing on shared human experiences and values helps to situate climate change in a broader context and uses common ground to bring diverse audiences together (Arteaga 2020).

2. Use metaphors, analogies, and simplified models to explain climate systems. There is a clear gap in understanding the mechanisms of climate change. Studies have found that while most Americans may understand that human actions have led to the climate crisis, "they lack a clear understanding of what humans are doing to change climate and how the process of climate change works" (Bales, Sweetland, and Volmert 2015, 4). Explanatory metaphors, such as carbon dioxide gas acting as a heat-trapping blanket, have been shown to increase understanding of how climate change works (Geiger et al. 2017, Somerville and Hassol 2011).

3. Provide community-oriented solutions that acknowledge the scale of the climate crisis and offer appropriate opportunities for action. Sharing small-scale actions, such as changing your lightbulbs or riding your bike, can be viewed as inappropriate or weak; 
instead, effective framing techniques utilize community-level actions that demonstrate impacts people are already having and ways to meaningfully add to them (Swim et al. 2017). Examples of community-level versions of the individual actions given above could be advocating for sustainable energy sources from utility companies or supporting public bike-sharing initiatives that increase access to sustainable transportation methods. Climate change communication has undergone a drastic and impressive evolution in the decades since climate change was introduced to the American people. The field of interpretation is expanding to study not just how to explain the science of climate change, but also how to advocate for sustained engagement and action on this issue that will only become more relevant and widespread as time goes on. And because climate change is a long-term issue that requires long-term solutions, investing in the education of future generations is paramount, and museums, zoos, and aquariums are uniquely situated to provide venues for these discussions. The next chapter will explore the history of education in museum settings, the role of museums in learning, and the status of climate change communication in museums, zoos, and aquariums today. 


\section{CHAPTER 3: EDUCATION IN MUSEUMS, AQUARIUMS, AND ZOOS}

Although there is no one definitive explanation of what learning means, we can define certain fundamental characteristics that learning entails; namely, learning involves change (of behavior, or in potential of behavior), endures over time, and occurs through experience (Schunk 2012). It is precisely this last feature that enhances the link between learning and the role that museums play in enabling learning through educational activities, outreach programs, and exhibits. Museums, aquariums, and zoos provide unique avenues for the public to learn about the natural world through experiential education; this is especially critical in youth learning.

This chapter will outline the role of museums in learning in two main sections. First, a brief overview of how education became a major focus of museums will be provided, followed by an outline of key learning strategies used in museums that are especially useful in climate change communication, and ending with a note on teen learning. The second section will review the emphasis of conservation education at museums, aquariums, and zoos and concludes with a short review of the prevalence of climate change education in these institutions today.

\section{Development of Museum Education}

While education and interpretation have emerged as distinct and specialized fields within museums today, learning has always been, in some way, central to a museum's function. From the Temple of Muses in Ancient Greece to the first cabinets of curiosities, or Wunderkammern, that sprang up in Europe in the 1400s, people have gathered together to gaze upon objects, to wonder, and to learn (Simmons 2010). These cabinets of curiosity were particularly popular amongst the wealthy elite, who developed their own classification and organization systems to 
best show off their extensive and varied collections (Amsel-Arieli 2012). Following the death of the collection's owner, the objects were often transferred to a public organization; thus began the modern museum (Friedman 2010).

This transition from personal collection to public display is perhaps best exemplified by the opening of the Ashmolean Museum, the first public natural history museum, in 1683 (Alexander, Alexander, and Decker 2017). The Ashmolean signaled a change in how collectors viewed their collection; rather than a warehouse of goods to be appreciated by a select few, the collection became an assemblage of artifacts to be studied and preserved for the public (MacGregor 2001). Museums in the coming decades followed a similar trend, shifting from primarily curatorial roles in society to places of learning, particularly towards the end of the 19th century (Simmons 2010). As museum scholar Stephen Weil wrote, the focus of museums shifted from being "focused primarily inward on the growth, care, and study of [their] collection" to one focused "outward to concentrate on providing a variety of primarily educational services to the public" (Weil 1999, 229).

This educational shift was especially pronounced in natural history museums, aquariums, and zoos, where institutions worked to make their dioramas and exhibits more naturalistic because research and education were seen as "parallel functions of the museum" (Alexander, Alexander, and Decker 2017, 64). While recreation and leisure remain the biggest draws for visitors today, the focus of these institutions has shifted from pure entertainment value to conservation work and public education and outreach (Ballantyne et al. 2007). 
The next section will outline key learning theories used in museums to achieve their goals in education and outreach, as they relate to best practices in climate change communication, before specifically diving into teen learning in museums.

\section{Key Learning Theories in Museums}

As museums shifted their focus from exhibiting and researching their collections and started to focus more on for whom they steward their collections, museum education emerged as a specialized function within the museum's mission. As such, a number of learning theorists, museum educators, and teaching strategies emerged. Of course, no one education model can fully capture the complexities of human learning, but several theories on the nature of learning have become prolific in the museum world (Dierking 1991). Because this thesis is concerned with climate change education, this section will focus primarily on those learning theories that are concerned with interactive experiences and social learning environments. Specifically, two learning theories that will be outlined below are John Dewey's work in underscoring participatory experiences in learning and Lev Vygotsky's emphasis on social interaction in learning.

The pedagogical theories of Dewey and Vygotsky can both be considered to fall under the umbrella term of constructivism, which broadly claims that learning is an active process where the learner constructs their own knowledge rather than having it imposed upon them, and that knowledge is constructed socially and is highly personal to the learner's life (Fox 2001; Popkewitz 1998). In summary, "learning is situated in contexts" (Schunk 2012, 231). John Dewey (1859-1952) was an American philosopher who wrote extensively on educational reform 
and "recognized prior knowledge and experience as the basis for meaning-making" (Hein 2004, 414). He was particularly interested in the educational role of museums and other informal learning centers. Dewey held that effective educational experiences are interactive, where students can learn by doing, but emphasized that the experience should not end once the activity is done and the student leaves the museum; to be successful, museum learning requires:

... integrated settings that foster discussion, challenge the learner, make connections to issues of interest to the learner, and provide guidance for application in the world outside the museum... the educative value of experience should be judged by its capacity to enable the learner to have future [educative] experiences (Hein 2004, 424).

Lev Vygotsky (1896-1934) was a Russian psychologist who worked primarily with children and is known for his work on the "sociocultural nature of learning" (Fox 2001, 29). While there is some debate today around the original meaning of his work and the ways his theories may have been distorted by the later constructivist movement, his work in social learning and his concept of the zone of proximal development (which represents "the amount of learning possible by a student given the proper instructional conditions") is largely accepted as a foundation for the social constructivist approach to education (Schunk 2012, 243; Amineh and Asl 2015; Fox 2001).

Together, Dewey and Vygotsky demonstrated that learning is social, participatory, and needs to be situated in a broader context. Furthermore, Vygotsky illustrated that learning difficult concepts often requires social mediation such as scaffolding, where an instructor helps guide the learner through complex learning by connecting ideas with known concepts or experiences (Falk and Dierking 2018). These theories about learning are especially applicable in climate change education. Studies have shown that successful climate change communication requires audiences 
to be able to connect the impacts of climate change to their own personal experiences and motivations, and to do so communicators need to offer interactive environments and deliberate discussion prompts (Kim and Dopico 2016; Monroe et al. 2017). Interactive environments and participatory activities are not limited to hands-on experiments in science labs, and indeed, should not be. To engage students more wholly, museums, aquariums, and zoos should offer engagements that also give students the room to interact with each other and consider how the activities and educational opportunities offered by the museum connect to their lives. As a recent paper by Kim and Dopico (2016), which discusses science education at informal learning centers explains:

Participatory and interactive engagement of museum visits could optimize the understanding of knowledge in collections. In our sense, 'participatory and interactive' does not mean only students' hands-on or bodily engagement but minds-on where students cognitively and socially construct and contextualize their observation and experiences with exhibited resources in their worldview and understanding of science. Shifting the understanding of museums from exhibitory to participatory place is necessary to develop museums as a place for active learning (Kim and Dopico 2016, 443).

Thus, many museums are employing these social constructivist teachings to design exhibits and programming that encourage communication and collaboration between visitors, connect to personal experiences, and inspire visitors to extend the museum experience at home (Foutz and Emmons 2017).

\section{Teen Learning}

Museums are critical partners in formal education and provide irreplaceable opportunities for experiential learning. The average museum in the United States "devotes three-quarters of its 
education budget to K-12 students," with a large number of the museum's programs tailored to meet state and national education standards (AAM 2021). This gives museums an edge when it comes to teen learning; they have the resources and ability to frame their programming around school standards such as the Next Generation Science Standards while retaining their position as informal learning spaces, with flexibility in providing students with unique out-of-school learning experiences.

According to Jean Piaget, a psychologist who was an avid proponent of constructivism and created an influential theory of cognitive development in youth, once students arrive at the age of 11 , they are better "able to think hypothetically and abstractly, although this is limited by lack of depth and breadth in knowledge" (Pritchard 2009, 19). This makes middle school and high school age students strong candidates for climate change programming because they are better able to grasp larger, more complex concepts and intangible issues. Teen learning is similar to adult learning in many ways, but there is vastly more brain development in the teenage years than at any other age of life besides 2-3-year-olds; specifically, extensive and significant changes in areas of the brain that involve decision-making, social interaction, and abstract reasoning take place (Schunk 2012; Starbuck 2018).

Because of these nuances in brain development, there are a few important notes to keep in mind when working with teens. Teens tend to thrive in environments that are nurturing and encourage them to think for themselves, since they are starting to experience more independence and tend to place "undue emphasis on social rewards" (Starbuck 2018). This has been seen in research on motivations in teenage students, where findings "show that students want to avoid 
appearing incompetent... especially... during the teenage years when their senses of self are developing” (Schunk 2012, 53). Learning environments that follow a social constructivist approach help teens learn because of the emphasis their brains place on social learning, and when those environments offer facilitated learning as outlined above in Vygotsky's research, they can help mitigate nervousness in students who are wary of social embarrassment if they get an answer wrong during an activity or class discussion.

\section{Conservation Education in Museums, Aquariums, and Zoos}

Recent studies show that most people obtain much of their knowledge on topics like science and conservation outside of school settings and through other formal learning environments (Falk 2014). While it is notoriously difficult to study exactly how visitor mindsets and actions change after visiting cultural institutions such as a museum, a great deal of literature has come out on the varying impacts of conservation programming in zoos and aquariums. Particularly since the 1970s and 1980s, environmental education, species conservation, and biodiversity preservation have emerged as key aspects of the educational missions of zoos and aquariums, as well as natural history museums and science centers (Nygren and Ojalammi 2018). Multiple studies have now shown that wildlife encounters and environmental education programs in zoos and aquariums are having significant impacts on the conservation knowledge, attitudes, and behaviors of visitors (e.g., Ballantyne et al. 2007; Clayton, Fraser, and Saunders 2009; Falk 2014; Rabb 1994).

Historically, the vast majority of environmental programming and conservation education has emphasized cultivating a sense of awe and wonder for the natural world. Today, as the world 
faces unprecedented climate and biodiversity crises, many have shifted to place more significance on the work the institution is doing beyond its front doors and on inspiring action in visitors. As George Rabb, zoologist and former director of the Brookfield Zoo in Chicago, once noted:

Until recently, the emphasis at zoos was on communicating messages in order to create appreciation for species and their habitats. Many zoos today also strive to motivate people to act on behalf of conservation from some understanding of the critical role our species plays in ecosystems locally and worldwide. To do this requires acquiring knowledge about zoo visitors and non-visitors, their interests and receptivity to information about environmental affairs. Fortunately there is a wealth of research about encouraging environmentally responsible behavior from psychologists, sociologists, and market researchers to aid such zoo education efforts (Rabb 1994, 160).

In the years since Rabb predicted that zoo educators would incorporate behavioral

research into their environmental education work, many institutions have added specific, actionbased asks of visitors at the end of their programs. Using active learning and constructivist theories as described earlier in this chapter, educators have found ways to successfully foster environmental literacy and encourage conservation-minded behaviors. Professors Roy Ballantyne and Jan Packer, who have done extensive research in environmental education and visitor evaluation in the tourism industry, particularly in museums and zoos, have suggested a framework to follow that incorporates a constructivist approach:

Focusing on the evidence of an environmental problem (particularly in relation to human impact and mismanagement), the effects of the problem (particularly in relation to wildlife and wildlife habitats), and the efforts needed to alleviate the problem (practical steps the learner can take), allows the cognitive, affective and behavioural elements of environmental education to be effectively integrated. It is suggested that learning experiences in informal settings that incorporate a clear focus on these three aspects, and that include (without exploiting) the affective element of each, will be most effective in 
promoting environmentally sustainable attitudes and behaviours (Ballantyne and Packer 2005, 291).

Since current best practices in climate change interpretation and communication also suggest implementing solution-based messaging, using a "proactive approach in which freechoice environmental learning experiences are used to motivate visitors to connect with postvisit learning materials once they leave the site" is a particularly apt strategy for museums, zoos, and aquariums (Ballantyne and Packer 2011,211). The conclusion of this chapter will provide some examples of the ways museums, aquariums, and zoos are incorporating climate change education in their programs, and in particular, their teen programming.

Climate Change Education in Museums, Aquariums, and Zoos

Museums, aquariums, and zoos hold a privileged position as trusted informal learning centers in society, where controversial issues can be broached. However, though species conservation has been highlighted extensively, climate change has not emerged as an explicit priority for most institutions (Hamilton and Ronning 2020). If the topic is discussed, many institutions approach education on climate change "as if action is an obvious and guaranteed byproduct," but, as decades of research has shown, knowledge has not been enough to move visitors towards significant, large-scale action on climate change issues (Sutton and Robinson 2020, 2).

As NNOCCI research details, community-based solutions tend to be the most effective ways museums can engage the public about climate change. To be sure, "effective museum education programming requires increasing a sense of civic empowerment among visitors" 
(Bunten and Arvizu 2013, 270). Combining action-based programming with proven effective education methods is now needed; for instance, many of the more successful communication strategies use social learning, as outlined earlier in this chapter. When confronting the very complex issue of climate change, social learning has emerged as a way to expand "the notion of communication beyond a linear process of information...[engaging] stakeholders in... knowledge creation that induces behaviour change through a shared process of learning by doing” (Harvey et al. 2012, 15).

Because teens are at the stage of life where they are beginning to be more independent and have the capacity to understand and make more significant, conscious decisions about their lives, they are an ideal age for new programming on climate change (Kraljevic 2011). And while formal education standards have improved in recent years to include anthropogenic climate change, many teachers are hesitant or uncomfortable teaching climate science in the classroom or are using less effective framing techniques (Henry and Carter 2021). Educators at the Monterey Bay Aquarium have launched teacher workshops to counter this hesitancy, showing teachers how to use the Next Generation Science Standards to scaffold climate change learning for appropriate age groups; while it is best to avoid heavier, "doom and gloom" type topics with early learners, providing “theoretical and real world examples of successful, student-led projects" with middle and high school age students has helped improve climate literacy as well as build critical thinking and problem solving skills (Callaghan 2020). Beyond programming at the museum, some institutions are creating or taking part in youth climate action networks, like the Seattle Youth Climate Action Network launched by the Seattle Aquarium, Woodland Park Zoo, and the Pacific Science Center (Sakowski 2020). These networks, as well as institution- 
sponsored summits and other events, give museums, aquariums, and zoos the opportunity to connect with and empower teens, fostering feelings of agency and giving them an opportunity to have impacts on the wider community (Kretser and Chandler 2020).

Museums, aquariums, and zoos have the opportunity and the obligation to educate and mobilize their visitors on climate change. Using learning theories that have been successful for decades, as well as more recent framing and communication techniques for climate change education, these institutions can create rewarding and compelling youth climate change programming. The next chapter will outline the methods behind this thesis, including an informal survey of the field, detailing the prevalence of climate change programming for teens, which is followed by a selection of case studies from institutions who offer this programming. 


\section{CHAPTER 4: METHODOLOGY}

In this thesis, climate change programming for teens in aquariums, zoos, and museums is examined. Questions to be explored include how prevalent this programming is across institutions in the United States, how these programs were developed, how these programs utilize museum collections, and what factors make these programs successful. An important goal of this thesis is to highlight climate change programming at three prominent institutions to offer practical assessments and suggest recommendations to museums interested in developing or expanding their own climate change programs.

The methods used in this thesis consisted of a literature review, an informal survey of the field, and case studies of institutions that offer programs for teens that specifically include climate change messaging. The literature review covered three main subjects: first, the field of climate change communication and education as a whole; second, a brief history of museum education, with an overview of notable learning theories followed by a review of youth engagement and programming; and third, an examination of how conservation education and climate change are approached in museums today. As outlined below, an informal survey of the field was conducted to determine the prevalence of climate change programs in museums, then three organizations were selected for case studies based on information outlined on their websites regarding relevant programming. Each case study also included an interview with a museum professional serving as a content expert.

In this chapter, the methods used in this thesis are outlined. First, an overview of the literature that was used to supply a basis for the thesis and to develop the questions for case study 
interviews will be detailed. Next, the process for conducting the informal survey of the field will be detailed. Lastly, the selection of case studies based on the survey will be presented, followed by a description of the interview questions asked of museum personnel who served as context experts in the case studies.

\section{Literature Review}

The literature review, presented here in Chapters 2 and 3, was conducted to provide context for the creation and implementation of climate change programming for teens in aquariums, zoos, and science museums, as outlined below. Chapter 2 examined the public perception of climate change, major challenges in communicating climate change, best practices in interpretation, and strategic framing techniques used in informal settings to interpret climate change. Sources included scholarly articles, webpages from the National Association for Interpretation (NAI) and the National Network for Ocean and Climate Change Interpretation (NNOCCI), and museum education and interpretation journals.

In this chapter, first a short explanation of climate change and a history of public perception about it was conducted in order to illustrate the dire nature of the issue, and to discuss the development of the field of climate change communication. Key sources included recent reports from the Intergovernmental Panel on Climate Change (IPCC) to provide scientific understanding of the causes and effects of climate change, and recent reports from the Yale Program on Climate Change Communication to provide an overview of climate change knowledge and behavior in the United States. Other sources included news articles on climate change impacts and the effects of political campaigns on public attitudes. 
Next, major challenges concerning the communication of climate change were discussed. This section was included because climate change is an issue with a wide range of impacts, not just physically, but emotionally and psychologically as well; this makes it a particularly difficult topic to interpret to youth. A key source was Susanne Moser's (2010) paper, "Communicating Climate Change: History, Challenges, Process and Future Directions," which provided a comprehensive overview of many of the challenges discussed in this thesis. Finally, Chapter 2 concluded with a review of strategic framing techniques and best practices in climate change interpretation today. The NAI and NNOCCI websites, and the scholarly articles that studied their practices, were major sources in this section.

In Chapter 3, the role of museums in learning is discussed, beginning with the history of education in museums, including youth education and teen programming, and ending with an examination of how conservation issues and climate change are approached in museums today. Sources for the history of museum learning included the books Museums in Motion: An Introduction to the History and Functions of Museums (2017) by Edward Alexander, Mary Alexander, and Juilee Decker, and Learning from Museums: Visitor Experiences and the Making of Meaning (2018) by John Falk and Lynn Dierking. These provided keen insights into the museum field as a whole and into different learning theories that have been developed since the 1900s. Sources for the description and inclusion of conservation and climate change learning in museum, zoo, and aquarium education and exhibitions came from web searches, academic journals (such as the Journal of Museum Education and Environmental Education Research) and scholarly articles, and the results of this thesis's informal survey, which is outlined below. 


\section{Informal Survey}

An informal survey of the field was conducted in order to assess the prevalence of climate change programming for youth today, and to develop a list of potential sites for a case study. One hundred and forty institutions throughout the United States were studied in total; the focus on American museums was determined due to the profound skepticism of climate change and scientific illiteracy in the U.S. when compared to other countries, as noted in the Literature Review. All institutions surveyed were either natural history museums, aquariums, zoos, botanical gardens, or science centers. To narrow the scope from all possible institutions in these categories in the United States, three lists were consulted:

1. The list of partner institutions on the NNOCCI website. Because NNOCCI is one of the leading resources for climate change communicators in informal settings, these institutions are presumed to include more climate change content in their educational programs.

2. The list of institutions accredited by the American Alliance of Museums (AAM). This criterion was included because institutions that have achieved accreditation by AAM have been held to high standards of excellence in education and collections stewardship.

3. The list of institutions accredited by the Association of Zoos \& Aquariums (AZA). AZA accreditation is a months-long process that involves a rigorous application and a multiday inspection by a team of evaluators, and so was included as a criterion for institutions in this study that house live animal collections to ensure the animals are receiving the highest levels of care possible. 
All NNOCCI partner institutions formed the base of the informal survey; however, this only included 56 institutions. To expand the pool, institutions along the West Coast of the United States were then reviewed. The West Coast was chosen based on proximity to the author and because of the existence of the Pacific Coast Action Plan on Climate and Energy. Because the governments along the West Coast are part of this plan, it seemed more likely that climate change programming would exist in museums in California, Oregon, and Washington. This led to 140 institutions studied as part of the informal survey; how the three case studies were chosen from this sample are outlined below.

\section{Case Study Selection Process}

Out of the 140 institutions studied in total, 41 were eliminated from the pool of possible case study sites because they were not accredited by both AAM and AZA. An additional 63 institutions were excluded because their websites showed no evidence of educational programming that explicitly included the phrase "climate change" in the description. The remaining 36 institutions were then narrowed down to 12 potential case studies, and each of these 12 were ranked based on a review of the webpages of museum education departments and the following criteria: (1) if institution was accredited by AAM and/or AZA, and partnered with NNOCCI; (2) if the program explicitly mentioned and was focused on climate change; (3) if the program was geared towards middle and/or high school age students; and (4) if the program mentioned the institution's unique collections and/or resources. The top three possibilities selected as case studies were: the New England Aquarium, the San Diego Zoo Wildlife Alliance, and the Monterey Bay Aquarium. 
Since this thesis deals specifically with climate change programming for youth in aquariums, zoos, and natural history museums, and because there is not one unified position title for this type of engagement, either the director of education, curriculum creator, program coordinator, head of outreach, etc. could have been interviewed as content experts for each institution. Due to the impacts of the COVID-19 pandemic, interviews were conducted on Zoom at all three institutions rather than in-person.

The first case study focused on the San Diego Zoo Wildlife Alliance. Victoria Dunch, Research Coordinator in the Community Engagement department, was interviewed concerning the "Polar Bear Bioacoustics and Energetics" program on August 6, 2021.

The second case study focused on the New England Aquarium. Lindsay Jordan, Supervisor in the Conservation Learning department, was interviewed about the "Blue Impact" program on August 19, 2021.

The third and final case study focused on the Monterey Bay Aquarium. Beth Callaghan, Teacher Programs Supervisor, and McKenzie Miller, Senior Education Specialist, were interviewed about the “\#TeensCan” program on August 30, 2021.

\section{Interview Questions}

Fourteen questions were developed for the interviews with content experts, as presented in detail below. The questions were divided into three main categories: (1) development of the program; (2) implementation of the program; (3) evaluation of and future plans for the program. For consistency when analyzing the case studies, the same questions were asked of each content expert interviewed. 


\section{Program Development}

The first set of questions posed concerned the development of youth programs about climate change. The first question asked, "What factors led to your institution creating a climate program aimed at this age group?" This question was asked to explore why a program specifically for youth and not adults had been developed. The next two questions asked about the educational models used in the program, so as to contextualize it within the broader museum learning field. Specifically, Question 2 asked, "What resources or curriculum models were used or consulted when developing this program?" and Question 3 asked, "What learning styles (e.g., object-based learning) are utilized in this program?" The fourth question in this set asked, "How are the museum's collections used as a part of this program?" Museums, zoos, and aquariums are unique among other nonprofits because they steward collections, so this question was designed to determine how much, if at all, those collections were leveraged for the programming. The fifth and last question in the Program Development category focused on determining how the program fit in with the institution's goals, asking, "Is this program part of the museum's strategic plan? How does this program support or advance the museum's mission or your departmental goals?"

\section{Program Implementation}

The second set of questions concerned the logistics behind how the institution implemented the program. The first question in this set, Question 6, asked, "What funding sources are used for this program?" This question was asked because financial burden is often a barrier to an institution launching new educational programs. Question 7 focused on staffing, so 
as to determine how the program is managed within day-to-day operations; it asked, "What staff are involved with this program? How often do you offer this program, or how often is it accessed by the public?" Next, Question 8 asked, "How long have you offered this program?" Because climate change communication is a relatively young field, this question was posed in order to ascertain how the program has evolved or incorporated new science. Question 9 focused on how the program fits into the community, asking, "What stakeholders are involved with this program?" Question 10, the final question in the Program Implementation set, asked, "What issues have been identified in implementing this program?" Since climate change is a challenging topic, as outlined in Chapter 2, identifying program issues is important in determining how to modify the program to better communicate climate change and better engage audiences.

\section{Program Evaluation}

The third set of questions builds on Question 10 to discuss if and how the program has changed in response to any issues identified and who is utilizing the program. Question 11, the first in this final set, asked, "Do you conduct informal or formal evaluation on this program?" Evaluations are often necessary when receiving grants for educational programs, and are useful when determining program effectiveness. Next, Question 12 asked, "What has your unit learned from evaluation of this program?" This question was posed to the content expert to determine evaluation results, which were further investigated in Question 13. This question asked, "Have evaluation results been used to inform program modifications or further program development, and if so, how?" Lastly, Question 14 asked, "What are the demographics of those who use this 
program?" This question was included to provide a broader understanding of the program audience.

\section{Summary}

In sum, in this thesis, a literature review of climate change communication and museum learning was completed, an informal survey of the field was conducted to determine climate change programming prevalence, and case studies were used to better understand the programs offered. In the next chapter, the first case study institution, the San Diego Zoo Wildlife Alliance, is discussed, followed next by the New England Aquarium, and the Monterey Bay Aquarium. Each case study consists of a brief background of the museum, a description of the museum's youth climate change programming, the results of the interview, and an analysis of the institution's programming. The case studies are followed by a discussion on key findings, similarities, and differences between the ways each institution offers youth climate change programs. Conclusions and recommendations are then presented in Chapter 9. 


\section{CHAPTER 5: SAN DIEGO ZOO WILDLIFE ALLIANCE}

\section{Organization Background and Mission}

The San Diego Zoo Wildlife Alliance (SDZWA) is an international nonprofit conservation organization based in San Diego, California. They operate both the San Diego Zoo (SDZ) and the San Diego Zoo Safari Park (SDZSP). Established in 1916, the San Diego Zoo is widely regarded as one of the best zoos in the world and is the most visited zoo in the United States (Johnston 2021). The Zoo has been a pioneer in creating naturalistic habitats for the animals they house; from building the then-tallest flight enclosure in the world for the Zoo's shorebirds in 1923 to opening a "natural environment zoo" (the Wild Animal Park, later renamed the Safari Park) in 1972, the SDZ was one of the first in the country to create open exhibits and showcase animals in realistic enclosures, not just behind bars with cement flooring (SDZWA 2021a; King 2019).

The San Diego Zoo was founded in 1916 after the formation of the Zoological Society of San Diego, spearheaded by Dr. Harry Wegeforth, who was to become the first President of the organization (SDZWA 2021a). Their plans were ambitious: beyond simply housing wild animals, their aims included "being an incorporation for the advancement of the study of wild life... furthering the study of animal diseases by the erection of a hospital... the protection of wild life and the education of children along the lines of natural history" (Benchley 1934, 6). The SDZ has expanded this work to a global stage, particularly with the establishment of the Center for Reproduction of Endangered Species in 1975 (SDZWA 2021a). Over the years, their work has included extensive conservation genetics, including using frozen sperm from the southern 
white rhino in an effort to boost population genetic diversity through assisted reproductive technology (SDZWA 2021b).

With this expansion in the Zoo's work, as well as internal organizational changes, came rebranding. In 2010, the Board of Trustees approved a plan to rename the Wild Animal Park to the San Diego Zoo Safari Park and rename the Center of Reproduction of Endangered Species to the San Diego Institute for Conservation Research (SDZWA 2021a). Additionally, the entire organization received a new umbrella title: San Diego Zoo Global. Just a decade later came another rebranding, after new President and Chief Executive Officer Paul Baribault was hired in 2019. Baribault previously worked at Disney overseeing Disneynature films and brought this interest in storytelling with him to the SDZ. "We as humans connect through stories," Baribault shared during an interview with the San Diego Union-Tribune, "Facts and figures are important, but we can't just rely on facts and figures to educate, inform and inspire" (Fikes 2019). To better reflect this shift in focus and the organization's work in conservation and collaborative projects, the San Diego Zoo Global adopted their current name in 2021: the San Diego Zoo Wildlife Alliance. This new name "better reflects the organization's focus on conservation and the interconnectedness of animal and human health" (Wosen 2021).

The mission of the SDZWA is, "San Diego Zoo Wildlife Alliance is committed to saving species worldwide by uniting our expertise in animal care and conservation science with our dedication to inspiring passion for nature" (SDZWA 2021c). One of their main goals is to promote empathy and inspire guests to care for wildlife, and then to advocate for wildlife through individual and collective action (SDZWA 2021c). Today, the Zoo and Safari Park 
combined house more than 15,000 individual animals from almost 1,000 species, many of which are endangered (SDZWA 2020). They also care for roughly two million plant specimens, including a 900-acre Biodiversity Reserve in the SDZSP that protects indigenous coastal sage habitat (SDZWA 2020). Globally, the SDZWA focuses their work in eight regional "hubs" and key species within them; these hubs are the Savanna, Amazonia, the Southwest (in North America), Oceans (the polar bear and African penguin are particular species of concern), Pacific Islands, African Forest, Asian Rainforest, and Australian Forest (SDZWA 2021d).

With over five million guests visiting the Zoo and Safari Park annually, and with more than 350 conservation partners around the world, the potential reach of this organization is enormous (SDZWA 2021e; SDZG 2020). And the SDZWA is trusted by their visitors and donors; Charity Navigator, the "world's largest and most trusted nonprofit evaluator," has awarded the Alliance with 4-star ratings for the last five consecutive years for excellence in transparency around their work and finances (Charity Navigator 2021). Their innovative work in animal care and research, their global collaborations, and their award-winning facilities all support the SDZWA's education initiatives and inspire millions of people to care for the natural world and act to support wildlife.

\section{Education Programs}

While the San Diego Zoo has been engaged in informing the public of the wonders of the natural world since its inception in 1916, collaborative education programs with schools only began in 1939 (SDZWA 2021a). The Zoo's first summer program began the following year in 1940, and their Education programs have since expanded to include a formal interpretive 
volunteer program (beginning in 2008), internships for teens, classroom programs (both inperson and virtual), a virtual training program for animal care staff that is accessed by zoos worldwide (the San Diego Zoo Academy, launched in 2012), and an Advanced Inquiry Master's Program that began in 2013 (SDZWA 2021a). In 2019 alone, over 390,000 students attended special youth programs, $75 \%$ of which came from Title 1 schools, "which augment education for low-income students" (SDZG 2020).

Most, if not all, of the SDZWA education programs include a conservation focus, in large part inspired by the organization's long history of caring for wildlife around the globe. Conservation efforts for the SDZWA began in earnest with the establishment of the Center for Reproduction of Endangered Species in 1975 (later renamed the San Diego Zoo Institute for Conservation Research in 2009), whose work has included a captive-breeding program for California condors (SDZWA 2021a). This program inspired a lesson in California condor genetics that is used during the Exploring Conservation Science field trip program, one of five program modules total (SDZWA 2021f). The aim of these programs is to educate and inspire youth, supporting the organization's goals to "help create a world where all life thrives" (Dunch 2021).

There are three education teams within the Wildlife Alliance: the San Diego Zoo, the Safari Park, and the Beckman Center for Conservation Research. The Zoo and Safari Park work with students from kindergarten to twelfth grade, while the Beckman Center focuses on middle school to undergraduate students; because the Center is a research facility and the students are learning in a lab setting, these programs are less appropriate for younger students (Dunch 2021). 
The Beckman Center is housed at the Safari Park, and most of the programming takes place in the Conservation Education Lab. Here, the Community Engagement team hosts 2.5 hour Exploring Conservation Science field trips where students engage in one of five lab modules that emulate conservation work that is being done by the SDZWA and their colleagues around the world (SDZWA 2021f). These five modules each offer a middle school (MS) and high school (HS) curriculum option that can be accessed without a field trip and is focused on understanding scientific literature (SDZWA 2021f). Each lesson plan is described below:

1. Polar Bear Bioacoustics and Energetics. The polar bear lessons are the only ones that explicitly include climate change and will be described in further detail in the next section. The MS lesson includes work on polar bear communication and global conservation partnerships, and the HS lesson discusses the effects of climate change on polar bear energy needs and research being done in zoos and in the wild.

2. Life in a Biodiversity Hotspot. The MS lesson focuses on the endangered Stephens' kangaroo rat and seed banks, and the HS lesson is about biodiversity worldwide and in coastal southern California.

3. Desert Tortoise Spatial Ecology. Both the MS and HS lessons focus on threats to the Mojave desert tortoises and conservation tools being used to protect them.

4. California Condor Genetics. The MS lesson focuses on the California condor captive breeding program at the San Diego Zoo and the HS lesson centers on conservation work in the field for the condor, including public education campaigns and field research.

5. African Elephant Reproductive Biology. While both lessons are about elephant behavior, the MS lesson focuses on human-wildlife conflict and the HS lesson is about breeding. 


\section{Climate Change Programming: "Polar Bear Bioacoustics and Energetics"}

It is virtually impossible to talk about polar bear conservation without talking about climate change. Studies show that the Arctic is disproportionately affected by our warming planet, and as sea ice is melting, polar bears "increasingly face a world where it is difficult to gather enough food to survive... [this] is correlated with declines in a polar bear's body condition, reproductive success, and survival" (SDZWA 2021h). The SDZWA is part of collaborative projects both at the SDZ and out in the field, partnering scientists with wildlife care professionals and working with Polar Bear International to study polar bear energetics and how they respond to sound disturbances (SDZWA 2021i; SDZWA 2021j).

Conversations about climate change and polar bear conservation are not just limited to research teams at the Zoo; the polar bear enclosure at the SDZ has an exhibit about climate change that features graphs of increasing $\mathrm{CO}_{2}$ levels (Dunch 2021). Paired with research being done by scientists, the SDZWA created educational programs that feature polar bears and discuss conservation work. The "Polar Bear Bioacoustics and Energetics" module is one such example.

\section{Program Development}

The "Polar Bear Bioacoustics and Energetics" lab is one of five modules offered by the Community Engagement team that use inquiry-based approaches to foster understanding of realworld conservation challenges. The modules are updated every year with new research, since the goal is to provide labs that emulate the work being done by the San Diego Zoo Wildlife Alliance (Dunch 2021). In addition to human dimensions and education research, the Next Generation Science Standards (NGSS) is the main guiding resource in developing and updating these 
modules (Dunch 2021). On the NGSS website, three primary dimensions of learning science are identified: Science and Engineering Practices (doing science), Disciplinary Core Ideas (key scientific ideas and facts), and Crosscutting Concepts (connecting science). Because critical thinking, practicing science, and interconnected systems are included in the Standards, NGSS is a useful tool for teaching climate change and allows the SDZWA modules to directly connect to what students are learning in the classroom (Le 2019; Dunch 2021).

Another resource that is consulted specifically for the polar bear module is the NNOCCI website. NNOCCI trainings and resources help ensure that educators are communicating everything, especially climate change, in the most effective way possible (Dunch 2021). Going forward, the team is looking into how to further incorporate NNOCCI framing techniques, because while climate change is not the main focus of most of the modules, it affects every part of the natural world (Dunch 2021).

One of the education practices that is utilized is the think-pair-share strategy. Think-pairshare is a cooperative learning strategy that gives students time for critical thinking and activating prior knowledge on their own before engaging in social learning by sharing with a partner or group, and finally sharing their discussion with the class (Bamiro 2015). This learning strategy is particularly useful in working through complex issues such as climate change and can deepen understanding, especially when combined with real-world action and solutions such as the work actively being done by the SDZWA and Polar Bear International (Bishop-Williams 2020). 
Each module in the Exploring Conservation Science field trip is hands-on in some way, including lab equipment, computer programs, and the Zoo's collections. Live animal cams from the exhibits are sometimes used, as well as photographs of the animals and from researchers and project studies. Biofacts, a term widely used in the zoo and aquarium world to refer to specimens such as pelts, bones, or eggs, are also used in module activities. Examples include an elephant tusk in the reproductive biology module, California condor feathers and tags in the conservation genetics module, and a polar bear taxidermy paw in the bioacoustics and energetics module (Dunch 2021).

\section{Program Implementation}

The Community Engagement team at the San Diego Zoo Wildlife Alliance was established about 16 years ago, and in the time since has worked extensively with Development teams to foster relationships with community partners, individual donors, and foundations (Dunch 2021). Much of the funding for the Exploring Conservation Science field trips to the Beckman Center comes from private foundations; the only funding from the federal government comes from the United States Fish and Wildlife Service, which focuses on a module that gets students outside in nature (Dunch 2021). About 70\% of field trips are fully funded and have Title 1 stipulations, serving primarily local students in southern California from historically excluded groups (Dunch 2021).

The team runs two modules a day during a typical school year, and the teacher is able to choose which module is used (unless there are specific funding requirements). The biotechheavy modules tend to be the most popular, e.g., the conservation genetics lab which uses 
expensive equipment such as micropipettes (Dunch 2021). The "Polar Bear Bioacoustics and Energetics" lab is not run as often as the others. This is likely because it uses simpler equipment, and teachers tend to be more interested in programs that utilize expensive equipment that their school cannot afford, better preparing their students for biotech opportunities in college and the workplace (Dunch 2021). The middle school level polar bear module is focused on bioacoustics (polar bear hearing) and research that is being conducted, so the students study conditioning behaviors and use equipment such as clickers. The high school level is focused on energetics and energy demands in polar bear behavior as they are affected by climate change, so students are using mostly computer systems.

\section{Program Evaluation}

Pre- and post- evaluations are conducted for each module, using the same general format. The evaluations are conducted using an iPad and consist of five multiple choice questions, which differ depending on the module being used; the Community Engagement team is looking for at least a $40 \%$ increase in knowledge for the class on average (Dunch 2021). If the field trip is grant-funded, photos are also taken during the lessons. Results from these evaluations are generally examined en masse in the late spring or early summer, after the school year wraps up. These results have informed limited program modifications; for instance, evaluation results might inform how specific parts of the module are run or might prompt a question to be reworded for better understanding (Dunch 2021).

While the contents of the modules have not changed significantly based on evaluation results, NNOCCI training completed by the Community Engagement staff has resulted in further 
development of the "Polar Bear Bioacoustics and Energetics" module. Because the point of the modules is to focus on bioacoustics and energetics, since the researchers are not climate scientists, for a while climate change was not emphasized or discussed as much during the field trip (Dunch 2021). After NNOCCI training was completed, however, the team now spends much more time discussing climate change with the students. They use NNOCCI framing techniques and end the module by talking about community actions and solutions, giving the students more agency and ending the lesson on a more uplifting and inspiring note (Dunch 2021).

\section{Assessment}

The San Diego Zoo Wildlife Alliance's approach to climate change programming in the "Polar Bear Bioacoustics and Energetics" module is noteworthy for two reasons: first, their use of the think-pair-share approach is particularly conducive to climate change programming, and second, their use of real-world technology and research procedures makes the program more attractive to teachers, as discussed below.

As stated previously, think-pair-share is a learning strategy that relies on students both working on their own as well as working socially. It is a useful method that works especially well in collaborative, informal learning environments like museums, zoos, and aquariums. Studies show that learning is not an isolated experience; it occurs in a physical and social context, so think-pair-share is conducive to creating these social learning environments (Dierking 1991). And because climate change is such a complex topic, providing students with space and time to work out problems and brainstorm solutions together in a social environment is critical. Over the 2.5-hour module, students are given the time to construct knowledge with each other as 
well as contextualize that knowledge, a crucial aspect of informal learning environments, alongside the examples of SDZWA polar bear research (Kim and Dopico 2016).

The second reason the "Polar Bear Bioacoustics and Energetics" module is noteworthy, and indeed the other four modules offered for the Exploring Conservation Science field trips, is its use of technology and materials not often found in the classroom. Utilizing biotech equipment and biofacts helps create learning opportunities that students might not otherwise have access to, which helps to build skills and generate experiences that mirror actual research being conducted by scientists (Dunch 2021). Rather than a simple worksheet that can be printed out and used in the classroom, these field trips take advantage of the resources at the SDZWA that teachers often do not have available to them. Because bridging science in school and science in out-of-school contexts is a key part of increasing scientific literacy (which can then make climate change science easier for students to grasp), these modules are a compelling example of the ways in which museums, zoos, and aquariums can leverage their resources and collections (Kim and Dopico 2016).

One area that can be expanded in these modules is giving students examples of ways they can apply their learning about climate change to their own life. Since providing real-world context is critical in learning, and because climate change can often feel like an overwhelming problem, giving students concrete examples of ways to combat climate change and supplying appropriate opportunities for action will help give students agency and hope (Dierking 1991; Swim et al. 2017). The research examples used in the modules, such as the polar bear behavior research being conducted by the SDZWA and Polar Bear International, are an excellent first step 
in providing context for climate change science, and creating activities that focus on solutions at the end of the modules would be even more beneficial in the students' learning.

\section{Summary}

The San Diego Zoo Wildlife Alliance, through their exhibits and animals at the San Diego Zoo and San Diego Zoo Safari Park as well as their conservation work with the San Diego Institute for Conservation Research and global partners, has a long history of inspiring the public to care for the natural world and be involved in wildlife conservation. This expertise in animal care and the global reach of their research gives the SDZWA a rich foundation from which to create engaging and unique educational programs, particularly with the creation of the Beckman Center for Conservation Research, which houses the Conservation Education lab alongside SDZWA research groups and laboratories.

The Exploring Conservation Science field trips are able to take advantage of these resources through on-site programs that center on research being conducted by the SDZWA and utilize hands-on activities and biotech equipment. For classes and students that are unable to visit in-person, online versions of the modules that focus on building reading skills (specifically of scientific literature) and encouraging critical thinking are available. Combining the topic of climate change with the study of polar bears is an effective strategy since it gives students a tangible example of the effects of climate change, something many people struggle with when learning about climate impacts. For students on field trips, using real-life examples of research and equipment used by scientists not only satisfies NGSS requirements (giving students the space to practice science) but also gives classes access to biotech tools that may not be available 
in their schools. The "Polar Bear Bioacoustics and Energetics" module is a compelling example of tying climate science to wildlife, giving students interested in animals a more holistic view of the effects of climate change on the natural world. 


\section{CHAPTER 6: NEW ENGLAND AQUARIUM}

\section{Organization Background and Mission}

The New England Aquarium (NEAq) is a world-class, nonprofit aquarium located on the waterfront in Boston, Massachusetts. Opened to the public in 1969, the NEAq was not the first aquarium established in Boston; three other aquariums had opened and closed their doors since 1859 (NEAq 2021a). The Boston Aquarial Gardens (1859-1860) was the first aquarium in the world that solely exhibited marine animals before it was moved and reopened as the Boston Aquarial and Zoological Gardens, then closing for good just three years later in 1863 (NEAq 2021a). The South Boston Aquarium opened fifty years later in 1912, but after budget restrictions and financial strains during the Great Depression and the Second World War, the building fell into disrepair and was closed in 1954 (Ryan 2011). The NEAq opened 15 years later, and was "designed with the intention of providing an underwater experience for visitors as well as a cultural institution that would connect Boston to its waterfront" (NEAq 2021a).

The NEAq serves over a million guests each year and houses thousands of aquatic animals in their exhibits. One of these exhibits, the Giant Ocean Tank, is a four-story exhibit that was the largest circular saltwater tank in the world when it was completed in 1970 (NEAq 2021a). Apart from their on-site exhibitions, the NEAq does extensive research in marine animal conservation, particularly with whales and sea turtles, and has several national education and interpretation programs centered on conservation and climate change.

Their work with marine mammals began in 1977 when the Aquarium launched a program to respond to marine mammal strandings in New England, and expanded to include more 
targeted conservation work after the discovery of dozens of Atlantic right whales in the Bay of Fundy in 1980, a species previously believed to be almost extinct (NEAq 2021a). The NEAq has since been working for over forty years to research Atlantic right whale behavior and advocate for conservation efforts and management measures, including pioneering work with Geographic Information System (GIS) mapping programs to help prevent vessel strikes and fishing gear entanglements (New England Aquarium 2021). Today, the NEAq offers a popular whale watch program that takes guests to the Stellwagen Bank National Marine Sanctuary for the chance to see not only the critically endangered Atlantic right whale but also humpback, finback, minke, and pilot whales (NEAq 2021b).

The mission of the New England Aquarium is, "The New England Aquarium is a catalyst for global change through public engagement, commitment to marine animal conservation, leadership in education, innovative scientific research, and effective advocacy for vital and vibrant oceans" (NEAq 2021a). To further their mission, the NEAq launched the Anderson Cabot Center for Ocean Life in 2016. The Anderson Cabot Center has a wide range of projects that advance marine conservation through research and science-driven solutions, partnerships, and policy recommendations (NEAq 2021c). These projects include partnerships with fishery managers as well as wildlife research on several key species: Atlantic cod, haddock, manatee, Kemp's ridley sea turtle, northern fur seal, common thresher shark, sand tiger shark, thorny skate, bowhead whale, and North Atlantic right whale (NEAq 2021d). 


\section{Education Programs}

Though the New England Aquarium has a vast range of research projects and a network of conservation partners around the globe, they are also deeply invested in education. Over the years, the NEAq has launched several education initiatives and received grants for new nationwide educational programs. Their Aquarium Lecture Series began in 1972, which provides free public lectures and film screenings by scientists, conservationists, educators, and more (NEAq 2021e). The NEAq later expanded their education work to include youth and family learning. The Aquarium's Education Center opened in 1995, with the Activity Center, a handson learning environment dedicated for families with young children, opening five years later in 2000 (NEAq 2021a).

The NEAq currently offers programming for all ages, including field trips for schools and homeschool groups, resources and lesson guides for educators, activities for caregivers, and volunteer and paid internship programs for teens. There are three core teen programs: the live blue ${ }^{\mathrm{TM}}$ Ambassador program, summer internship program, and ClimaTeens (NEAq 2021f). The live blue ${ }^{\mathrm{TM}}$ Ambassador program is a volunteer program for youth ages 14-18 who are “interested in serving the Aquarium's mission beyond the walls of the Aquarium...[including] different service-learning opportunities [such as] habitat cleanup and restoration, public education and outreach, and citizen science” (NEAq 2021g). Six-week long paid internships are offered in the summers, where youth learn skills and are trained in public speaking, marine biology, and climate change science (NEAq 2021h). The third teen program, ClimaTeens, is for 14-18-year-olds who are already involved in NEAq programs and it focuses on climate change and public engagement (NEAq 2021i). The youth act as climate change ambassadors, and adult 
guests to the Aquarium tend to engage with the teens more than the adult educators (Jordan 2021). ClimaTeens projects have included work on community organizing, participating in climate strikes, presenting at climate change summits, and learning how to apply for grants that will fund further community-based climate change education projects (Ceresia 2019; Reisner and Mulgund 2019).

Beyond teen programs, the NEAq offers a wide array of climate change education programs. For instance, in 2009 the Aquarium co-sponsored a major symposium with the Woods Hole Oceanographic Institution that centered on the effects of climate change on oceans and coastlines (NEAq 2021a). On-site, the Aquarium has an interactive exhibit space called the Blue Planet Action Center that engages visitors in climate action and research being conducted by the NEAq (NEAq 2021j). But the program with arguably the largest nationwide impact is the NNOCCI training program.

NNOCCI, as mentioned in Chapter 2, is the National Network for Ocean and Climate Change Interpretation. The initiative was started by the NEAq in 2010 and works to "change the public conversation about climate change to be inviting, interesting, empowering, and solutionsfocused" (NEAq 2021k). Designed to create universal content for anyone to share, NNOCCI was born out of a gap in knowledge; many climate change experts are not skilled communicators, and many communicators lack backgrounds in climate science (Jordan 2021). The NEAq is the "birthplace" of many climate change communication grants, and in 2012 the Aquarium received a \$5.5 million grant from the National Science Foundation (NSF) to further NNOCCI's work of creating climate change communication workshops and building a network of engaged informal 
science educators and climate scientists (CCEP Alliance n.d.; Jordan 2021; NEAq 2021a). Today, the NEAq is a host institution for NNOCCI (the other host institution being the Monterey Bay Aquarium) and works in partnership with the Association of Zoos and Aquariums, the Frameworks Institute, the National Aquarium at Baltimore, and the Woods Hole Oceanographic Institution with grant funding from the National Science Foundation and the National Oceanic and Atmospheric Administration (Arteaga 2019).

\section{Climate Change Programming: "Blue Impact"}

The New England Aquarium approaches their climate change programming with two different angles: one, informing people about the underlying mechanisms of climate change, and two, engaging people with climate change solutions (Jordan 2021). The NEAq offers both formal presentations about climate change on the floor (e.g., above an aquarium tank) as well as informal, hands-on activities at a cart for older children and families, facilitated by an Aquarium educator (Jordan 2021). Four examples of these interactive activities include:

1. Connect-It! This activity involves different tiles that must be put in the correct order to illustrate connections between individual behaviors, ocean animals, and climate-level impacts.

2. Ecofootprint. This is a competition-style game where guests "compete" against each other using scales and blocks that indicate different lifestyle choices.

3. Sink or Source. This activity uses sorting levers that guests use to guess whether things are carbon sinks or carbon sources, ending with a conversation about actions that can be taken to mitigate carbon footprints. 
4. Biomimicry. This app looks towards the ocean and ocean animals to find climate solutions, with guests searching for inspiration in the natural world that has led to innovative technologies.

While much of the research being done by the NEAq, NNOCCI, and others is aimed at communicating climate change to adults, not much is done for younger audiences (Jordan 2021). With very young children, however, educators can do more harm than good by exposing them to intense conservation issues; with younger audiences, it is better to focus on fostering awe, wonder, and a feeling of interconnectedness with the natural world (Jordan 2021; Sobel 2019). Thus, the NEAq saw an opportunity to create climate change programming for older youth and teens, leading to the creation of programs like ClimaTeens as well as the "Blue Impact" video series and lessons.

\section{Program Development}

The "Blue Impact" series was originally created as an audio tour for guests to listen to as they walked around the Aquarium before being adapted to a video series (Jordan 2021; NEAq 20211; NEAq 2021m). The videos were developed and put online in 2013 thanks in part to a grant from NOAA Climate Collaborative (Scharf 2013). There are seven short science videos (each video running for five minutes or less) in the series, each with their own student worksheet, detailed below:

1. Introduction. This video introduces the science of climate change, using animation and metaphors (such as describing atmospheric gases like carbon dioxide and methane as a “heat trapping blanket"). 
2. Coral Breakup - A Tragic Love Story. This video uses footage from coral reef research and expeditions to discuss the ways rising ocean temperatures are affecting corals.

3. Thermal Expansion - Rising Oceans. This video covers the molecular reasons why sea levels will rise with increasing ocean temperatures, using examples from the Boston waterfront.

4. Sea Jellies Take Over the Ocean Maze. This video features an interview with a biologist from Woods Hole and discusses adaptations of jellies that are allowing their populations to increase thanks to climate change.

5. Shorebirds on Stage. This video is about phenology and food webs, discussing the ways climate change is affecting shorebirds, their migrations, and their prey.

6. Sea Turtles - A Temperature Tale. This video includes background information on temperature-dependent sex determination in sea turtles and the effects of rising temperatures on sea turtle populations. Additionally, the video includes footage and details about rescue work the NEAq conducts with sea turtles in the New England area.

7. Whales - Roadwork Ahead. This video covers the ways climate change is affecting oceanic currents, which in turn affect whales' food sources.

These videos and worksheets are an example of the Aquarium's "mission-based interpretation" work, centering the conversation on their mission rather than a specific animal and framing the issues in a collaborative sense, e.g., how individuals can work together to accomplish the mission of the NEAq with the community and various stakeholders (Jordan 2021). But because climate change can often be a difficult issue to visualize, and because many of the visitors to the New England Aquarium are local, each video and lesson includes examples 
of animals and stories that are close to home (Jordan 2021). These can include work being done in the Boston Harbor, the NEAq's sea turtle rescue and rehabilitation program, and examples of sea level rise in the area (Jordan 2021).

After the science videos, the "Blue Impact" series concludes with three "Take action!" videos, which "highlight examples of community-scale actions already underway to minimize energy and waste, and to encourage positive social and civic policy" (NEAq 20211). These include programs on community recycling, bicycle commuting, and energy efficiency in the home. Each video concludes with a call to action and an invitation to join the conversation on social media. NNOCCI research shows that successful climate change communication involves framing the issues in a solution-oriented, hope-based way to empower people towards action rather than paralyze them with the size and scope of the work needed (Jordan 2021).

\section{Program Implementation}

The "Blue Impact" series was developed thanks to national grants, and because the videos and worksheets are available online for free, anyone in the world can access them to use at home or in a classroom. While they are geared towards older students (middle and high school age), the worksheets can be adapted and incorporated into classroom discussions or serve "as a starting point for group and community action to reduce the impacts of global climate change while supplementing [the teacher's] curriculum” (NEAq 2021m). The series is not regularly promoted, but because the program was originally used as an audio tour, there are scattered placards at various exhibits around the Aquarium that reference it (Jordan 2021). 


\section{Program Evaluation}

There are no specific evaluations conducted on the online "Blue Impact" video series and worksheets, although on-site programs do go through a formal evaluation process (Jordan 2021). As visitors leave the NEAq, they are invited to take an exit survey that includes questions about climate change, e.g., if guests feel as though they have a better understanding of climate change issues and if they are likely to make a change in their personal life to combat climate change (Jordan 2021). After analyzing these surveys and using NNOCCI research results, one of the biggest takeaways has been that while many people self-identify as environmentalists and care about the climate, many do not understand the underlying mechanisms that cause climate change and cannot think productively about solutions (Jordan 2021). For instance, not understanding that the burning of fossil fuels such as coal, gas, and oil is the main contributor to climate change means that rather than carbon-based solutions, guests and students might focus on actions such as recycling or reducing plastic water bottle use. While these are helpful and important actions to take in regards to reducing waste and preventing pollution, they do not address climate change. Thus, in all of the programming at the NEAq, educators address these gaps in public understanding by including initial causes of climate change (at least a brief explanation of the underlying mechanisms) and ending with impacts and solutions (Jordan 2021). One important point to note is that much of this initial research and work was developed a decade ago around 2010; at that time, many climate change communicators were not looking at environmental issues with an intersectional lens. Now, educators at the NEAq are stepping back and reevaluating their work to reshape climate change communication and weave in stories that address diversity, equity, accessibility, and inclusion (Jordan 2021). 


\section{Assessment}

The New England Aquarium's work in climate change communication is significant due to their national reach, alongside programs like the "Blue Impact" series that take advantage of local animal conservation research to make points about global issues. With national grants supporting the NEAq's work launching NNOCCI, the Aquarium has been able to have an impact beyond just visitors in Boston; by educating the educators at other institutions, the NEAq has indirectly impacted countless guests at parks, museums, zoos, and aquariums across the country. Over 150 institutions have participated in NNOCCI trainings on research-based climate change communication strategies, so visitors to those institutions are receiving consistent messaging (Swim et al. 2017). By having a free and open exchange of best practices across nature-based museums, and with educators using the same descriptions of climate science, utilizing effective climate change metaphors, and framing programming with community-based solutions, this consistency and repetition of messaging gives visitors better background information on climate change issues and hammers home examples of the most effective solutions (Jordan 2021).

What makes the "Blue Impact" series particularly notable among other video series offered by museums, zoos, and aquariums is that it is focused explicitly on climate change and uses local wildlife to illustrate climate change in action rather than being focused on an animal or habitat and having climate change issues tacked on at the very end. Centering the worksheets and videos on the mechanisms of climate change and using animation helps students understand the causes behind processes like ocean acidification or global oceanic currents. Then, using habitats like coral reefs (which are well-known biodiversity hotspots that most students, even if they have not seen a coral reef in-person, understand to be critical ecosystems) and local concerns like sea 
level rise in the Boston waterfront, the video series is able to bridge the causes of climate change with its effects, helping to make the issues more real.

To further inspire youth and create a broader impact with the "Blue Impact" series, the NEAq could further develop the "Take action!" videos at the end to incorporate more current climate change solutions and action being done today. Linking the videos to the ClimaTeens program and providing resources for finding youth climate summits could inspire teens elsewhere in the country to create or join their own climate youth movements. While this series does an exemplary job in explaining how climate change happens, bolstering and updating the closing videos with climate action being done today would help propel teens towards exploring solutions.

\section{Summary}

The New England Aquarium has a rich history in climate change communication work. From writing comprehensive reviews and co-hosting symposiums to conducting conservation research, the NEAq has done extensive work looking into the impacts of climate change. Their research on Atlantic right whales and sea turtles that call the waters around the Aquarium home has given them a strong footing in conservation work, which they have used to open the Anderson Cabot Center for Ocean Life and illustrate the importance of not just conducting marine research but also investing in conservation and climate change solutions.

The establishment of the National Network for Ocean and Climate Change Interpretation, combined with the NEAq's in-person teen programming and the "Blue Impact" series, means the Aquarium is able to leverage their research to create an impressive foundation from which 
climate change communicators nationwide can work. Because the video series and worksheets are available online at no cost, teachers can easily take advantage of these resources to bolster their students' learning. Using animation, metaphors that have been proven to be effective, and footage from the Aquarium's displays and research, the "Blue Impact" series is able to give learners a solid background in the mechanisms behind climate change and the impacts it is having today. 


\section{CHAPTER 7: MONTEREY BAY AQUARIUM}

\section{Organization Background and Mission}

The Monterey Bay Aquarium (MBA) is a world-renowned, nonprofit, public aquarium in Monterey, California. Since opening on October 20, 1984, the MBA is one of the most visited aquariums in the world and their pioneering work in conservation education, California marine life research, and groundbreaking exhibitions has led them to be oft-referred to as one of the best aquariums in the world (e.g., Kacharoo-Levine 2021; MBA 2021a). In their almost 40 years of operation, since 1986 they have been continuously accredited by the Association of Zoos \& Aquariums, showcasing their commitment and dedication in caring for the over 80,000 live animals and plants in their collection (AZA 2021; MBA 2021b).

While the Monterey Bay is now known to be one of the most biodiverse and productive marine habitats in the world, thanks to the nutrient-rich waters offshore, the region was not always protected (Gordon 1999; MBNMS 2006; MBA 2021c; MBA 2021d). In the early 1900s, the sardine canning industry was thriving in California and entrepreneurs flocked to Monterey where the sardines were plentiful; the rapid growth of the fishing industry combined with an influx of tourists who read John Steinbeck's popular novel Cannery Row led to an economic boom in the area (Fotsch 2004). But years of overfishing led to a collapse of sardine populations in the 1950s, and the fisheries in Monterey, which once enjoyed international recognition for their canned sardines and fish meal products, collapsed (Ueber and MacCall 2005). The largest and last sardine packing plant of Cannery Row, the Hovden Cannery, finally closed in 1973 and 
the site was taken over by Stanford University's Hopkins Marine Station (MBA 2021e; van Dusen 1985).

As interest in environmental science began to pick up in the United States, a group of friends, local residents, and marine scientists came together in 1977 to propose a new, worldclass aquarium in Monterey that showcased local marine life rather than faraway coral reefs like many other aquariums around the country did (Palumbi and Sotka 2011). Thanks to a gift of over \$55 million from the David and Lucile Packard Foundation, the Monterey Bay Aquarium Foundation was formed in 1978 and began construction of the new Aquarium on the site of the old Hovden Cannery (MBA 2021e). The Monterey Bay Aquarium finally opened in 1984 and welcomed over two million guests in the first year alone; the Aquarium “overturned everyone's assumptions about the ability of marine life to entertain, educate, and promote a city" and continues to do so today (Palumbi and Sotka 2011, 151).

The MBA was borne from a desire to feature the unique life off the coast of Monterey, from the kelp forests teeming with life just offshore to the mysterious depths of the Monterey Canyon, a 70-mile-long trench that reaches over 10,000 feet deep at its lowest point (van Dusen 1985). When it opened, the MBA was the first major public Aquarium in the world to house permanent exhibitions that featured marine life of California's Central Coast; these exhibits helped inspire and mobilize the public to later support the designation of the Monterey Bay National Marine Sanctuary in 1992, the largest marine sanctuary in the continental United States (Gordon 1999; MBA 2021f). 
Their mission is concise but impactful: "to inspire conservation of the ocean" (MBA 2021a). With this in mind, the MBA exhibits unique wildlife to inspire guests, has launched research programs focused on conservation and exploration of the Monterey Bay National Marine Sanctuary, and takes action to advocate for ocean-friendly policies. In their exhibits, the Monterey Bay Aquarium has inspired countless guests; their Open Sea tank is particularly impressive, where they were the first aquarium to successfully house juvenile great white sharks and are the only aquarium outside of Japan to exhibit the ocean sunfish as well as both yellowfin and bluefin tuna (MBA 2021f). The MBA has also been a pioneering institution since 1989 in rescuing, rehabilitating, researching, and returning stranded sea otters using a unique "surrogacy" program where non-releasable female sea otters act as surrogate mothers to rescued pups (MBA 2021e).

To consolidate the Aquarium's research projects, the Monterey Bay Aquarium Research Institute (MBARI) was founded in 1987 "with the vision of bringing scientists and engineers together to explore the ocean," and now operates as a sister institution to the MBA (MBA 2021e). The MBA is also active in supporting environmental policies, including bans on plastic, providing online contact forms that the public can use to contact their state or county representatives, and helping to enact laws that protect the coastlines of California (MBA 2021g). One of their farthest-reaching initiatives was the creation of the Seafood Watch program in 1999, which includes an "online program and consumer pocket guide to help consumers and businesses make sustainable seafood choices" (MBA 2021e). Seafood Watch is just one example of a program created by the MBA that is designed to educate and empower visitors; other education programs, including on-site and teen programming, will be detailed next. 


\section{Education Programs}

The Monterey Bay Aquarium began their programs for schoolchildren just one year after opening in 1985; to date, the Aquarium has hosted over 2.5 million students for field trips or classes (MBA 2021e). Their education programming potential expanded in June 2019 with the opening of the Bechtel Family Center for Ocean Education \& Leadership, a four-story building with classrooms and labs, live animals, exhibits, and a living roof. The Bechtel Education Center was built to support the Aquarium in delivering "the most robust suite of ecosystem-based education and youth development of any aquarium in the nation" (MBA 2021e). While in-person education programs were paused in 2020 due to the COVID-19 pandemic, the MBA offers a variety of educational resources on their website (including worksheets for at-home use as well as workshops for teachers and educators), virtual programs and field trips, and online courses (MBA 2021h).

There are several teen programs at the MBA, including the Young Women in Science (YWS) program, the Watsonville Area Teens Conserving Habitats (WATCH) program, and the Teen Conservation Leaders (TCL) program. YWS is a bilingual, week-long, day camp program for girls in middle school, created to encourage young women to be involved in science and ocean conservation (MBA 2021i). WATCH is a year-long program for high school students in Watsonville, California; students learn about local environmental issues, become involved in community restoration work, and develop their own research projects (MBA 2021i). The TCL program is a volunteer-based position where students receive training in marine biology and ocean conservation while developing interpretation skills (MBA 2021j). They generally volunteer on the public floor at the Aquarium, but also assist in special events and education 
programs (MBA 2021j). In general, the overall goal of the MBA's teen programs is to support teens in thinking about systems and "developing a sensitivity to opportunity in taking action" (Callaghan and Miller 2021). Trainings that the MBA educators use with teens include how to have conversations with Aquarium guests about climate change; Aquarium educators use "story arcs" to help give teens the tools they need (Callaghan and Miller 2021). These include how to begin conversations and establish rapport, connect Aquarium animals with habitats and ecosystems, connect people to the story using universal values, transition to climate change issues, use metaphors and appropriate framing techniques to help guests understand the causes of climate change, and give examples of community-level actions and solutions (Callaghan and Miller 2021). Many of the aspects of these trainings follow NNOCCI guidelines and resources, as the Monterey Bay Aquarium is one of the host institutions for the national network.

Because on-site teen programming was put on hold in 2020 due to the COVID-19 pandemic, the MBA pivoted to developing online courses for students grades PreK through 12. The courses require an account to be made but are free to enroll in, and learners can go through the course at their own pace. There are currently nine courses total, including one for caregivers that is designed to support them in learning with their child, and each one focuses not only on teaching scientific concepts, but also "encouraging a sense of wonder and connection to the natural world" (MBA 2021k). Four of the courses are bilingual (offered both in English and in Spanish), and there are plans to make Spanish versions of the remaining five soon (Callaghan and Miller 2021). Courses for younger audiences aim to inspire and nurture a love of the natural world; courses for middle and high school students include conservation messaging, including discussions on climate change and ocean plastics (Callaghan and Miller 2021; MBA 2021k). 


\section{Climate Change Programming: “\#TeensCan”}

The “\#TeensCan Make a Difference" online course (abbreviated as “\#TeensCan”) is an "interactive course influenced and inspired by teens to help [students] find [their] spark for conservation and take action" (MBA 20211). The curriculum is divided into nine parts, described below:

1. Rethink. This is a brief introduction to the contents and purpose of the course.

2. Recreate $\mid$ Re-Create. This section encourages teens to think about what excites them about the natural world and ocean conservation, and to think about what systems they most want to have an impact on.

3. Repurpose. This section deals with repurposing goods, including craft ideas and tips on composting and limiting food waste.

4. Restore. This section focuses on watersheds and fostering a sense of place for each student.

5. Reach. This section centers on social media and activism.

6. Register. This section includes resources for registering to vote and how students can get out the vote in their communities.

7. Reflect. This penultimate section gives students the opportunity to reflect on what they have learned.

8. Resources. This last section provides background on the individuals who collaborated to make “\#TeensCan" possible and further resources for learning.

While "\#TeensCan" was originally developed as an online course in April 2020, it was adapted in the summer to be a 6-week virtual program for TCL program students as they were 
unable to come on-site to the MBA (Callaghan and Miller 2021). The remainder of this chapter will include details of both the online course version and the virtual program version of “\#TeensCan.”

\section{Program Development}

Many of the MBA's teen programs include a conservation focus of some kind, especially since the new strategic plan includes a piece about addressing climate change and supporting the next generation of changemakers (Callaghan and Miller 2021). However, educators have found that it has consistently been more difficult to help inspire action at the program's close (Callaghan and Miller 2021). While it is relatively simple to give the students information about a given topic or climate change issue, providing them with the tools they need for action and an opportunity to explore specific content that they are interested in is more difficult. The idea behind "\#TeensCan" arose from this need to give students the tools and show them what others are doing, and to make the program accessible around the globe (Callaghan and Miller 2021). The coronavirus pandemic provided an opportunity for educators at the MBA to use their resources to work collaboratively between education departments and create resources that would be useful to both teachers and students, and specifically, to make teen courses that could be completed without parental support but still gave teens time and space to build community (Callaghan and Miller 2021). The self-paced online course was developed first in the spring of 2020, and in the summer, it was adapted to a facilitated virtual program when, as the pandemic wore on, educators at the Aquarium realized that the TCL program would not be returning inperson during the summer. 
Before "\#TeensCan" was launched, the MBA focused on creating educational programs and teacher development programs about plastics (Callaghan and Miller 2021). One of the MBA's online courses, "The Ocean, Plastic, and Me" is geared towards a middle school audience and is focused entirely on plastics, giving students resources to explore the ways in which human choices can both positively and negatively affect marine life (MBA 2021k). Because plastic pollution is a more tangible issue (easier for students to wrap their minds around as opposed to a larger, more abstract topic like climate change), this helped MBA educators delineate their pedagogical approach and then extrapolate their findings to inform a climate change-oriented course for older students (Callaghan and Miller 2021). The primary goal of the online "\#TeensCan" course is to make learning about climate change fun and engaging while building skills for empathy and opportunity for advocacy (Callaghan and Miller 2021). The MBA had experience prior to the pandemic in conducting virtual programs (including teacher professional development programs) so the Education teams had an idea of what would be inscope and out-of-scope for them to provide and had a list of best practices for virtual and distance learning they could consult during course development (Callaghan and Miller 2021).

Each online course includes many ways of learning, including visual components like images, videos, and gifs of Aquarium animals, reading materials, narration/audio elements, and, for the "\#TeensCan" online course and virtual program, many opportunities for community time. Peer-to-peer learning is crucial, especially in teen learning, so "\#TeensCan" includes discussion times and breakout rooms as well as individual synthesis and reflection times (Callaghan and Miller 2021). “\#TeensCan provides a few options for follow-up activities between course lessons, such as resources students could discuss in a collaborative space using communication 
platforms like Slack or Discord, but none of the activities between lessons are mandatory (Callaghan and Miller 2021). This choice was made to avoid the course from feeling too much like formal school with homework, and instead to give students the room to learn at their own pace in a collaborative environment.

\section{Program Implementation}

While the MBA receives various national grants for specific STEM programs, Aquarium educators developed the "\#TeensCan" course and virtual program during the time they normally would be teaching school programs on-site, so no specific funding source was used to kickstart the program's creation (Callaghan and Miller 2021). And although “\#TeensCan” was created during the pandemic, the MBA had already started dabbling in online and virtual courses. MBA educators have been working to create educational opportunities for new youth audiences who have circumstances that prevent them from attending regular schooling environments, such as youth who are incarcerated or in hospitals (Callaghan and Miller 2021).

The online "\#TeensCan" course is hosted on the platform Thinkific, which provides the Aquarium with analytics like tracking students who sign up and if they complete the course (Callaghan and Miller 2021). There was a high retention in the program during the summer course, likely because they were students in the TCL program and had a vested interest in staying connected to the MBA (Callaghan and Miller 2021). Both TCL program students who participated in the "\#TeensCan" course and educators who implemented and facilitated their own programs reported that the course was well-received and enjoyable, and they particularly appreciated the opportunity to talk with like-minded people (Callaghan and Miller 2021). The 
MBA intentionally tried to bring in guest speakers who were also teens and/or persons of color to better reflect intersectional youth-led climate movements today.

When leading conversations and discussions with the students, especially when doing training about how to effectively share conservation messages, Monterey Bay Aquarium educators use the "heartwired" mindsets to help students think about the different ways they can frame climate change messages (Callaghan and Miller 2021). The researchers behind heartwired mindsets for ocean conservation investigate the "factors that shape how people relate to the ocean," and using their six mindsets helps communicators use different messages to activate motivational states of minds in the public depending on their ethos (Simon et al. 2019). Heartwired mindsets include individuals who are motivated by their awe and passion for wildlife, individuals who are motivated by family traditions, and more; having students in the TCL program understand these different motivations helps them become better climate change communicators (Callaghan and Miller 2021).

\section{Program Evaluation}

Although there was no formal evaluation conducted on the "\#TeensCan" online course or virtual program, the MBA education teams received informal and anecdotal feedback from teachers and teens after they completed "\#TeensCan." The most notable feedback from teachers and educators was to make the online resources more accessible and user-friendly; to that end, the MBA is developing a facilitation guide so educators who would like to use the "\#TeensCan" online course can recreate the virtual program that the MBA used with the TCL students in the summer of 2020 (Callaghan and Miller 2021). 
One of the hardest aspects of doing climate change programming in museums, zoos, and aquariums is the "action" piece of the conversation; talking with guests about the conservation message is simple, but having the guest then turn around and take action themselves is something many institutions struggle to with (Callaghan and Miller 2021). With the "\#TeensCan" program and an advocacy summit led by alumni from the TCL program, students reported that they felt empowered to start their own conservation projects because they were exposed to student-led and student-driven projects around the world; "\#TeensCan" gave the students a sense of "I can do this too!" and that environmental work can and should be done collaboratively (Callaghan and Miller 2021).

\section{Assessment}

The Monterey Bay Aquarium's approach to climate change programming in the “\#TeensCan" online course and virtual program stands out for two reasons: first, it is youth-led and adaptable, and second, it is action-based and focuses on both individual and communitylevel solutions.

Teens in the TCL program were not only students in the "\#TeensCan" program, but also collaborators. When the MBA education teams worked on transitioning the online course to a virtual program, students helped to make new pieces of the program using their experiences and skills in interpretation and ocean science (Callaghan and Miller 2021). Community time is important in teen learning, so building a sense of place with them, giving them activities to do in groups, and keeping the focus of the program on their interests helped create a youth-led atmosphere since they were driving the direction of each session. This means the program is 
malleable in many ways; depending on student interests and experiences, different conservation projects and solutions can be explored. The online course is also adaptable and flexible, and can be used not just in formal teaching classrooms, but also in after school programs, clubs, and inperson learning environments.

The self-paced "\#TeensCan" course was designed for use by any teen who is interested in taking action, in exploring what conservation issues exist in the world, and in learning about what other teens are doing around the world (Callaghan and Miller 2021). This last aspect is especially key in the program's success; instead of a lecture-based program about climate change issues, "\#TeensCan" gives individual students the opportunity to explore content and questions as they arise alongside their peers, and with tools they can use to create or join their own climate change projects. Climate change is at many times an overwhelming and frightening issue, but “action helps counter powerlessness" (Callaghan and Miller 2021). Teens in the online course and in the virtual program were connected with youth-led climate movements and advocacy summits around the country.

Keeping this action and individual and community based-level solutions feature in mind, one area that the Monterey Bay Aquarium could explore in the future is how to follow-up with students who have completed "\#TeensCan" as an online course or as a virtual program. The MBA has an alumni network with students who have completed the TCL program, and something similar could be created and implemented for interested teens who go through “\#TeensCan.” It is notoriously difficult for museums, zoos, and aquariums to get long-term data on how educational programs and conservation messages at the institution affect the actions of 
visitors, but tapping into this group of teens would be a good place to start in assessing the efficacy of action-based climate change programming.

\section{Summary}

The Monterey Bay Aquarium is able to leverage their exhibits, existing connections with NNOCCI, history with virtual programming and workshops, extensive research with MBARI, and experiences advocating for policy changes in the state of California to create successful and inspiring educational programming for all ages. The MBA has a large platform, and as climate change will only become a more pressing and intersectional issue in the years to come, the Aquarium has an exceptional opportunity to use their platform to forward climate change action and empower the next generation of ocean advocates. Many of the Aquarium's programs look at science through a lens of empathy for humans and animals, focusing on the ways in which humans rely on and affect natural systems. "\#TeensCan" takes this to a new level in which youth are not only learning about the world around them and their impacts on it but providing them with explicit tools they can use to take action on climate and building a community of changemakers. With a youth-led approach that is based on community-level solutions and taking action, the "\#TeensCan" online course and virtual program is an impressive example of how to engage teens in not just learning about the natural world, but in learning how they can make a difference. 


\section{CHAPTER 8: DISCUSSION AND CONCLUSIONS}

As poet and activist Muriel Rukeyser wrote, "The universe is made of stories, / not of atoms" (Rukeyser 2005, 465). And people learn best through stories; museum learning theorists and cognitive researchers have demonstrated that "universally, people can mentally organize more information effectively if they hear it through a story" (Falk and Dierking 2018, 43). Throughout our history, humans have used stories to explain who we are, what our connections to the natural world are, where we stand in the universe, and how we should live our lives. But stories must be told accurately and interactively if we want to leverage their use in climate change communication and education programming.

Show a class a composite curve of the monthly concentration of carbon dioxide measurements, displaying both seasonal oscillations and long-term trends, and they have fallen asleep. Give a student a video to watch of Rapa Nui and touchable natural history specimens from the area, and discuss with them how a flourishing civilization with sufficient technological prowess to erect large stone monuments in a resource-rich and lush tropical environment can go from a thriving society to total collapse in a matter of a few centuries; now, you have their attention to learn about the devastating impacts of colonialism and the values of responsible resource management and sustainability (Hunt and Lipo 2009). Using leaves collected recently from the area around the classroom or cultural institution, and fossilized leaf specimens, you can practice graphing skills with a class and study how paleontologists can use what we learn from the Earth's past to better understand the Earth today and what might be in store for our future (Smithsonian Institution 2021). 
It is precisely such multimedia storytelling features that are best suited for educational programs in aquariums, zoos, and museums. These are dynamic and adaptable institutions, holding vast collections of information. Aquariums, zoos, and museums bring people and objects together to foster discussion and debate, to enable visitors to address their concerns and find solutions, and to give guests the space to create meaning, build understanding, and influence their choices.

Each case study examined in this thesis tackles climate change communication and education for teens in different ways, using a range of techniques and resources. Each of the organizations approaches telling a story about climate change in its own way, leveraging the institution's collections to create engaging and encouraging programming. Using these case studies as springboards, this chapter outlines three key practices that museums should have in place when creating climate change programming for teens. After, three major conclusions concerning the development, implementation, and evaluation of these programs are presented.

\section{Discussion}

Earlier chapters examined aquariums and zoos that conduct climate change-specific programs for middle and high school students. A literature review covered the challenges of communicating climate change and current best practices in interpretation, in addition to examining the development of museum education; key learning theories, particularly in teens, and trends in conservation education in museums, zoos, and aquariums today, were outlined. Three different institutions that offer climate change programming for youth were then examined: the San Diego Zoo Wildlife Alliance (SDZWA) and the "Exploring Conservation 
Science" field trips; the New England Aquarium's (NEAq) video lessons and their work in creating a national network on climate change interpretation; and the Monterey Bay Aquarium (MBA) and their creation of action-based, youth-led programming.

All three of these institutions offer successful, innovative programming on climate change for teens, albeit in different ways. Specifically, three key practices in creating engaging and noteworthy teen programs centered on climate change can be identified: 1) while each program is formatted differently, all include interactive components and social learning; 2) each program is adaptable and can be completed individually or incorporated into a formal or informal learning environment; and 3) all programs outline real-world impacts of climate change to support tangible and/or action-based messaging for individuals and communities. Each of these key themes is discussed below in light of the broader literature on climate change education and programming.

Incorporating Interactive and Social Learning in Climate Change Programs

While written curriculum can be a useful tool for educators, climate change programming becomes truly effective when it is presented with appropriate framing, interpretation, and communication techniques. This is where it is particularly helpful to have trained aquarium, zoo, and museum educators who know how to communicate climate science and have experience in social and participatory learning, which are hallmarks of social constructivism. Using NNOCCI (National Network for Ocean and Climate Change Interpretation) techniques that were developed by expert communicators and climate change scientists, educators at the San Diego Zoo Wildlife Alliance, New England Aquarium, and Monterey Bay Aquarium have created 
engaging and interactive teen programming, whether that included giving teens the space to create their own climate change solutions in "\#TeensCan" at the MBA or utilizing think-pairshare learning in the "Polar Bear Bioacoustics and Energetics" module at the SDZWA. Studies have shown that "written or verbal communications tend to enable learning and active engagement less well than dialogic and interactive forms of communication," especially in regard to climate change, and the case studies are prime examples of this (Moser 2010, 41).

\section{Adaptability of Teen Programming}

The COVID-19 pandemic exposed in stark relief the need for adaptable education programming; while in-person, social learning environments are ideal for teens, it is essential for programs to be versatile when situations change. It is useful, then, to have programs that can be accessed by a wide variety of learners in different settings, whether they are using the curriculum individually or as a group in a formal classroom, an after-school program, or community club. For instance, educators at the MBA are working to pivot the "\#TeensCan" online module to one that can be more easily accessed by groups off-site, whether virtually or in-person.

At the same time, however, aquariums, zoos, and museums should work to leverage their role as places of informal learning for more effective climate change programs. As previously noted in this thesis, extensive research has been done that investigates the role of museums as crucial partners in formal education spaces. As Kraljevic emphasizes in the context of environmental learning, museum field trips and exhibitions allow learners to explore more freely and construct knowledge much differently than in classrooms, particularly in allowing the 
participants to "engage with and in the environment [and] to observe the evidence and effects of environmental mismanagement" (Kraljevic 2011, 13).

\section{Including Individual- and Community-Level, Action-Based Solutions}

Recently, the museum field has experienced an uptick of interest in returning to their roots as community-centered institutions, recognizing that "community encounters can take place beyond the walls of museums" (AAM 2012, 11). Combined with the need for communityoriented solutions in climate change messaging, aquariums, zoos, and museums have a rich opportunity. The Science Museum of Minnesota is a model example of community work; in recent years, staff have shifted their mindsets to foster more open dialogue in the community about climate change through partnerships and strategic public programming:

While helping people to connect personal action to climate change is important, in order to promote the broader goals of community scientific literacy and collective action, our museum has employed a stance of pivoting from questions of "What can I do?" to "What should we do?," to help public audiences grasp that the enormous scope and scale of climate change requires comparable societal responses (Hamilton and Ronning 2020, 23).

Best practices in climate change communication suggest this focus on collective action, and all programs examined in the case studies include real-world impacts of climate change at some level as well as action-based messaging. There are a myriad of climate change activist networks that have emerged in the last several years, including Project Drawdown and the All We Can Save Project, that can provide jumping off points for institutions looking to incorporate community-focused actions to their programming but lack the immediate resources to create the initiatives on their own. 


\section{Conclusions}

We have seen that there are a number of ways that aquariums, zoos, and museums can conduct climate change programming for teens. The literature review covered best practices in museum education and climate change communication, and the three case studies presented different directions that can be pursued when creating programs. Whether the program relies on videos of institutional and location-based research, specimen-based inquiry, or empathy-building and action-based conversations, this chapter has so far discussed traits of successful youth climate change programming as being interactive, participatory, adaptable, and solutionsoriented.

This chapter now closes with three conclusions concerning the development, implementation, and evaluation of climate change programming for teens in aquariums, zoos, and natural history museums: 1) Climate change is the most consequential issue that life on Earth faces today, and aquariums, zoos, and museums are well-positioned, and have an obligation, to tackle it; 2) There is a dearth of programming focused on climate change in aquariums, zoos, and museums; and 3) As the next generation of changemakers, teens are an ideal group to target for solutions-based climate change programming.

These conclusions are discussed below in further detail and include ideas and further considerations for institutions interested in creating their own teen programming on climate change and climate action.

1) Climate change is the most consequential issue that life on Earth faces today, and aquariums, zoos, and museums are well-positioned, and have an obligation, to tackle it. 
There is almost nothing on this planet that will remain unimpacted by the climate crisis. This not only includes the natural world (different species of animals or plants, microbiome diversity, ecosystem and habitat health, etc.) but also societal injustices. Climate change is having a disproportionate impact on women and communities of color throughout the world and can be considered a "powerful 'threat multiplier,' making existing vulnerabilities and injustices worse" (Johnson and Wilkinson 2020, xviii). Climate change is an intersectional issue, not separated from systems of oppression, and can only be addressed successfully with an intersectional lens. Using universal values in educational programs and empathy-building techniques can help make climate change's connections to the biodiversity crisis, human health, financial security, youth education, and social justice clearer to the program's learners, and there is a growing clamor for people in power to recognize these links and act accordingly.

So where do aquariums, museums, and zoos come into play? Collections. These institutions have a unique position as being trusted knowledge-bearers that steward collections (including, but certainly not limited to, live animal collections and natural history specimens) the public often would not otherwise be able to access or experience.

Each object stewarded by a cultural institution can be used to tell a story, a story that can be powerful and moving, and can cultivate a sense of wonder and awe for the natural world. Collections can be used strategically by museum educators to inspire individuals with universal values like protection (for future generations) and regeneration (of the natural world and our relationship with it). And rather than stopping at the title of knowledge-bearer, museums should move forward to becoming better knowledge-sharers, working with communities to promote 
scientific literacy, foster a connection to the natural world, and find effective, community-based actions that benefit local communities while tackling the global effects of climate change.

Curriculum packets or downloadable lesson plans with pictures or diagrams can be created by any organization, but learning with a live animal or education specimen cannot be replaced.

2) There is a dearth of programming focused on climate change in aquariums, zoos, and museums.

The informal survey of the field outlined in Chapter 4 revealed a surprising lack of programming centered on climate change in aquariums, zoos, museums (namely natural history museums and science centers) throughout the United States. While climate change may be referred to in exhibits or in informal engagements on the public floor, this speaks to the fact that there are very few visible educational programs that mention climate change in a meaningful way. If mentioned at all, climate issues were often tacked on at the end of the program like an after-thought.

And if climate change is considered at all, many still frame it primarily as an environmental issue and fail to recognize its multifarious nature and the need for multi-pronged solutions. In their 2013 article "Representing Climate Change in Museum Space and Places," Cameron, Hodge, and Salazar powerfully noted the following:

Relations between climate change, science, culture, and social practices need to be reframed. Current approaches to representing the science of climate change in museums and science centers are based on a separation of the science from its social and cultural 
dimensions. Climate change must be embedded in all programs. Climate change as a phenomenon is now part of the ecology of life, and it must be embraced as a fundamental element of living in the contemporary world. (Cameron, Hodge, and Salazar 2013, 14).

Museums should not be afraid to address potentially polarizing topics such as climate change, but rather should be confident in encouraging their visitors to explore ideas, deepen understanding, and to challenge the present state of affairs if it is not serving the future they hope to see. Museums have often been considered places of dialogue throughout history, home to lectures and lively discussions. Educational programs at museums, such as field trips and lectures, are prime opportunities for climate change discourse; as Hamilton and Ronning explain in reference to their work at the Science Museum of Minnesota:

Contrary to possible concerns about perceived divisiveness of climate change, the more that the Science Museum does to convene public discussions, to develop a sense of collective action and information-seeking among professional, public, and scientific community members around climate change, the more the museum is being sought out to convene these conversations (Hamilton and Ronning 2020, 25).

3) As the next generation of changemakers, teens are an ideal group to target for solutions-based climate change programming.

There has been an almost explosive increase in recent years of youth activism. The platform Intersectional Environmentalist (IE) is one such example; founded by activist and writer Leah Thomas, IE is a climate justice community that creates resources around environmental issues and climate change centered on historically excluded voices (Hirsh 2020). Xiuhtezcatl Roske-Martinez, who was the youth director of Earth Guardians and works to train other youth in civic engagement, spoke to the UN General Assembly on Climate Change as a teen to urge immediate action on the climate crisis (Steyer 2015). And Greta Thunberg is perhaps the most 
well-known face of youth climate activism, since founding the Fridays for Future youth climate strike movement in 2018 and giving numerous passionate and articulate speeches to world leaders $(\operatorname{Read} 2021)$.

Thanks perhaps in part to outspoken young climate leaders and activists, increased attention has been given in recent years to climate anxiety and despair. However, there are not as many studies that have explored the impacts of action-based messaging and climate hope. A study of middle school students in North Carolina in 2015 found that while despair was negatively related to pro-environmental behavior, utilizing teaching that focuses on climate change hope and concern led to increased pro-environmental behavior (Stevenson and Peterson 2016). These promising results, combined with the wave of youth climate activists, should be more than enough impetus to encourage aquariums, zoos, and museums to invest in teen programs focused on climate change and climate change solutions.

\section{Epilogue}

As I wrote this thesis, I watched the world burn. I woke up to hazy, smoke-filled, orange skies, checked in with friends and family in California and in Greece to verify their safety, and donned my face mask before going to work. Living in this new reality, of a seemingly endless pandemic, ever increasing wildfires, and constant updates about newly-endangered species was certainly taking its toll on my mental health (not to mention being steeped in literature on climate change not only for this thesis but also for my job). So, I began a weekly habit on Sunday mornings of going down to the aquarium at the California Academy of Sciences where I work, before we opened to the public, to watch the hundreds of Philippine coral reef fishes swim and to 
remember that the world is beautiful. I committed to seeking out stories of climate leadership to remember that the world is dynamic. And I went on morning bike rides to watch the fog roll across the Golden Gate Bridge and took sunset walks to the beach to read poems by Mary Oliver and passages from Dr. Johnson and Dr. Wilkinson's All We Can Save: Truth, Courage, and Solutions for the Climate Crisis to remind myself of all the good in the world, and yes, all that we can save in the world if we work for it and all that we can make better if we try.

Museums are made of stories. And at the end of the day, it is stories and experiences, not numbers, that move hearts. Effective climate change interpretation, communication, and programming must create hands-on experiences and include stories of empathy, of action, and most importantly, of hope. Beck and Cable, in their decades of work on interpretation in cultural institutions, have affirmed that interpretation is a profound method of gift-giving, with hope being perhaps the greatest gift of all:

Our world is a place of incredible beauty and great joy, but also a place of environmental degradation and tremendous human suffering. We live amidst acts of cowardly terrorism and heroic compassion. If we are mired in fear, helplessness, or pessimism, then we are immobilized. Hope is indispensable...Interpreters can offer hope to individuals for a rich, fulfilled life and hope in a future whereby generations to come inherit a prosperous and beautiful world. The beauty of human integrity commemorated in events of the past and the beauty of the intricacies of nature give rise to hope, and these are the tools of the interpreter (Beck and Cable 2002).

As many have said before, children are our future. Aquariums, zoos, and museums have done an incredible job over the years in fostering a sense of wonder for the natural world and inspiring the public to act on behalf of this big, blue marble we call home. Looking to nature, seeing its resilience and perpetual renewal even when it falters, and "focusing on how we can 
support and be a part of that renewal can be a unifying, restorative and hopeful approach" in programming on climate change for youth (Callaghan 2020). It is time now to use those years of education expertise and experiences in conservation and environmental learning to turn to the climate crisis and act. It is time to employ transformational leadership and give tools to teens, since as the next generation of changemakers their voices are more important than ever. It is time to use the collections we steward to tell new stories, stories that move hearts as well as minds, because as Robin Wall Kimmerer reflects in her book Braiding Sweetgrass: "For what good is knowing, unless it is coupled with caring? Science can give us knowing, but caring comes from someplace else.”

Perhaps more than hard data and science, we need hope, caring, and determination. We need not only to teach our youth the ways in which we impact the climate and the planet, but the ways in which we can fight to protect it. Today's youth are not just an audience, but an ally in this work. We need to use our resources and collections to weave stories of optimism, change, and action.

The tide is rising. And we must rise together to meet it. 


\section{REFERENCES}

AAM. 2021. "Museums and P-12 Education." American Alliance of Museums. Accessed September 24, 2021. https://www.aam-us.org/programs/museums-and-p-12-education/.

American Association of Museums. "Takin' It to the Streets." 2012. TrendsWatch 2012: Museums and the Pulse of the Future. American Association of Museums. https://www.aamus.org/wp-content/uploads/2017/12/2012_trendswatch.pdf.

Alda, Alan. 2017. If I Understood You, Would I Have This Look on My Face? New York: Random House.

Alexander, Edward P., Mary Alexander, and Juilee Decker. 2017. Museums in Motion: An Introduction to the History and Functions of Museums. Third Edition. Lanham, Maryland: Rowman \& Littlefield.

Amineh, Roya Jafari, and Hanieh Davatgari Asl. 2015. "Review of Constructivism and Social Constructivism." Journal of Social Sciences, Literature and Languages 1 (1): 9-16.

Amsel-Arieli, Melody. 2012. "Cabinets of Curiosity (Wunderkammers)." History Magazine 13: 40-42.

Arteaga, Allison. 2019. “NNOCCI Governance.” Climate Interpreter (blog). July 2, 2019. https://climateinterpreter.org/content/nnocci-governance.

Arteaga, Allison. 2020. "Thinking Bigger On Solutions." Climate Interpreter (blog). February 28, 2020. https://climateinterpreter.org/content/thinking-bigger-solutions.

AZA. "Quarter Century Award." n.d. Association of Zoos \& Aquariums. Accessed September 17, 2021. https://www.aza.org/quarter-century-award.

Bales, Susan Nall, Julie Sweetland, and Andrew Volmert. 2015. "How to Talk about Climate Change and the Ocean: A FrameWorks MessageMemo." Washington, DC: FrameWorks Institute.

Ballantyne, Roy, and Jan Packer. 2005. "Promoting Environmentally Sustainable Attitudes and Behaviour through Free-choice Learning Experiences: What Is the State of the Game?" Environmental Education Research 11 (3): 281-95. https://doi.org/10.1080/13504620500081145.

Ballantyne, Roy, Jan Packer, Karen Hughes, and Lynn Dierking. 2007. "Conservation Learning in Wildlife Tourism Settings: Lessons from Research in Zoos and Aquariums." Environmental Education Research 13 (July). https://doi.org/10.1080/13504620701430604.

Ballantyne, Roy, and Jan Packer. 2011. "Using Tourism Free-choice Learning Experiences to Promote Environmentally Sustainable Behaviour: The Role of Post-visit 'Action Resources." Environmental Education Research 17 (2): 201-15. https://doi.org/10.1080/13504622.2010.530645. 
Bamiro, Adekunle Oladipupo. 2015. "Effects of Guided Discovery and Think-Pair-Share Strategies on Secondary School Students' Achievement in Chemistry." SAGE Open 5 (1): 2158244014564754. https://doi.org/10.1177/2158244014564754.

Beck, Larry, and Ted Cable. 2002. "The Meaning of Interpretation.” Journal of Interpretation Research 7 (1): 7-10. https://doi.org/10.1177/109258720200700102.

Benchley, Belle. 1934. "The Zoological Gardens of San Diego: Its Story and Its History." Zoonooz, March 1934.

Bishop-Williams, Katherine E. 2020. "Wicked Problems through a New Lens: Combining Active Learning Strategies for Solutions-Oriented Teaching." Journal of the Scholarship of Teaching and Learning 20 (1): 158-62.

Bostrom, Ann, Gisela Böhm, Adam L. Hayes, and Robert E. O’Connor. 2020. "Credible Threat: Perceptions of Pandemic Coronavirus, Climate Change and the Morality and Management of Global Risks." Frontiers in Psychology 11 (October): 578562. https://doi.org/10.3389/fpsyg.2020.578562.

Brulle, Robert. 2018. “30 Years Ago Global Warming Became Front-Page News - and Both Republicans and Democrats Took It Seriously.” The Conversation. June 19, 2018. http://theconversation.com/30-years-ago-global-warming-became-front-page-news-and-bothrepublicans-and-democrats-took-it-seriously-97658

Bunten, Alexis, and Shannon Arvizu. 2013. "Turning Visitors into Citizens: Using Social Science for Civic Engagement in Informal Science Education Centers." The Journal of Museum Education 38 (3): 260-72.

Callaghan, Beth. 2020. "Age Appropriate Climate Education and Conservation Messaging." California Classroom Science, from the California Association of Science Educators. https://classroomscience.org/articles/fyi/age-appropriate-climate-education-and-conservationmessaging.

Callaghan, Beth and McKenzie Miller. 2021. Interview by Kathryn Papoulias. August 30, 2021.

Cameron, Fiona, Bob Hodge, and Juan Francisco Salazar. 2013. "Representing Climate Change in Museum Space and Places.” WIREs Climate Change 4 (1): 9-21. https://doi.org/10.1002/wcc.200.

Ceresia, Isabella. 2019. "ClimaTeens Participate in Climate Strike.” New England Aquarium (blog). September 27, 2019. https://www.neaq.org/blog/climateens-participate-in-climate-strike/.

Charity Navigator. 2021. "Historical Ratings for San Diego Zoo Wildlife Alliance." Charity Navigator. May 1, 2021.

http://www.charitynavigator.org/index.cfm?bay=search.history\&orgid=4803.

Clayton, Susan, John Fraser, and Carol D. Saunders. 2009. "Zoo Experiences: Conversations, Connections, and Concern for Animals." Zoo Biology 28 (5): 377-97.

https://doi.org/10.1002/zoo.20186. 
Clayton, Susan, Jerry Luebke, Carol Saunders, Jennifer Matiasek, and Alejandro Grajal. 2014. "Connecting to Nature at the Zoo: Implications for Responding to Climate Change."

Environmental Education Research 20 (4): 460-75.

https://doi.org/10.1080/13504622.2013.816267.

Clayton, Susan. 2020. "Climate Anxiety: Psychological Responses to Climate Change." Journal of Anxiety Disorders 74 (August): 102263. https://doi.org/10.1016/j.janxdis.2020.102263.

Dierking, Lynn. 1991. "Learning Theory and Learning Styles: An Overview." Journal of Museum Education 16 (1): 4-6.

Dunch, Victoria. 2021. Interview by Kathryn Papoulias. August 6, 2021.

Dunn, Peter O, and David W Winkler. 1999. "Climate Change Has Affected the Breeding Date of Tree Swallows throughout North America." Proceedings of the Royal Society of London. Series B: Biological Sciences 266 (1437): 2487-90. https://doi.org/10.1098/rspb.1999.0950.

Ennes, Megan. 2020. "NNOCCI Climate Science Fundamentals.” Climate Interpreter (blog). July 15, 2020. https://climateinterpreter.org/content/nnocci-climate-science-fundamentals.

Falk, John H. 2014. "Evidence for the Educational Value of Zoos and Aquariums." World Association of Zoos and Aquariums, 2014.

Falk, John H., and Lynn D. Dierking. 2018. Learning from Museums: Visitor Experiences and the Making of Meaning. Walnut Creek, CA: AltaMira Press.

Fikes, Bradley. 2019. "Paul Baribault Takes Charge as the San Diego Zoo's First New Leader in 34 Years." San Diego Union-Tribune, November 8, 2019, sec. Environment.

https://www.sandiegouniontribune.com/news/environment/story/2019-11-08/paul-baribault-zooceo.

Fotsch, Paul M. 2004. “Tourism's Uneven Impact: History on Cannery Row.” Annals of Tourism Research 31 (4): 779-800. https://doi.org/10.1016/j.annals.2004.02.004.

Foutz, Susan, and Claire Thoma Emmons. 2017. "Application and Adaptation of an Institutional Learning Framework.” Journal of Museum Education 42 (2): 179-89. https://doi.org/10.1080/10598650.2017.1306663.

Fox, Richard. 2001. “Constructivism Examined.” Oxford Review of Education 27 (1): 23-35. https://doi.org/10.1080/03054980125310.

Friedman, Alan J. 2010. The Evolution of the Science Museum. Physics Today, 63(10): 45-51.

Geiger, Nathaniel, Janet K. Swim, John Fraser, and Kate Flinner. 2017. "Catalyzing Public Engagement With Climate Change Through Informal Science Learning Centers." Science Communication 39 (2): 221-49. https://doi.org/10.1177/1075547017697980.

Gilden, Jaime, and Ellen Peters. 2017. "Public Knowledge, Scientific Literacy, Numeracy, and Perceptions of Climate Change." Oxford Research Encyclopedia of Climate Science. April 26, 2017. https://doi.org/10.1093/acrefore/9780190228620.013.305. 
Gordon, David G. 1999. "The Monterey Bay National Marine Sanctuary.” In A Natural History of the Monterey Bay National Marine Sanctuary, 1-10. Monterey, California: Monterey Bay Aquarium Foundation.

Hamilton, Pat, and Evelyn Christian Ronning. 2020. "Why Museums? Museums as Conveners on Climate Change." Journal of Museum Education 45 (1): 16-27.

https://doi.org/10.1080/10598650.2020.1720375.

Harvey, Blane, Jonathan Ensor, Liz Carlile, Ben Garside, Zachary Patterson, and Lars Otto Naess. 2012. "Climate Change Communication and Social Learning - Review and Strategy Development for CCAFS." CCAFS Working Paper No. 22. Copenhagen, Denmark: CGIAR Research Program on Climate Change, Agriculture and Food Safety (CCAFS). www.ccafs.cgiar.org.

Hein, George E. 2004. "John Dewey and Museum Education." Curator: The Museum Journal 47 (4): 413-27. https://doi.org/10.1111/j.2151-6952.2004.tb00136.x.

Henry, Catherine, and Kate Carter. 2021. "Communicating Climate Change Content in Small and Mid-Sized Museums: Challenges and Opportunities." Journal of Museum Education 46 (3): 321-33. https://doi.org/10.1080/10598650.2021.1937791.

Hirji, Zahara. 2021. “'It Is Unequivocal': Humans Are Driving Worsening Climate Disasters, Hundreds Of Scientists Said In A New Report.” BuzzFeed News. August 9, 2021. https://www.buzzfeednews.com/article/zahrahirji/ipcc-climate-change-report-2021.

Hirsh, Sophie. 2020. “'Intersectional Environmentalist' Platform Launches to Dismantle Racism in the Climate Movement." Green Matters. August 18, 2020.

https:/www.greenmatters.com/p/intersectional-environmentalist-leah-thomas.

Hunt, Terry L., and Carl P. Lipo. 2009. "Revisiting Rapa Nui (Easter Island) 'Ecocide."' Pacific Science 63 (4): 601-16. https://doi.org/10.2984/049.063.0407.

IPCC. "About the IPCC." n.d. Intergovernmental Panel on Climate Change. Accessed September 2, 2021. https://www.ipcc.ch/about/.

Jericho, Greg. 2021. "The IPCC Report Is a Massive Alert That the Time for Climate Action Is Nearly Gone, but Crucially Not Gone Yet.” The Guardian. August 11, 2021. http://www.theguardian.com/business/grogonomics/2021/aug/12/the-ipcc-report-is-a-massivealert-that-the-time-for-climate-action-is-nearly-gone-but-crucially-not-gone-yet.

Jerving, Sara, Katie Jennings, Masako Melissa Hirsch, and Susanne Rust. 2015. "What Exxon Knew about the Earth's Melting Arctic.” Los Angeles Times, October 9, 2015. https:/graphics.latimes.com/exxon-arctic/

Johnson, Ayana Elizabeth, and Katharine K. Wilkinson, eds. 2020. All We Can Save: Truth, Courage, and Solutions for the Climate Crisis. 1st ed. New York: One World.

Johnston, David. 2021. "25 Best Zoos in the US to Visit in 2021." Road Affair (blog). July 13, 2021. https://www.roadaffair.com/best-zoos-in-the-usa/.

Jordan, Lindsay. 2021. Interview by Kathryn Papoulias. August 19, 2021. 
Kacharoo-Levine, Maya. 2021. "10 Best Aquariums in the U.S.” Travel + Leisure. July 19, 2021. https://www.travelandleisure.com/attractions/zoos-aquariums/best-aquariums-in-the-us.

Kelly, Lisa-Anne DeGregoria, Jerry F. Luebke, Susan Clayton, Carol D. Saunders, Jennifer Matiasek, and Alejandro Grajal. 2014. "Climate Change Attitudes of Zoo and Aquarium Visitors: Implications for Climate Literacy Education." Journal of Geoscience Education 62 (3): 502-10.

Kim, Mijung, and Eduardo Dopico. 2016. "Science Education through Informal Education." Cultural Studies of Science Education 11 (2): 439-45. https://doi.org/10.1007/s11422-014-96393.

Kimmerer, Robin Wall. 2013. Braiding Sweetgrass: Indigenous Wisdom, Scientific Knowledge, and the Teachings of Plants. Minneapolis, MN: Milkweed Editions.

King, Susan. 2019. "Zoos Have an Image Problem. Can Animal Planet and the San Diego Zoo Fix That?" Los Angeles Times. August 7, 2019. https://www.latimes.com/entertainmentarts/tv/story/2019-08-06/animal-planet-the-zoo-san-diego-safari-park.

Kraljevic, Gabriel M. 2011. "Does the Manitoba Science Curriculum Help Teach Teens to Be More Environmentally-Minded?” M.Ed., Canada: University of Manitoba (Canada). http://www.proquest.com/docview/1236697263/abstract/14B1404AD9CB42DCPQ/1.

Kretser, Jennifer, and Katie Chandler. 2020. "Convening Young Leaders for Climate Resilience." Journal of Museum Education 45 (1): 52-63.

https://doi.org/10.1080/10598650.2020.1723994.

Le, Kelley Tuong-Vy. 2019. "Keeping It Cool: Approaching Global Climate Change as a Socioscientific Issue to Support Science Teachers Looking to Address the NGSS.” Ed.D., University of California, Los Angeles. http://www.proquest.com/docview/2247141669/abstract/B5DEBE86CDA446E9PQ/1.

Lee, Katharine, Nathalia Gjersoe, Saffron O'Neill, and Julie Barnett. 2020. "Youth Perceptions of Climate Change: A Narrative Synthesis.” WIREs Climate Change 11 (3): e641. https://doi.org/10.1002/wcc.641.

Leiserowitz, A., Maibach, E., Rosenthal, S., Kotcher, J., Carman, J., Wang, X., Marlon, J., Lacroix, K., and Goldberg, M. 2021. Climate Change in the American Mind, March 2021. Yale University and George Mason University. New Haven, CT: Yale Program on Climate Change Communication. https://climatecommunication.yale.edu/publications/climate-change-in-theamerican-mind-march-2021/

MacGregor, Arthur. 2001. "The Ashmolean as a Museum of Natural History, 1683-1860." Journal of the History of Collections 13 (2): 125-44. https://doi.org/10.1093/jhc/13.2.125.

Markowitz, Ezra, and Azim Shariff. 2012. "Climate Change and Moral Judgment." Nature Climate Change 2 (March): 243-47. https://doi.org/10.1038/NCLIMATE1378.

Monroe, Martha C., Richard R. Plate, Annie Oxarart, Alison Bowers, and Willandia A. Chaves. 2017. "Identifying Effective Climate Change Education Strategies: A Systematic Review of the 
Research." Environmental Education Research 25 (6): 791-812. https://doi.org/10.1080/13504622.2017.1360842.

Monterey Bay National Marine Sanctuary. "Ecosystem Observations: Annual Report for the Monterey Bay National Marine Sanctuary.” 2006. Annual Report. Monterey, California: National Oceanic and Atmospheric Administration, Monterey Bay National Marine Sanctuary. https://nmsmontereybay.blob.core.windows.net/montereybay$\mathrm{prod} / \mathrm{media} /$ reports/2006/eco/ecoobs2006.pdf.

Moser, Susanne C. 2010. "Communicating Climate Change: History, Challenges, Process and Future Directions." WIREs Climate Change 1 (1): 31-53. https://doi.org/10.1002/wcc.11.

Moser, Susanne C. 2016. "Reflections on Climate Change Communication Research and Practice in the Second Decade of the 21st Century: What More Is There to Say?" WIREs: Climate Change 7 (3): 345-69. https://doi.org/10.1002/wcc.403.

NAI. "Mission, Vision, and Core Values." n.d. National Association for Interpretation. Accessed September 2, 2021.

https://www.interpnet.com/NAI/interp/About/About_NAI/What_We_Believe/nai/_About/Missio n_Vision_and_Core_Values.aspx?hkey=ef5896dc-53e4-4dbb-929e-96d45bdb1cc1.

New England Aquarium. 2021. "Human-Caused North Atlantic Right Whale Deaths Are Being Undercounted: As Recent Sightings of Entangled Whales Raise Alarm, Scientists Say Annual Counts of Right Whale Carcasses Do a Poor Job of Indicating True Death Toll." ScienceDaily. February 25, 2021. https://www.sciencedaily.com/releases/2021/02/210225082449.htm.

"NNOCCI - CCEP Alliance." n.d. Climate Change Education Partnership Alliance (blog). Accessed September 11, 2021. https://ccepalliance.org/nnocci/.

Nygren, Nina Viktoria, and Sanna Ojalammi. 2018. "Conservation education in zoos: A literature review." TRACE $\therefore$ Journal for Human-Animal Studies 4: 62-76.

https://doi.org/10.23984/fjhas.66540.

O’Neill, Saffron J., and Mike Hulme. 2009. “An Iconic Approach for Representing Climate Change.” Global Environmental Change 19 (4): 402-10.

https://doi.org/10.1016/j.gloenvcha.2009.07.004.

Oliver, Mary C., and Michael J. Adkins. 2020. “'Hot-Headed' Students? Scientific Literacy, Perceptions and Awareness of Climate Change in 15-Year Olds across 54 Countries." Energy Research \& Social Science 70 (December): 101641. https://doi.org/10.1016/j.erss.2020.101641.

Palumbi, Stephen R., and Carolyn Sotka. 2011. The Death and Life of Monterey Bay: A Story of Revival. Island Press.

Piao, Shilong, Qiang Liu, Anping Chen, Ivan A. Janssens, Yongshuo Fu, Junhu Dai, Lingli Liu, Xu Lian, Miaogen Shen, and Xiaolin Zhu. 2019. "Plant Phenology and Global Climate Change: Current Progresses and Challenges.” Global Change Biology 25 (6): 1922-40. https://doi.org/10.1111/gcb.14619. 
Plumer, Brad, and Henry Fountain. 2021. "A Hotter Future Is Certain, Climate Panel Warns. But How Hot Is Up to Us." The New York Times, August 9, 2021, sec. Climate.

https://www.nytimes.com/2021/08/09/climate/climate-change-report-ipcc-un.html.

Popkewitz, Thomas S. 1998. "Dewey, Vygotsky, and the Social Administration of the Individual: Constructivist Pedagogy as Systems of Ideas in Historical Spaces:" American Educational Research Journal 35 (4): 535-70. https://doi.org/10.3102/00028312035004535.

Pritchard, Alan. 2009. Ways of Learning: Learning Theories and Learning Styles in the Classroom. Second edition. New York, NY: Routledge.

Rabb, George B. 1994. "The Changing Roles of Zoological Parks in Conserving Biological Diversity." American Zoologist 34 (1): 159-64. https://doi.org/10.1093/icb/34.1.159.

Read, Rupert. 2021. “This Year's Nobel Peace Prize Should've Gone to Greta Thunberg What's More Important than Climate Action?” The Independent. October 9, 2021.

https://www.independent.co.uk/voices/greta-thunberg-nobel-peace-prize-climate-b1935328.html.

Reisner, Nick, and Sonia Mulgund. 2019. "ClimaTeens: Teens Combating Climate Change." New England Aquarium (blog). April 19, 2019. https://www.neaq.org/blog/climateens-teenscombating-climate-change/.

Rosenzweig, Cynthia, David Karoly, Marta Vicarelli, Peter Neofotis, Qigang Wu, Gino Casassa, Annette Menzel, et al. 2008. "Attributing Physical and Biological Impacts to Anthropogenic Climate Change.” Nature 453 (7193): 353-57. https://doi.org/10.1038/nature06937.

Rukeyser, Muriel. 2005. "The Speed of Darkness." In The Collected Poems of Muriel Rukeyser, edited by Janet E. Kaufman and Anne F. Herzog, 1st ed., 465. Pittsburgh, PA: University of Pittsburgh Press.

Ryan, Jerry. 2011. The Forgotten Aquariums of Boston. Third Revised Edition. Boston, Mass.: Finley Aquatic Books.

Sakowski, Danielle N. 2020. "Exploring Climate Change and Community Engagement in the Museum.” MA Thesis, Seattle, WA: University of Washington.

http://www.proquest.com/docview/2439587003?pq-origsite=primo.

Scharf, Sylvia. 2013. "Blue Impact Videos.” Climate Interpreter (blog). August 13, 2013. https://climateinterpreter.org/resource/blue-impact-videos.

Schunk, Dale H. 2012. Learning Theories: An Educational Perspective. Sixth Edition. Boston, MA: Pearson Education, Inc.

SDZG. "2019 Highlights.” 2020. Annual Report. San Diego Zoo Global.

Simmons, John Edward. 2010. "History of Museums." Encyclopedia of Library and Information Sciences, 1812-23.

Simon, Amy, John Whaley, Robert Pérez, and Justin Adams. 2019. "Heartwired to Love the Ocean: A Messaging Guide for Advocates." Goodwin Simon Strategic Research and Wonder: Strategies for Good. 
Skibins, Jeffrey C., Robert B. Powell, and Marc J. Stern. 2012. "Exploring Empirical Support for Interpretation's Best Practices.” Journal of Interpretation Research 17 (1): 25-44. https://doi.org/10.1177/109258721201700103.

Smithsonian Institution. "Reading Climate Change from Fossil Leaves." 2021. Smithsonian National Museum of Natural History. Accessed October 8, 2021. http://naturalhistory.si.edu/education/teaching-resources/paleontology/reading-climate-changefossil-leaves.

Sobel, David. 2019. "Beyond Ecophobia: Reclaiming the Heart in Nature Education." Community Works Journal, June 1, 2019.

https://magazine.communityworksinstitute.org/beyond-ecophobia-reclaiming-the-heart-innature-education/.

Somerville, Richard C. J., and Susan Joy Hassol. 2011. "Communicating the Science of Climate Change.” Physics Today 64 (10): 48-53. https://doi.org/10.1063/PT.3.1296.

Starbuck, Juliet. 2018. "Adolescence and Learning - the Teenage Brain.” World of Better Learning | Cambridge University Press (blog). September 4, 2018.

https://www.cambridge.org/elt/blog/2018/09/04/adolescence-learning-teenage-brain/.

Stern, Marc J., Robert B. Powell, Kevin D. McLean, Emily Martin, Jennifer M. Thomsen, and Bethany A. Mutchler. 2013. "The Difference Between Good Enough and Great: Bringing Interpretive Best Practices to Life.” Journal of Interpretation Research 18 (2): 79-100. https://doi.org/10.1177/109258721301800205.

Stevenson, Kathryn, and Nils Peterson. 2016. "Motivating Action through Fostering Climate Change Hope and Concern and Avoiding Despair among Adolescents." Sustainability 8 (1): 6. https://doi.org/10.3390/su8010006.

Steyer, Caroline. 2015. "15-Year-Old Climate Activist Speaks to UN General Assembly." HuffPost. July 2, 2015. https://www.huffpost.com/entry/xiuhtezcatl-speaks-to-un_n_7715192.

Suarez, Andrew V., and Neil D. Tsutsui. 2004. "The Value of Museum Collections for Research and Society." BioScience 54 (1): 66-74. https://doi.org/10.1641/00063568(2004)054[0066:TVOMCF]2.0.CO;2.

Sutton, Sarah, and Cynthia Robinson. 2020. "Museums and Public Climate Action." Journal of Museum Education 45 (1): 1-4. https://doi.org/10.1080/10598650.2020.1722513.

Swanson, Rachel, and Stephanie Joseph. 2021. "The Final Straw: New York Aquarium Youth Remind You to 'Give a Sip.'” Association of Zoos and Aquariums, Conservation Education Committee Newsletter, 15 (1): 6-7.

Swim, Janet K., Nathaniel Geiger, John Fraser, and Nette Pletcher. 2017. "Climate Change Education at Nature-Based Museums." Curator: The Museum Journal 60 (1): 101-19. https://doi.org/10.1111/cura.12187. 
“To Frame Climate Change, Lead with a Researched Value-Not a 'Rogue' One.” 2017. Climate Interpreter (blog). January 20, 2017. https://climateinterpreter.org/content/frameclimate-change-lead-researched-value $\%$ E2\%80\%94not- $\%$ E2\%80\%9Crogue $\%$ E2\%80\%9D-one.

Tomovic, Cynthia, Sueanne McKinney, and Clair Berube. 2017. "Scientific Literacy Matters: Using Literature to Meet Next Generation Science Standards and 21st Century Skills." K-12 STEM Education 3 (2): 179-91.

Tschaenn, Nate M., Robert E. Lyons, Dottie Miles, and Jules Bruck. 2014. “Analysis of Best Practices for Interpretation Development at Public Gardens." Journal of Interpretation Research 19 (2): 65-78. https://doi.org/10.1177/109258721401900206.

Ueber, Edward, and Alec MacCall. 2005. "The Rise and Fall of the California Sardine Empire." In Climate Variability, Climate Change and Fisheries, by Michael H. Glantz, 31-48. Cambridge University Press.

van Dusen, Debra. 1985. “The Nation's Newest Aquarium.” BioScience 35 (10): 614-17. https://doi.org/10.2307/1309983.

Walther, Gian-Reto, Eric Post, Peter Convey, Annette Menzel, Camille Parmesan, Trevor J. C. Beebee, Jean-Marc Fromentin, Ove Hoegh-Guldberg, and Franz Bairlein. 2002. "Ecological Responses to Recent Climate Change." Nature 416 (6879): 389-95. https://doi.org/10.1038/416389a.

Weil, Stephen. 1999. "From Being about Something to Being for Somebody: The Ongoing Transformation of the American Museum.” Daedalus 128 (3): 229-258.

Worland, Justin. 2017. "Climate Change Used to Be a Bipartisan Issue. Here's What Changed." TIME, July 27, 2017. https://time.com/4874888/climate-change-politics-history/.

Wosen, Jonathan. 2021. "Zoo and Safari Park Parent Organization Rebrands as San Diego Zoo Wildlife Alliance." San Diego Union-Tribune. March 3, 2021.

https://www.sandiegouniontribune.com/business/story/2021-03-03/zoo-and-safari-park-parentorganization-rebrands-as-san-diego-zoo-wildlife-alliance. 


\title{
APPENDIX A: SAN DIEGO ZOO WILDLIFE ALLIANCE WEBSITE SOURCES
}

\author{
San Diego Zoo Wildlife Alliance. 2021a. "San Diego Zoo Wildlife Alliance Timeline." \\ https://library.sandiegozoo.org/sdzg-history-timeline/
}

\section{6}

- Drs. Harry Wegeforth, Paul Wegeforth, Fred Baker, Joseph C. Thompson and naturalist Frank Stephens hold their first organizational meeting. 10/02/1916

- One of San Diego Zoo's first animals arrives: “Caesar” (photo), Kodiak bear. 11/1916. Died 9/12/1936.

- Articles of incorporation are submitted to the city, park commission, and state. They are duly executed on $12 / 11 / 1916$. Dr. Wegeforth is president of the Society. (Related article).

\section{3}

- Zoo's grand opening: 10 cent admission for adult non-members. Children free. Entrance is through the Reptile House (the International Harvester Building from the 1915-1916 Exposition). 1/1/1923.

- Intense development of zoo infrastructure, mission and collection. (Related article).

- First lion grotto constructed: “Prince“, “Julia”, and “Sara” have a new home thanks to Ellen B. Scripps' donation. 4/1923 (Demolished in 1999 to build Douc Langur enclosure.)

- First Asian elephants, “Empress” and “Queenie”, arrive from Bombay Lumber Co., via Frank Buck. Dr. Wegeforth and Harry Edwards ride the elephants from the Santa Fe Depot to the Zoo. 5/20/1923

- Frank Buck, “Bring 'em back alive”, signs a three-year contract as Zoo director. Three months later he is fired and sues the Zoo. 6/13/1923

- Tom Faulconer (Park Board secretary) accepts the Directorship of the Zoo. 6/13/1923.

- Two dromedary camels (one hump), “Turk” and “Scar”, received from the Lasky Film Corp. One Bactrian camel, “Dick”, received from Ringling Circus. $6 / 24 / 1923$

- First elephant seal arrives. $7 / 20 / 1923$

- Scripps' flight cage for shore and wading birds (then the tallest in the world: 82 ' high, 150 ' long, $74^{\prime} 3^{\prime \prime}$ wide at one end and $62^{\prime}$ at the other). Built at a cost of $\$ 15,000$. Located on the south side of Primate Mesa. Dedicated 9/8/1923. (photo)

- Mr. \& Mrs. P.F. O'Rourke purchase the Nevada State Building. They pay to move it and the Standard Oil Building to Zoo grounds for use as the Children's Education Center and Junior Zoological Society departments. Planned completion is Christmas, 1923.

- First American alligators in the Zoo, donated by General Terry.

- First Malayan sun bear on exhibit, “Sunny”. 12/02/1923 
Home Search Research News Archives About Help

- First recorded animal death from Coccidioidomycosis (a fungal disease)-a tropical American monkey. This is the same disease that kills Mbongo in 1942.

- Grizzly bears born. 1/08/1936.

- First Galapagos albatross. 1/20/1936

- First Gray mangabey for the Zoo and first for the U.S.

- First Babirusa and first Sambar deer. June/1936

- Construction begun on new Reptile House (still in use) and Elephant Barn. International Harvester Building becomes a cafe

- Wegeforth Bowl and Fern Canyon landscaping begun (WPA Projects).

- "Puddles" the hippo (born at the Brookfield Zoo 7/8/1935) arrives. First time a hippo is exhibited in a Pacific Coast zoo. 8/19/1936

\section{7}

- A second flight cage, originally called "the Great Eagle cage", is built to house birds of prey on the north side of Primate Mesa. It is the world's largest bird cage of its time. (This aviary is later expanded and converted to a walk-through tropical rain forest aviary.) Dedicated 03/07/1937

- Reptile Mesa is completed with outdoor pits, a Galapagos tortoise enclosure, land tortoise pens and pools for alligators and crocs.

- First emu hatching.

\section{8}

- Two giraffes arrive, "Lofty" and "Patches".

- First zoo concessions manager hired.

- First spectacled bears received. 3/11/1938

\section{9}

- Zoo begins collaborative education program with San Diego schools.

\section{0}

- First cheetah arrives, “Bong”.

- Hippos "Rube" and "Rubie" arrive

- Belle Benchley publishes My Life in a Man Made Jungle.

- First Bornean orangutan arrives, "Bujang”.

- First Zoo lectures, "Caesar, the Kodiak bear", by Commander J.C. Thompson.

- First Lesser pandas arrive, reproduce in 1941.

- First De Brazza's guenons arrive. First offspring June/1945.

- First Zoo summer school program is begun.

\section{1}

- Dr. Harry Wegeforth dies at the age of $59 .(1 / 07 / 1882-6 / 25 / 1941)$

- Dr. Charles Schroeder resigns at the Zoo's Veterinary Pathologist to become assistant Director to the Veterinary Department of Lederle Lab (4/15/1941). Returns to Zoo as Director in 1954.

- Dr. Frank D. McKenney takes over from Dr. Charles Schroeder as Zoo's Veterinary Pathologist. 6/1941

- WWII: Zoo plants its own vegetables in Mission Valley to save money during the war years.

\section{2}

- First number drawn by Selective Services belongs to a young Zoo employee, Howard Lee. The publicity given Lee's leaving his job was carried all over the world.

- First jungle fowl turned loose in the Zoo 


\section{9}

- Inauguration of Skyfari aerial tram, spans approximately 1,800' of Zoo canyons and mesas. 3/20/1969

- First Przewalski's horse born, “Bolinda”. 4/08/1969

- New kiwi enclosure (first SDZ nocturnal exhibit) dedicated. 6/18/1969

- First year with 3 million attendance. Admission is $\$ 1.50$ for adults, kids free.

- Zoo increases membership cost to $\$ 12.50$

- Society president Anderson Borthwick signs agreement with Mayor Frank Curran to establish wildlife preserve on San Diego City land. Ground breaking for development of 1,800 acres leased by the San Diego Zoo for development of a "natural environment zoo" in San Pasqual. 5/14/1969

\section{2}

- Wild Animal Park (1800 acre preserve) Opens to the public 9am, 5/10/72. 3,000 visitors on first day. Admission $\$ 1.25$ for adults, free for Zoo members and children 15 years and younger. $\$ 1.50$ to ride the tram. More than $\$ 10$ million spent on construction. (\$4 million society funds, $\$ 6$ million bond issue approved 11/3/70).

- Wild Animal Park Monorail is dedicated 02/18/72. Mayor Pete Wilson drives in the last "golden spike". Opens to the public 5/10/72.

- First and only Blue bear in captivity (a color morph of the American black bear) acquired by a zoo expedition to Alaska.

- Dr. Schroeder retires as Director of Zoo. Began tenure in 1954. 5/1972

- Dr. Donald J. Kinter assumes directorship. 8/16/1972 (Resigns under pressure 2/12/1973).

- First North African ground hornbill hatched at Wild Animal Park, receives Bean Award.

- First White rhino calf born at the Wild Animal Park, "Zibulo". 10/11/1972

- Six (6) Arabian oryx (4 males, 2 females) are transferred from the world herd at the Phoenix Zoo to the Wild Animal PArk. 11/15/1972

- Conservation medals awarded to Philip L. Boyd and Mervyn Cowie.

\section{5}

- CRES (Center for Reproduction of Endangered Species) is established by Dr. Kurt Benirschke and Zoo Director Charles Bieler. Dr. Benirschke assumes directorship on 1/01/1975.

- Conservation Medals awarded to Bernhard Grzimek (Frankfurt Zoo) and Roland Lindeman (Catskill Game Farm) 


\section{0}

- San Diego Zoo partners with Nature and Culture International $(\mathrm{NCl})$ to protect the Cazaderos Forest Preserve through the Living Forest Carbon Offset Program.

- San Diego Zoo hosts a conference of world experts to discuss “The Future of Zoos”. 2/23-24/2010

- Conrad Prebys Polar Bear Plunge re-opens at the Zoo after a \$1 million renovation. 3/26/2010

- Board of Trustees approves rebranding the organization's three facilities as the San Diego Zoo (no change), San Diego Zoo Safari Park, and San Diego Zoo Institute for Conservation Research, under the new umbrella title San Diego Zoo Global. 6/30/2010

- Fetter Family Galapagos Tortoise Exhibit, a \$1 million renovation project, opens at the Zoo. 9/16/2010

- Creepy Crawly Festival is first held at the Park. 10/23/2010

- Safari Park Elephant habitat expands to 5.5 acres 12/7/2010

- 2010 Conservation Medal awarded to Ivan Gayler, of Nature and Culture International. 2010 
San Diego Zoo Wildlife Alliance. 2021b. "How We're Helping to Save the White Rhino." https://science.sandiegozoo.org/species/white-rhino

\title{
\begin{tabular}{l|l} 
San Diego Zoo & Science
\end{tabular}
}

\author{
\begin{tabular}{|l|l|}
\hline Search Palantir & Submit \\
\hline & Search \\
Science BlogCareersOur Family of Sites
\end{tabular}
}

RESOURCESINVESTOPPORTUNITIESOUR SCIENCEOUR TEAMWHO WE ARE

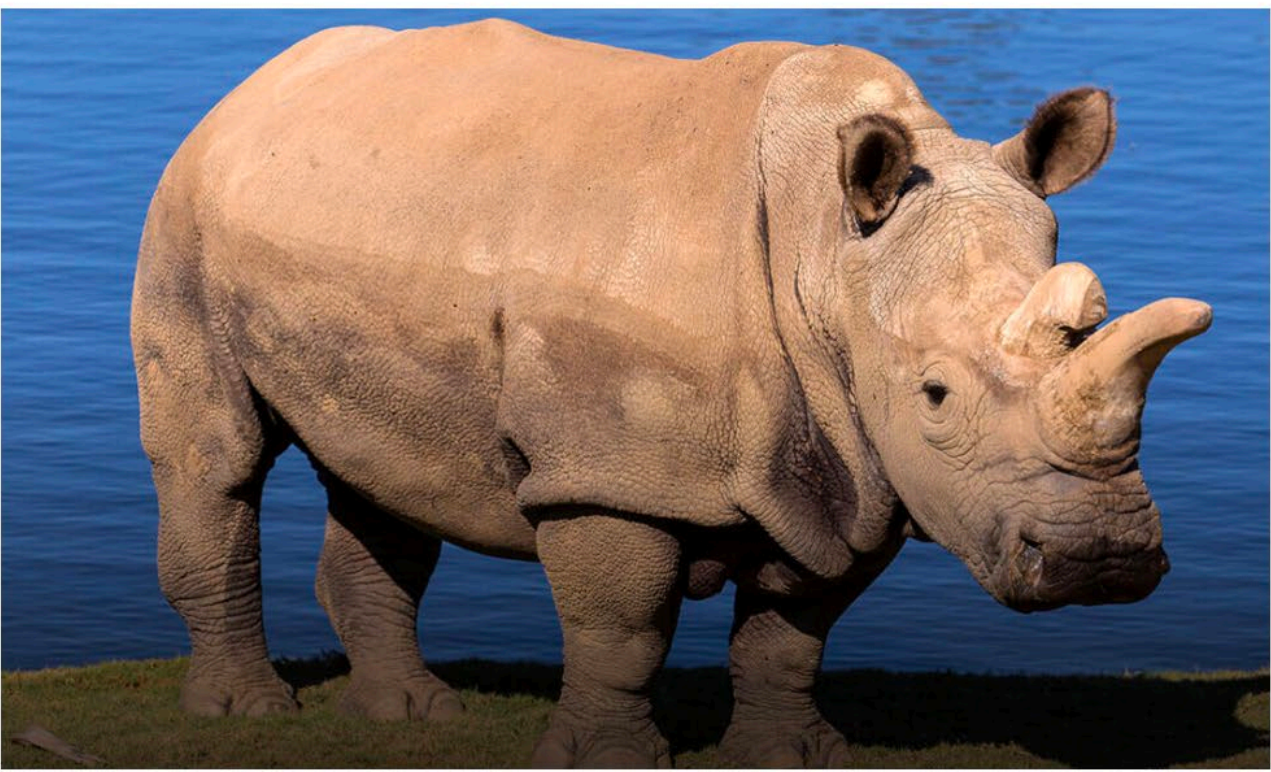

Home
Who We Are

Our Team

Opportunities

Invest

Resource

Science Blog

Institute Careers
Our Family of Site

\section{White Rhino}

Critically endangered

How We're Helping to Save the White Rhino

Conservation Status: Southern white rhino, IUCN Red List - Near Threatened; Northern white rhino, IUCN Red List - Critically Endangered

Threats to Survival: Poaching

\section{Toward a Sustainable Assurance Population}

With over 90 calves born at the San Diego Zoo Safari Park, we are the world's leader in white rhino breeding. However, the zoo population is no longer self-sustaining due to limited reproduction in females born at our institution and others across the globe. As poaching reaches unprecedented levels, a healthy, productive zoo population of white rhinos that can serve as a safety net against extinction has never been more important. San Diego Zoo Wildlife Alliance conservation workers have been working on this problem for decades. Our Recovery Ecology scientists have ruled out behavioral differences between wild and zoo-born females as a probable cause. More recently, our Reproductive Sciences researchers have assessed current and historic diets for zoo-housed rinos in relation to decreased reproduction. They have discovered that a significant portion of rhino diets contain estrogen-mimicking compounds that have the potential to alter reproductive development and contribute to diminished breeding 
$8 / 30 / 2021$

White Rhino I San Diego Zoo Wildlife Alliance

success. Currently, efforts are underway in collaboration with our Nutritional Services Department to formulate improved diets for white rhinos in zoos that will maintain their reproductive health.

\section{Partnering to Protect Rhinos in the Wild}

Together with our partners, we are committed to enhancing the survival of rhinos in the wilderness. San Diego Zoo Wildlife Alliance has a long partnership with the International Rhino Foundation as a member of their Zoo Partners Program. With funding assistance from the San Diego Zoo, the International Rhino Foundation works to protect vulnerable white rhino populations in South Africa, while also helping to develop new methods to combat and reduce poaching.

\section{The Northern White Rhino Initiative}

There are only two northern white rhinos remaining in the world. Consistent with our vision to lead the fight against extinction, San Diego Zoo Wildlife Alliance has made an organization-wide commitment to rescue the northern white rhino from the brink of extinction. With so few animals remaining, saving the northern white rhino will require cutting-edge science and the resources of the Erozen Z0o®. Researchers in our Reproductive Sciences team are developing assisted reproductive technologies, including artificial insemination, in vitro fertilization, and embryo transfer, using southern white rhinos as a model species that may one day serve a surrogate mother role. Meanwhile, our Conservation Genetics team is analyzing whole genome sequences of nine northern white rhinos and four southern white rhinos. The 12 northern white rhino cell lines in the Frozen Zoo® will be used to develop stem cells to create northern white rhino sperm and oocytes for the generation of embryos. One day we hope to see this species saved through successful births of northern white rhino calves at the Nikita Kahn Rhino Rescue Center.

\section{Our Partners}

Association of Zoos and Aquariums partner institutions Mars Hill College

Southeastern Zoo Alliance for Reproduction and Conservation

U.S. Environmental Protection Agency

International Rhino Foundation

North Carolina Zoological Society

The Scripps Research Institute 


\section{San Diego Zoo Wildlife Alliance. 2021c. "About." https://sandiegozoowildlifealliance.org/about-us/about-san-diego-zoo-wildlife-alliance}

\section{Who We Are}

San Diego Zoo Wildlife Alliance is an international, nonprofit conservation organization with two front doors: the San Diego Zoo and the San Diego Zoo Safari Park. We integrate wildlife health and care, science, and education to develop sustainable conservation solutions.

\section{Our Mission}

San Diego Zoo Wildlife Alliance is committed to saving species worldwide by uniting our expertise in animal care and conservation science with our dedication to inspiring passion for nature.

\section{Our Vision}

A World Where All Life Thrives

\section{San DiegoZoo}

\section{Implementing Full-spectrum Conservation Solutions}

Today's most pressing drivers of biodiversity loss include climate change, invasive species, habitat degradation, humanwildlife conflict, wildlife trafficking, and emerging diseases. San Diego Zoo Wildlife Alliance seeks to address and provide solutions for these challenges through our approach to conservation.

- We implement full-spectrum conservation strategies that are collaborative, innovative, and multidisciplinary. We want to enhance the skills and capacity of our local community partners, so that in the long term they remain independent, and are much stronger due to our partnership. Our intent is to partner with the local community, share learnings, and further develop skills and expertise-so that communities, and wildlife that shares the ecosystems, thrive.

- We apply a "One Health" approach to our conservation work, recognizing that the health of humans, animals, plants, and the environment are inextricably linked and dependent on biodiversity and functional ecosystems.

- We protect and restore wildlife populations by implementing evidence-based solutions to address the issues leading to the loss of biodiversity around the world.

- We have an expert team of conservation scientists, nutritionists, veterinarians, wildlife care specialists, and educators who innovate to solve even the toughest conservation challenges. 


\section{Our Values}

\section{- Collaborate}

We nurture alliances with diverse teams, peers, partners, and communities to expand and deepen our impact.

\section{- Innovate}

Together we pioneer new ideas and approaches to ensure the long-term health and survival of wildlife.

\section{- Inspire}

We share our passion for nature to increase understanding, empathy, advocacy, and action for wildlife.

\section{- Thrive}

When we collaborate, innovate, and inspire. We help people and wildlife thrive together for a healthy planet.

\section{Our Work}

\section{Building Alliances to Thrive}

- Working collaboratively with our committed partners, we contribute to larger, global initiatives that aim to restore biodiversity and amplify our impact.

- We develop strategies that further the equitable and sustainable management of the biodiversity upon which so many lives depend.

- We seek to inspire our members, visitors, and donors to join us in cultivating a world where all life thrives. Through respecting and valuing our interconnectedness, together we can make lasting change.

\section{Strengthening Connections Between People and Nature}

- Conservation is first about people. Since 1916, we have created enduring connections between people and wildlife, and our commitment to that mission is stronger than ever.

- We believe that a strong connection to nature is fundamental to saving the world's wildlife.

- We seek to promote empathy and inspire people in ways that will cultivate a shared appreciation for nature and urge individual action on behalf of wildlife.

- We empower members and guests to advocate for policies and initiatives that support responsible collective action to protect the environment for wildlife and people. 
San Diego Zoo Wildlife Alliance. 2021d. "San Diego Zoo Wildlife Alliance 2021 Fact Sheet." https://sandiegozoowildlifealliance.org/pressroom/san-diego-zoo-wildlife-alliance-fact-sheet2021

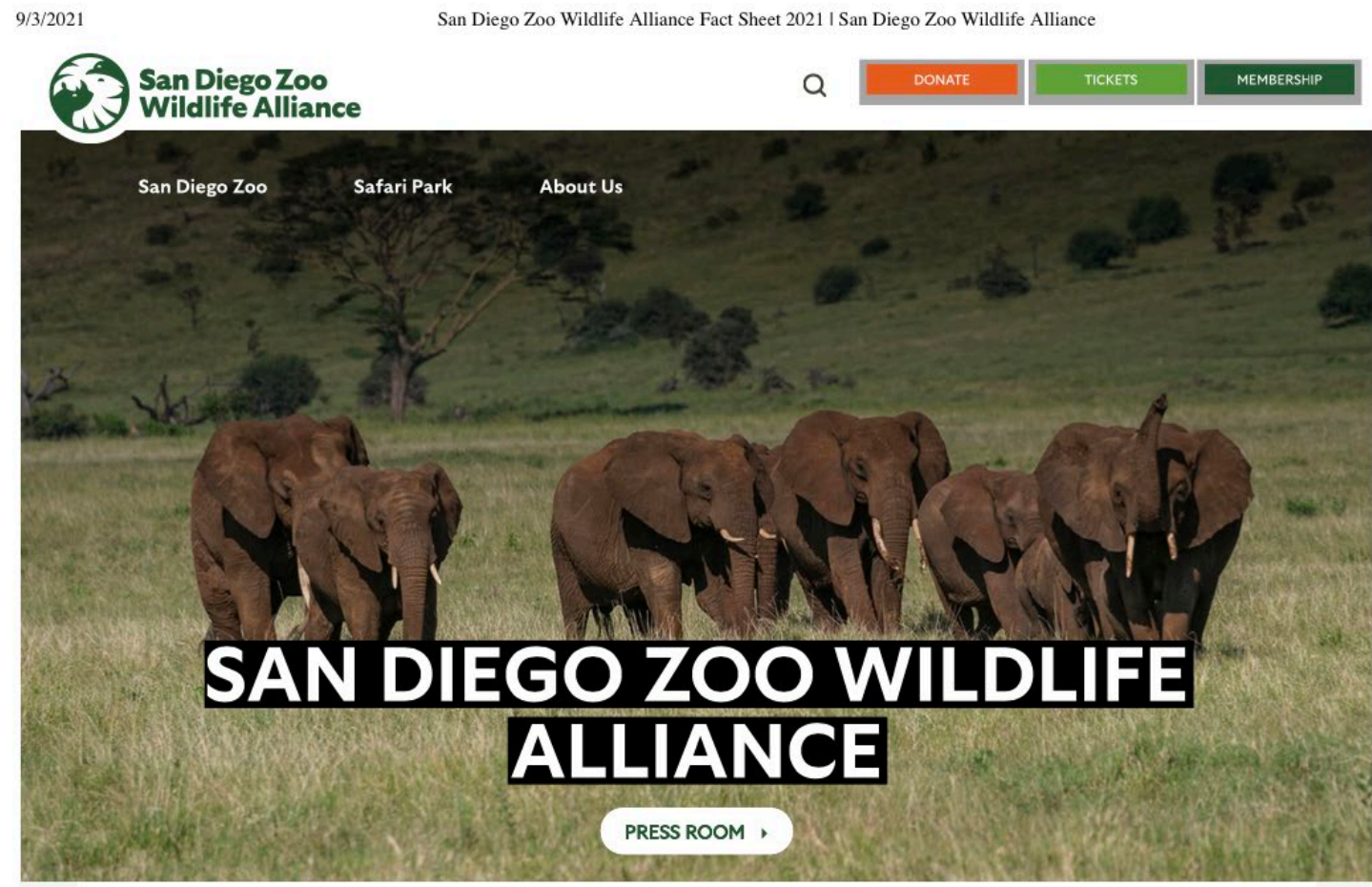

FOR IMMEDIATE RELEASE

CONTACT:

San Diego Zoo Wildlife Alliance

Public Relations

619-685-3291

WEBSITE:

sdzwa.org

WHAT:

San Diego Zoo Wildlife Alliance is an international nonprofit conservation organization that operates two world-class parks, the San Diego Zoo and the San Diego Zoo Safari Park, and empowers people to connect with plants and animals, develop an understanding of nature, and contribute to safeguard wildlife everywhere by becoming Wildlife Allies. With a focus on global health and the interconnectedness of human, wildlife, and habitat health, San Diego Zoo Wildlife Alliance aims to drive greater conservation outcomes including improving biodiversity and developing strong ecosystems. San Diego Zoo Wildlife Alliance collaborates, in partnership with hundreds of individuals and organizations in field projects worldwide, to innovate and implement full-spectrum conservation strategies. This synergy between work at home and in the field inspires and catalyzes conservation action on behalf of wildlife in unparalleled ways and helps create a world where all life thrives.

\section{MISSION:}

San Diego Zoo Wildlife Alliance is committed to saving species worldwide by uniting our expertise in animal care and conservation science with our dedication to inspiring passion for nature.

VALUES:

Collaborate: We nurture alliances with diverse teams, peers, partners and communities to expand and deepen our impact. Innovate: Together, we pioneer new ideas and approaches to ensure the long-term health, welfare and survival of wildlife. Inspire: We share our passion for nature to increase understanding, empathy, advocacy and action for wildlife. 
Thrive: When we collaborate, innovate and inspire, we help people and wildlife to thrive together for a healthy planet.

\section{WHERE:}

\section{San Diego Zoo}

The San Diego Zoo is a 100-acre wildlife park and home to over 12,000 rare and endangered animals, representing more than 650 species and subspecies. Located just north of downtown San Diego in Balboa Park, the Zoo is also an accredited botanical garden, caring for more than 700,000 individual plants, including a prominent curated assemblage of close to 13,000 specimens, representing 3,100 species. Guests are invited to take part in exciting educational experiences and create lasting memories, while supporting San Diego Zoo Wildlife Alliance's conservation efforts worldwide.

\section{San Diego Zoo Safari Park}

The San Diego Zoo Safari Park, an 1,800-acre wildlife park, is home to more than 3,600 animals representing over 300 species. Located in Escondido, California, the Safari Park welcomes more than 1 million guests each year to see animals in herds of mixed species, in expansive savanna habitats. The Safari Park is a vast accredited botanical garden featuring more than 1.3 million plants, representing over 3,700 species. Guests are invited to take part in thrilling safari experiences and create lasting memories, while supporting San Diego Zoo Wildlife Alliance's conservation efforts to save wildlife worldwide.

\section{San Diego Zoo Kids}

San Diego Zoo Kids raises awareness, promotes empathy and inspires a passion for wildlife in a younger audience, including the next generation of wildlife care experts, conservationists and educators. Through a vast array of educational opportunities, San Diego Zoo Kids provides learning experiences for families, students and teachers to experience firsthand our approach to saving wildlife, and support responsible collective action to protect the environment. San Diego Zoo Kids provides free and discounted education programs in San Diego that meet LEAD standards for science curriculum, and provides teacher training. Using powerful storytelling, the San Diego Zoo Kids channel broadcasts enlightening television programming 24 hours a day to more than 350 children's hospitals and Ronald McDonald Houses around the world-providing joy, comfort, laughter and learning to millions of children and their families each year who are experiencing challenging times, and might not otherwise be able to experience the wonders of wildlife. To learn more, visit San Diego Zoo Kids on Facebook and YouTube.

\section{CONSERVATION FOCUS:}

Over the past 105 years, San Diego Zoo Wildlife Alliance has conceptualized, developed, and honed a unique set of skills and strengths that have become a big part of the role the organization plays in greater conservation efforts globally. This unique "Conservation Toolbox" includes expertise in conservation technology, ecological applications, reproductive management; community engagement; disease surveillance; genetic rescue; education; wildlife health, nutrition and care, and is also home to one of the Alliance's most valuable assets-the Wildlife Biodiversity Bank-a resource consisting of nonliving samples, and living cell lines that can be used to bring species back from the brink of extinction.

The work of San Diego Zoo Wildlife Alliance centers around key species in eight regional "hubs" reaching around the world. The following Tier One hubs represent our highest-priority areas, and the species of main concern within them:

- Savanna: Elephant, rhino, lion, hirola, giraffe, cheetah, vulture and cycad

- Amazonia: Jaguar, Andean bear, yellow-tailed wooly monkey and giant otter

- Southwest: Quino checkerspot butterfly, monarch butterfly, burrowing owl, desert tortoise, mountain yellow-legged frog, Pacific pocket mouse, thick-billed parrot, coastal scrub oak, boojum and Torrey pine.

- Oceans: Polar bear and African penguin.

The additional hubs in Tier Two signify areas of high concern, and the key species within them:

- Pacific Islands: 'Alalā, akikiki, palila, Galápagos pink iguana and orchid

- African Forest: Gorilla, chimpanzee, red colobus monkey and coral tree

- Asian Rainforest: Tiger, orangutan and sun bear

- Australian Forest: Koala, platypus, Tasmanian devil and Lord Howe stick insect.

\section{COLLABORATIVE EFFORTS:}

San Diego Zoo Wildlife Alliance is dedicated to collaborative conservation programs that safeguard and restore biodiversity, engage communities, foster human-wildlife coexistence, reintroduce wildlife into native habitats, contribute to ecosystem restoration and health, mitigate disease, preserve genetic resources, and inspire change through education and outreach. Through its joint efforts with a global network of nearly 200 leading and renowned conservation organizations, in 45 countries and on six continents, San Diego Wildlife Alliance is working toward a future in which all life thrives. To date, San Diego Zoo Wildlife Alliance has helped reintroduce over 40 species into native habitats, many of which were born at the Zoo, the Safari Park or one of the five conservation stations it manages.

San Diego Zoo Wildlife Alliance's most notable multidisciplinary field conservation programs include the Hawaii Endangered Bird Conservation Program in the Hawaiian Islands, the Loggerhead Shrike Breeding Facility on San Clemente Island in Southern California, Cocha Cashu Biological Station in Peru's Manu National Park and three field stations in Central Africa's Ebo Forest. These programs promote and sustain conservation and recovery of endangered wildlife and their habitats, while providing training opportunities for scientists and resource managers. 
WHO:

Wildlife care specialists, veterinarians, nutritionists and other team members at the San Diego Zoo and the San Diego Zoo Safar Park, as well as hundreds of wildlife conservation scientists working around the world, are dedicated to the conservation of plants, animals and habitats, to save wildlife through innovative wildlife health, science, recovery and management programs, and educational outreach. San Diego Zoo Global Wildlife Alliance members, donors and guests contribute to the conservation work at each of these world-class facilities.

\section{BOILERPLATE:}

San Diego Zoo Wildlife Alliance is a nonprofit international conservation leader committed to inspiring a passion for nature and creating a world where all life thrives. Empowering people from around the globe to support our mission to conserve wildlife through innovation and partnerships, San Diego Zoo Wildlife Alliance supports cutting edge conservation and brings the stories of their work back to two world famous wildlife sanctuaries at the San Diego Zoo and San Diego Zoo Safari Park-giving millions of guests in person and virtually the opportunity to experience conservation in action. The work of San Diego Zoo Wildlife Alliance extends from San Diego to strategic and regional conservation "hubs" across the globe, where their strengths, via their

"Conservation Toolbox," including the renowned Wildlife Biodiversity Bank, are able to effectively align with hundreds of partners in regions to improve outcomes for wildlife in more coordinated efforts. By leveraging these tools in wildlife care and conservation science, and through collaboration with hundreds of partners, San Diego Zoo Wildlife Alliance has reintroduced more than 44 endangered species to their native habitats. Each year, San Diego Zoo Wildlife Alliance's work reaches over 1 billion people in 150 countries via news media, social media, its websites, educational resources and the San Diego Zoo Kids channel, which is in children's hospitals in 13 countries. Success is made possible by the support of members, donors and guests to the San Diego Zoo and San Diego Zoo Safari Park, who are Wildlife Allies committed to ensuring all life thrives. Visit us at sdzwa.org.

\#\#\#

Check here to agree to the terms \& conditions of usage in order to download media assets.

\section{DOWNLOAD}

\section{Link includes:}

- Additional Information detailing San Diego Zoo Wildlife Alliance's 8 "conservation hubs".

- Photos depicting key wildlife from some of San Diego Zoo Wildlife Alliance's 8 "conservation hubs" and conservation partners. 
San Diego Zoo Wildlife Alliance. 2021e. "News Release: San Diego Zoo Global Evolves into the San Diego Zoo Wildlife Alliance, Integrating Collaboration, Innovation, and Partnerships to Tackle Wildlife's Largest Challenges."

https://sandiegozoowildlifealliance.org/pressroom/news-releases/san-diego-zoo-global-evolvessan-diego-zoo-wildlife-alliance-integrating

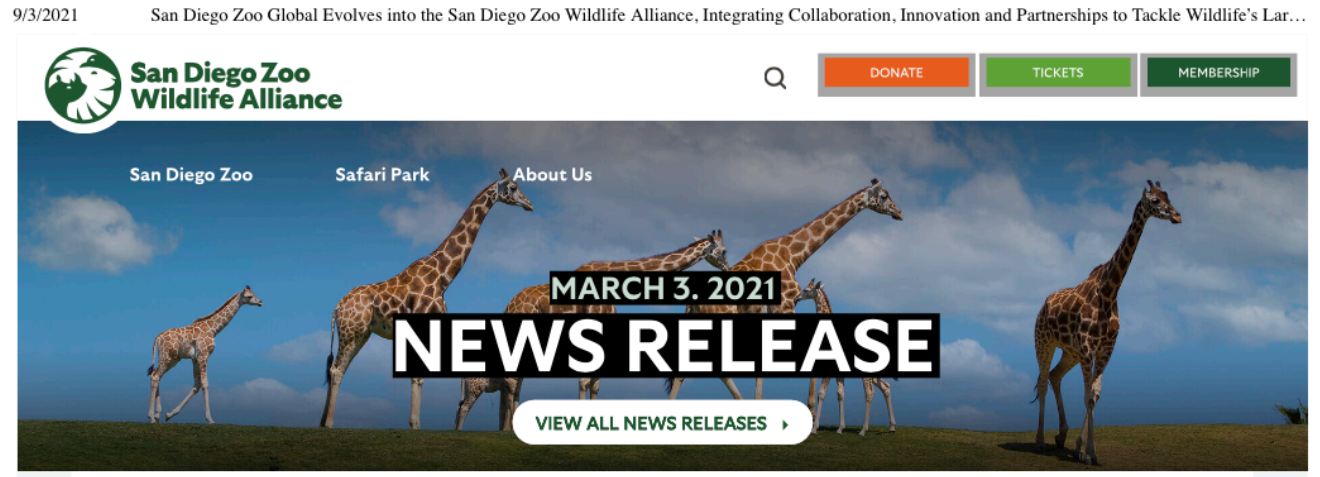

FOR IMMEDIATE RELEASE

March 3, 2021

CONTACT:

San Diego Zoo Wildlife Alliance

Public Relations

619-685-3291

WEBSITE:

SDZWA.org

NEWS RELEASE

San Diego Zoo Global Evolves into the San Diego Zoo Wildlife Alliance, Integrating Collaboration, Innovation and Partnerships to Tackle Wildlife's Largest Challenges

To commemorate the transformation, world-renowned artist Romero Britto commissions one-of-a-kind masterwork, to represent the importance and urgency of San Diego Zoo Wildlife Alliance's mission

SAN DIEGO (March 3, 2021) - Today, on World Wildlife Day, San Diego Zoo Global is evolving into the San Diego Zoo Wildlife Alliance (SDZWA), broadening integrated approaches to protecting and conserving wildlife around the globe, an all-new brand identity which emphasizes the health of wildlife, people, and the environment are interconnected and linked to the health of our planet. The new name and vision of a world where all life thrives more accurately reflects the organization's focus on wildlife conservation which started in Southern California over 100 years ago.

"While the San Diego Zoo is synonymous with some of the greatest advancements in wildlife care and conservation, our future depends on a sustained and committed focus to the health and well-being of all life on earth," said Paul Baribault, president and CEO of San Diego Zoo Wildlife Alliance. "We must evolve to meet the growing needs of wildlife in the 21st century and we can't do this alone. We are placing partnerships and hope at the heart of our organization through this transformation. As the first responders to wildlife in need, our reason for existence, and our responsibility, is to share our expertise to improve outcomes. That requires global collaboration in animal care, innovative solutions to halt the loss of biodiversity, and dedication to a one health approach.

San Diego Zoo Wildlife Alliance's expertise in caring for wildlife is at the core of what makes them a unique player in conservation. The deep and extensive knowledge from more than a century of experience around wildlife care, health, nutrition, and conservation science makes the Alliance invaluable in the global effort to save species. Their evidence-based approach leverages the diverse skills of their teams and partners, showcasing the limitless potential of how together, partners can change outcomes for wildlife in their native habitats. And it all starts with the plants and animals the Alliance supports at home in San Diego.

Unique to the San Diego Zoo Wildlife Alliance are the two "front doors" of the organization, the San Diego Zoo and Safari Park. These parks are essential to fulfilling the mission of San Diego Zoo Wildlife Alliance, transferring the knowledge that team members garner on the ground in San Diego, into meaningful and impactful conservation work around the globe. Over five million visitors annually walk through these two front doors, where they get to engage with and directly learn about some of the wildlife the organization is dedicated to saving.

At the core of their commitment to the wildlife at the San Diego Zoo and Safari Park, the San Diego Zoo Wildlife Alliance is showing up as a strong partner and collaborator with a global network of nearly 200 leading and renowned conservation organizations, 

including Save the Elephants, Polar Bears International, U.S. Fish and Wildlife Service, Northern Rangelands Trust, and many others with a common goal of protecting the world's wildlife.

"Saving wildlife starts with people and community involvement is key to successful conservation efforts," says Nadine Lamberski, chief conservation and wildlife health officer at San Diego Zoo Wildlife Alliance. "We share our expertise, learn from the experiences of our partners, and work together with local communities to develop the tools needed to safeguard biodiversity which is necessary for a healthy, thriving planet."

Over the past 105 years, the Alliance has conceptualized, developed, and honed a unique set of skills and strengths that have become a big part of the role they play in greater conservation efforts globally. This unique "Conservation Toolbox" includes expertise in conservation technology, ecological applications, reproductive management; community engagement; disease surveillance; genetic rescue; education; wildlife health, nutrition and care, and is also home to one of the Alliance's most valuable assets for the world's wildlife - the Wildlife Biodiversity Bank - a resource consisting of living cell lines that can be used to bring species back from the brink of extinction, as we just witnessed with the Przewalski's horse and black footed ferret, to help us restore populations to their native habitats one day.

However, while the San Diego Zoo Wildlife Alliance has had major successes globally, there remain a host of threats to the planet, including climate change, biodiversity loss, invasive species, habitat degradation, human-wildlife conflict, wildlife trafficking, and emerging diseases, that require conservation organizations to step up their efforts more rapidly and more strategically than ever before, with a greater commitment to changing outcomes for wildlife.

"If the past twelve months have shown us anything, it's that everything is interconnected," says Lamberski. "2020 was our wake-up call and 2021 provides a turning point. We have the opportunity to build back better, to restore the balance of nature, and foster a healthy, equitable world where all life thrives."

That's the first step. The San Diego Zoo Wildlife Alliance further aims to make wildlife conservation understandable by all, providing our audiences with a heightened awareness of the opportunities and challenges that wildlife face today, and showing how real impact is achieved through partnerships around the globe. And, with their partners around the world, San Diego Zoo Wildlife Alliance is aligning to transform the future of conservation and save threatened species worldwide.

Tied to the launch, San Diego Zoo Wildlife Alliance sought to collaborate with a world-renowned artist whose art defines transformation and shares a mutual view of the world with a lens filled with hope. San Diego Zoo Wildlife Alliance partnered with world-renowned artist, Romero Britto, to unveil a commissioned one-of-a-kind mural to help convey the importance of this change and the urgent nature of the challenge wildlife faces. Britto's work represents the importance of conservation, the urgency of the San Diego Zoo Wildlife Alliance's mission and a renewed hope and awareness to the importance of saving wildlife worldwide.

"As an artist, I am in the business of hope. These wonderful creatures don't have a voice, so we must advocate for their future," says Britto. "I believe my art can inspire someone and make them stop and really think about something in a new way that sparks action, awareness and hope. With this grand focus by San Diego Zoo Wildlife Alliance on the importance of partnerships, I look to share how l've been inspired by their mission, and can inspire more people to get involved and support their efforts to save wildlife."

In the spirit of global conservation, Alaska Airlines has joined forces with San Diego Zoo Wildlife Alliance to donate 1 million miles to support San Diego Zoo Wildlife Alliance's efforts.

San Diego Zoo Wildlife Alliance is committed to turning all guests into "Allies For Wildlife" to help support solutions to the greatest conservation challenges of our lifetime. San Diego Zoo Wildlife Alliance family and friends can help save the world's wildlife by joining the Alliance by becoming a member, donating at SDZWA.org, visiting the San Diego Zoo and Safari Park and by using \#SDZWA on social.

\section{About San Diego Zoo Wildlife Alliance}

San Diego Zoo Wildlife Alliance is a nonprofit international conservation leader, committed to inspiring a passion for nature and creating a world where all life thrives. The Alliance empowers people from around the globe to support their mission to conserve wildlife through innovation and partnerships. San Diego Zoo Wildlife Alliance supports cutting-edge conservation and brings the stories of their work back to the San Diego Zoo and San Diego Zoo Safari Park-giving millions of guests, in person and virtually, the opportunity to experience conservation in action. The work of San Diego Zoo Wildlife Alliance extends from San Diego to strategic and regional conservation "hubs" across the globe, where their strengths-via their "Conservation Toolbox," including the renowned Wildlife Biodiversity Bank-are able to effectively align with hundreds of regional partners to improve outcomes for wildlife in more coordinated efforts. By leveraging these tools in wildlife care and conservation science, and through collaboration with hundreds of partners, San Diego Zoo Wildlife Alliance has reintroduced more than 44 endangered species to native habitats. Each year, San Diego Zoo Wildlife Alliance's work reaches over 1 billion people in 150 countries via news media, social media, their websites, educational resources and the San Diego Zoo Kids channel, which is in children's hospitals in 13 countries. Success is made possible by the support of members, donors and guests to the San Diego Zoo and San Diego Zoo Safari Park, who are Wildlife Allies committed to ensuring All Life Thrives. 
San Diego Zoo Wildlife Alliance. 2021f. "Learning to Read Scientific Literature." https://sandiegozoowildlifealliance.org/scientific-literature-lessons

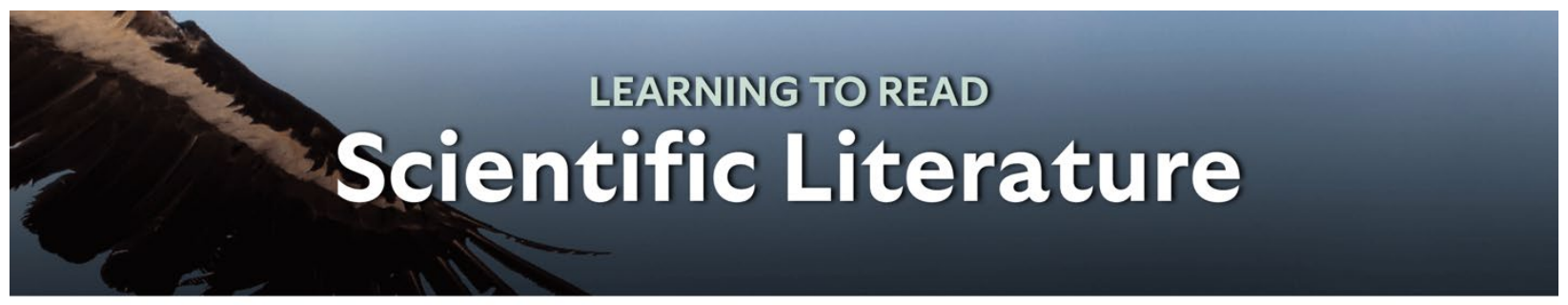

Learning to read scientific literature is an important and useful skill. These lessons were developed by the San Diego Zoo Wildlife Alliance for use in conjunction with Exploring Conservation Science field trips to the Beckman Center and the adjacent Safari Park. All of these lesson plans are related to research being done by San Diego Zoo Wildlife Alliance scientists.

Teachers may use these lesson plans and supplied reading materials in coordination with lessons about the conservation issues presented. If the reading is to be done independently, or without a more comprehensive lesson on the scientific topic, students reading at grade level will find the post-lesson reading selections very challenging, and it is fine to skip them.

There are five lessons provided, with middle school and high school options for each:

Polar Bear Bioacoustics and Energetics -

Life in a Biodiversity Hotspot -

Desert Tortoise Spatial Ecology .

California Condor Genetics -

African Elephant Reproductive Biology -

Polar Bear Bioacoustics and Energetics

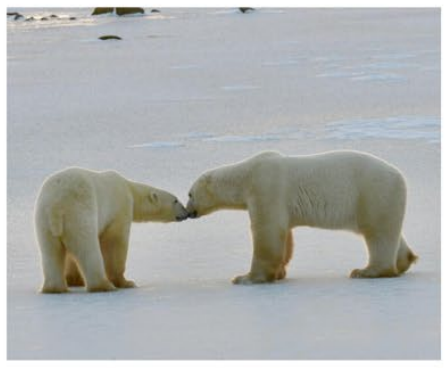

Middle School

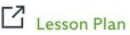
$\left[\begin{array}{c}7 \\ \text { Post-Lesson Reading }\end{array}\right.$

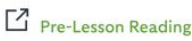

In the pre-lesson reading, we follow a trip to Arctic Norway to check on a polar bear den site as part of a postdoctoral project with San Diego Zoo Wildlife Alliance. In the post-lesson article, you will learn how zoos partner with other organizations to address issues facing wild polar bears. 


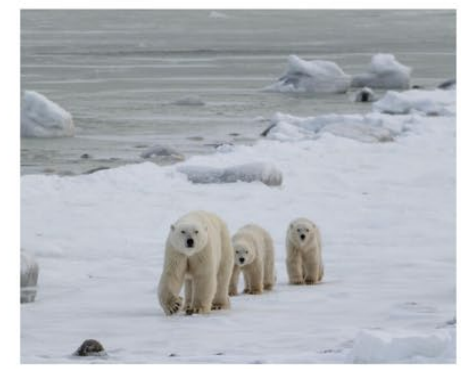

$\lceil$ Lesson Plan

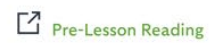

High school
The pre-lesson reading describes how climate change is affecting polar bears' energy needs. The two post-lesson articles describe research to measure polar bear activity in the wild, and how their high-energy, high-fat lifestyle is challenged by changing conditions.
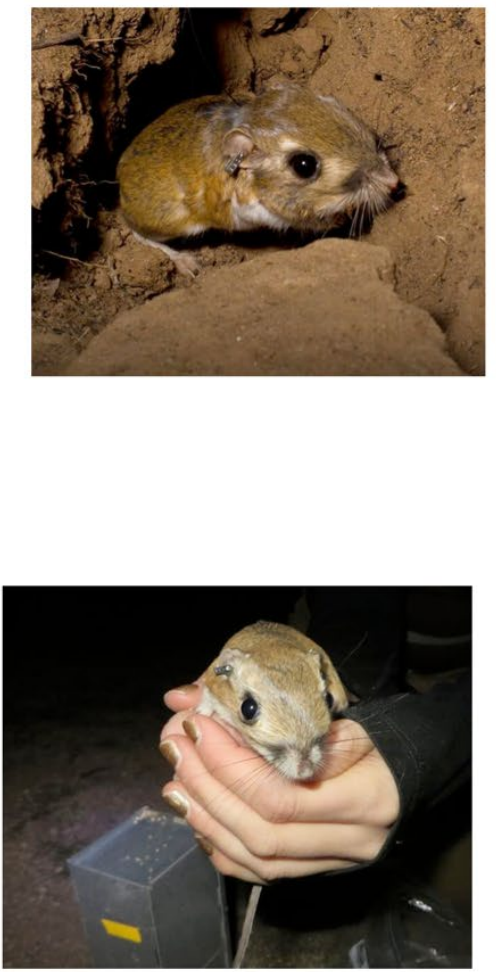

\section{MIDDLE SCHOOL}
$\lceil$ Lesson Plan
¿

$[$ Post-Lesson Reading

The Stephens' kangaroo rat is described to visitors at an Earth Day event in the pre-lesson reading. The postlesson reading describes freezing rare plant seeds in a seed bank.

\section{HIGH SCHOOL}
$\lceil$ Lesson Plan
$\square$ Pre-Lesson Reading

$\lceil$ Post-Lesson Reading

The pre-lesson reading is about the development of biodiversity hotspots over two decades. The post-lesson reading evaluates the California gnatcatcher as an umbrella species for the Southern California sage scrub habitat. 


\section{Desert Tortoise Spatial Ecology}

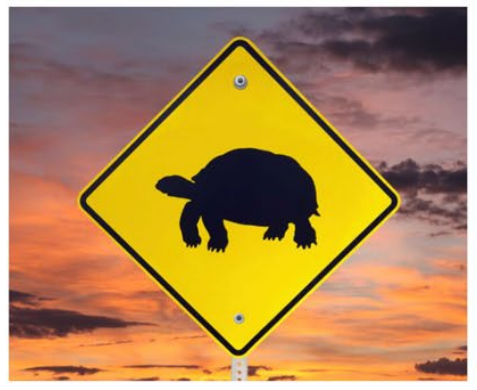

\section{MIDDLE SCHOOL}
$\lceil$ Lesson Plan
$[$ Post-Lesson Reading
$\lceil$ Pre-Lesson Reading

In the pre-lesson reading, scientists have to get creative to protect juvenile desert tortoises from predators. The post-lesson article describes the challenges of managing desert tortoises in their native habitat range-from translocation, to protection from cars, to handling potentially fatal viruses.

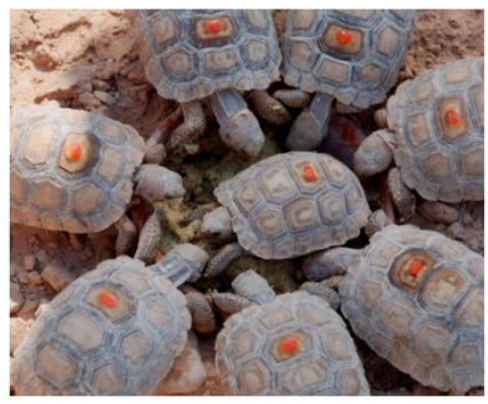

\section{HIGH SCHOOL}
$[$ Lesson Plan
$\lceil$ Post-Lesson Reading
$\lceil$ Pre-Lesson Reading

The pre-lesson journal reading is about how upper respiratory disease impacts the behavior of Mojave desert tortoises. The post-lesson reading examines translocation of desert tortoises as a conservation tool.

\section{California Condor Genetics}

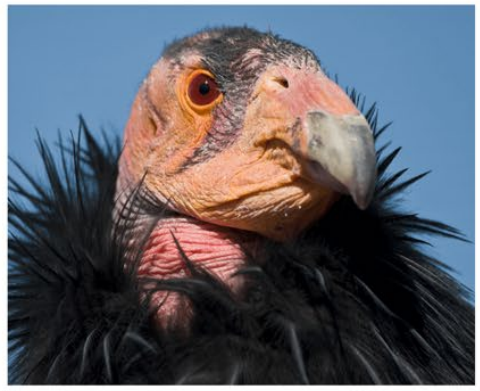

\section{MIDDLE SCHOOL}
$\left[\begin{array}{c}\tau \\ \text { Lesson Plan }\end{array}\right.$
$[$ Post-Lesson Reading
$\lceil$ Pre-Lesson Reading

In the pre-lesson blog post, a wildlife care specialist at the Safari Park describes the progress of California condor breeding in our care in 2018 . In the post-lesson reading, a scientist describes her work maintaining the Frozen Zoo, a collection of samples from over 400 species. 


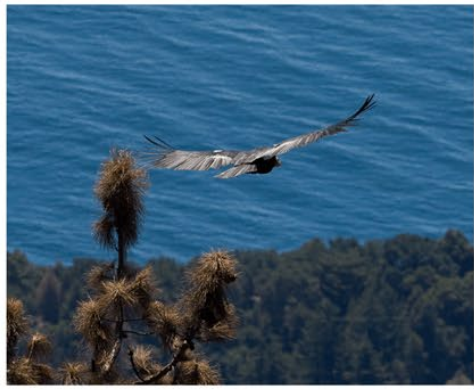

\section{HIGH SCHOOL}
$\lceil$ Lesson Plan

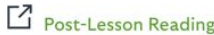

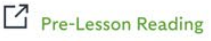

In the pre-lesson reading, you'll learn about the use of voluntary lead reduction in the California condor's wild range to reduce chances of lead poisoning of wild condors. In the post-lesson reading, scientists describe using DNA to determine the sex of animals whose sex cannot be easily determined by outside visible characteristics.

\section{African Elephant Reproductive Endocrinology}

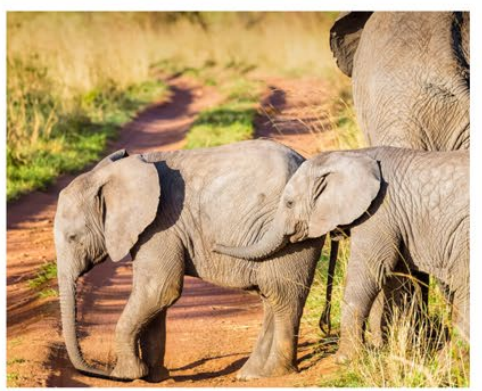

\section{MIDDLE SCHOOL}

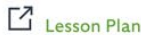
[7. Pre-Lesson Reading 2016

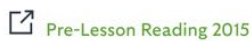
$\lceil$ Post-Lesson Reading

The pre-lesson readings for this lesson discuss studying wildlife behavior to reduce human-animal conflict. The post-lesson article examines elephant vocal communication.

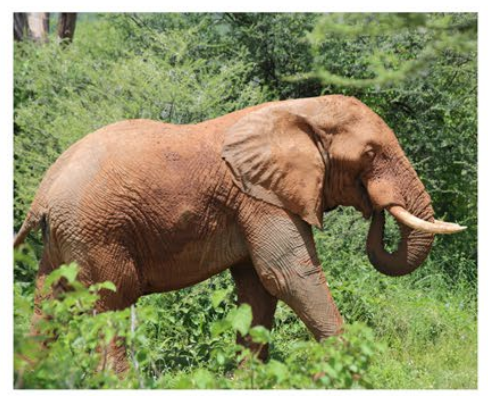

\section{HIGH SCHOOL}

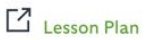

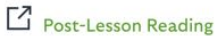

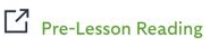

The pre-lesson reading studies how African elephants can use scent cues to keep track of the locations of other elephants in their social group. The post-lesson article studies traits of male elephants that lead to breeding success. 
San Diego Zoo Wildlife Alliance. 2021g. "Exploring Conservation Science Field Trips." https://science.sandiegozoo.org/opportunities/exploring-conservation-science-field-trips

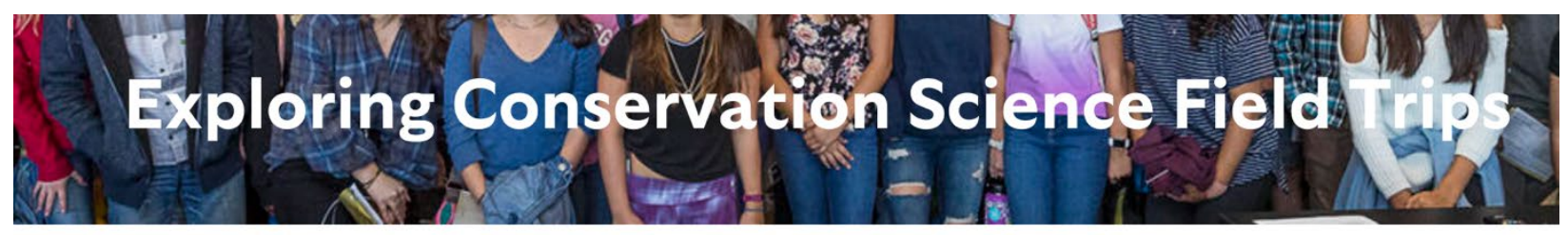

Our Community Engagement team has been working since 2005 to make San Diego Zoo Wildlife Alliance's scientific staff and facilities available to challenge, engage, and inspire students from middle school to college. In our state-of-the-art Conservation Education Lab and Eddy Family Outdoor Learning Lab, students, teachers, and community members have direct experience with research scientists, gain access to powerful research tools, and are involved in lessons that connect them to the science of conservation in new and exciting ways.

Our approach provides the opportunity to share a full, in-depth look at the work of conservation biology and the many fields of study that help guide conservation decisionmaking. Our specialized facilities offer the chance to work firsthand with the tools and techniques used in conserving endangered species. All of our programs are developmentally appropriate, relevant to real-world problems, and emphasize understanding through inquiry.

\section{Exploring Conservation Science Field Trips}

The Community Engagement team offers a 2.5 hour lab field trip program, titled Exploring Conservation Science, to interested science teachers and their classes. This program is open to all interested middle school, high school, and undergraduate classes, and includes visits to both the Beckman Center for Conservation Research and the adjacent San Diego Zoo Safari Park in Escondido, CA. For more information and to reserve a field trip, please refer to our Program and Module Packets.

To add your email to our notification list when field trip registrations open, please fill out our notification form.

Program Contact: conservationeducation@sdzwa.org 
San Diego Zoo Wildlife Alliance. 2021h. "Take Action: Climate Change." https://sandiegozoowildlifealliance.org/take-action/climate-change

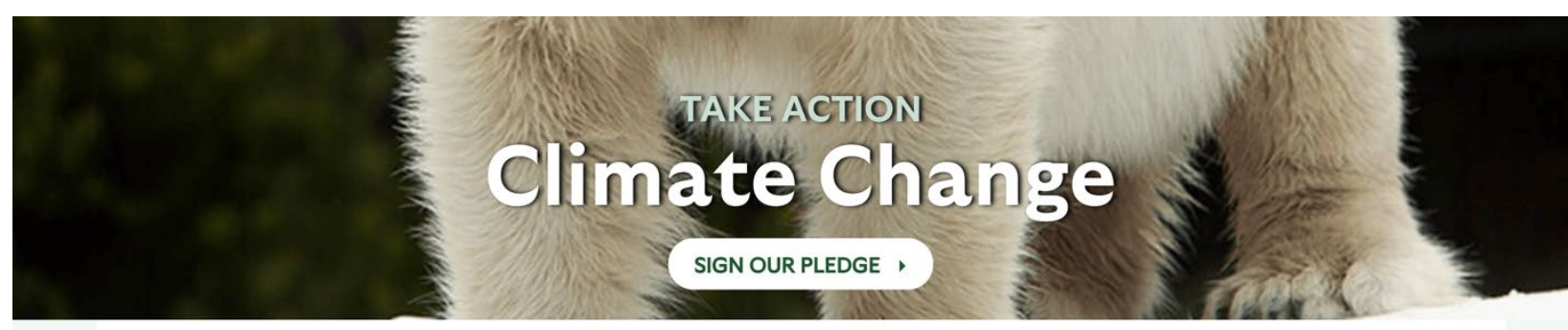

\begin{abstract}
Help Us Slow Climate Change
Human activities are changing the composition of the atmosphere, accelerating the rate of global climate change. As our climate is now changing more rapidly than ever before, so are regional climates, environments, and habitats. Impacts of global climate change include altered precipitation patterns, more intense storms, flooding, drought, and wildfires.

As animals, pathogens, and disease vectors shift their distribution in response to changing climatic conditions, we know that changes in disease transmission patterns are changing, too. As average temperatures increase, disease vectors such as mosquitoes will move into areas that were once too cold for them to develop.
\end{abstract}

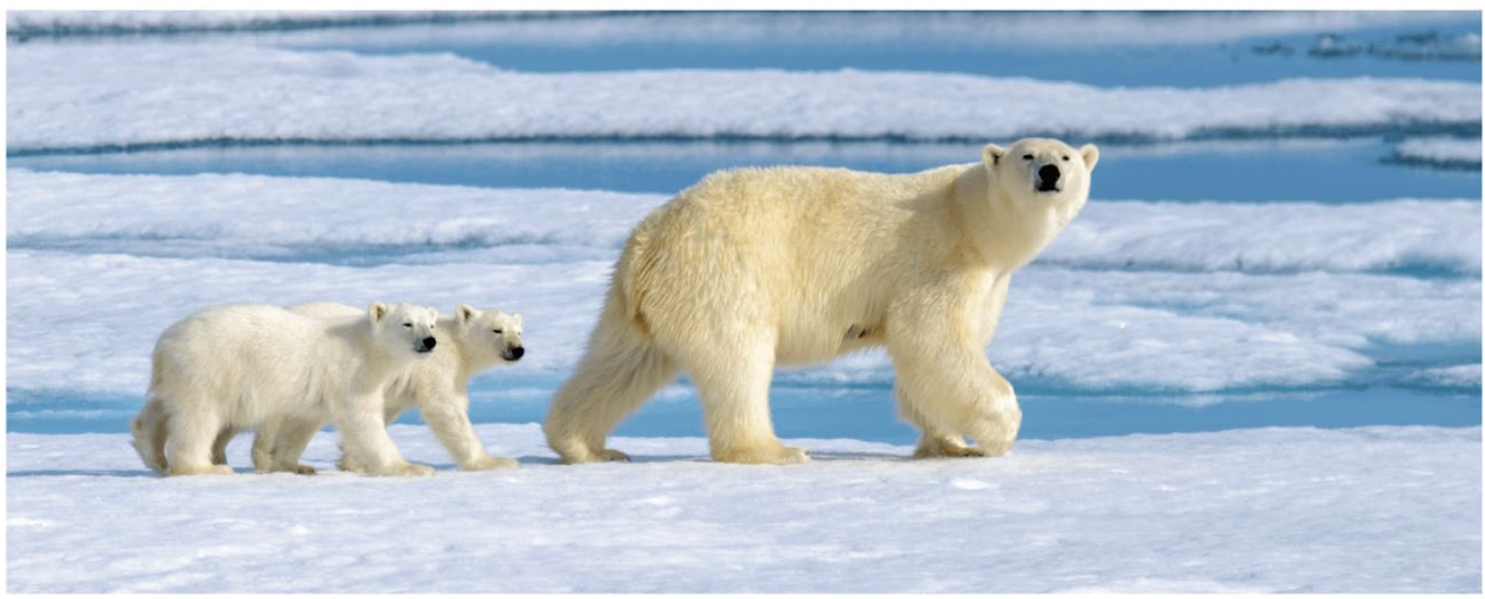

\title{
Polar Bears in the Arctic Sea
}

The Arctic is warming twice as fast as the rest of the planet, and as sea ice shrinks, polar bears increasingly face a world where it is difficult for them to gather enough food to survive. Their habitat is literally melting away. Evidence shows that loss of sea ice is correlated with declines in a polar bear's body condition, reproductive success, and survival.

Shrinking sea ice is causing some polar bear populations to gradually shift to more terrestrial food sources. These changes in foraging behavior are also changing the disease exposure dynamics for polar bears, resulting in an increasing prevalence of terrestrial diseases, such as those of domestic dogs. 
San Diego Zoo Wildlife Alliance. 2021i. "The Oceans: Polar Bear." https://sandiegozoowildlifealliance.org/species/polar-bear
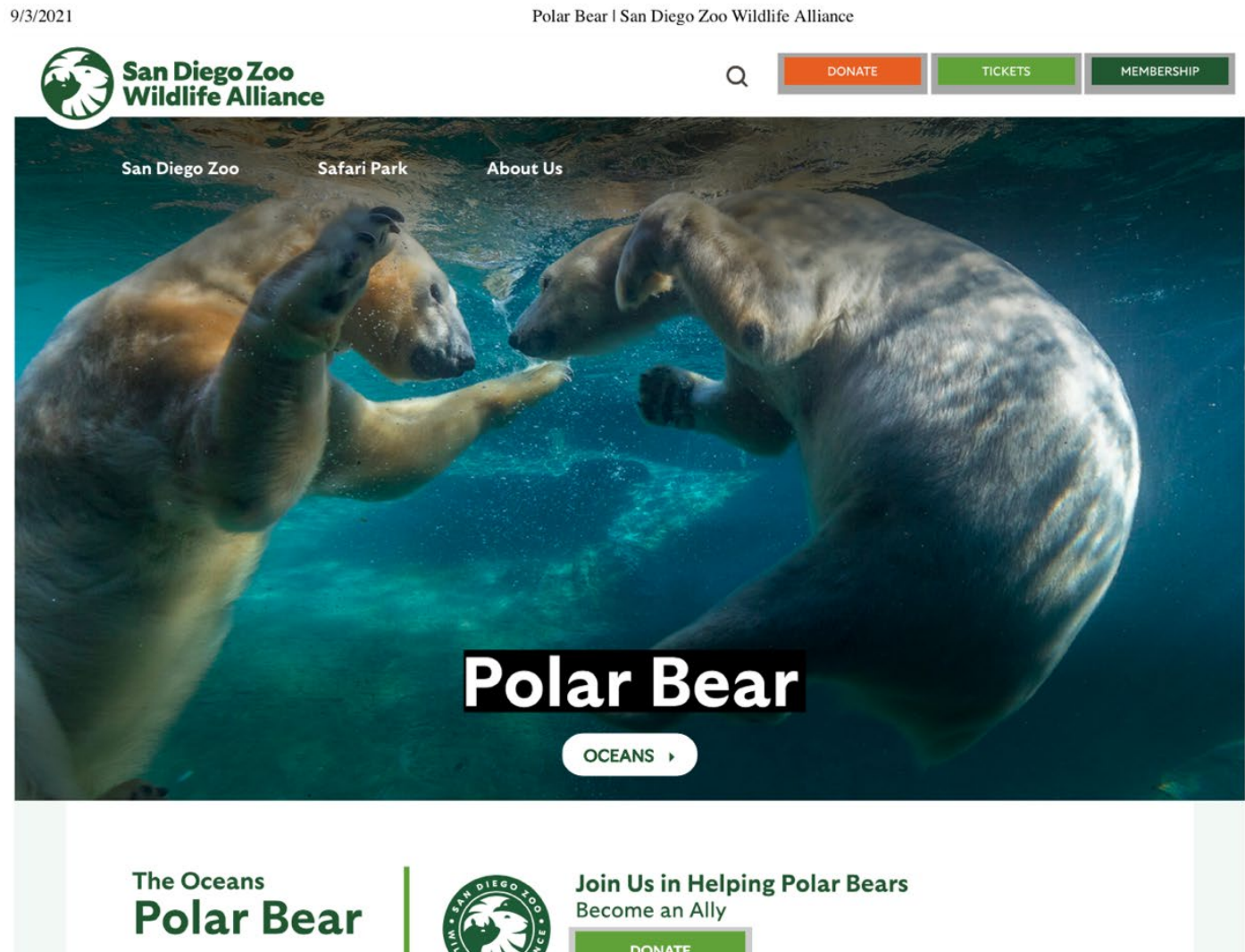

Join Us in Helping Polar Bears

Become an Ally

DONATE

Polar Bears: Icons of the Arctic

IUCN Conservation Status: Vulnerable

There is perhaps no other species that symbolizes the earth's frozen oceans like the polar bear. And for us at San Diego Zoo Wildlife Alliance, there are few other species that embody our commitment to saving wildlife more than these majestic bears, with the help of our innovative partners around the world.

Standing up to 12 feet tall and weighing up to 1,600 pounds, polar bears have no natural predators. Intelligent, patient, and strong, they are built to rule the Arctic.

Although they are the largest land carnivore on Earth, polar bears are excellent swimmers and spend most of their lives traversing between sea ice floes. In fact, their scientific name, Ursus maritimus, means sea bear. They have waterrepellent fur and a thick layer of fat under their skin, which keeps them warm in subzero temperatures.

Their habitat is literally melting away, as climate change endangers their existence. The Arctic is warming twice as fast as the rest of the planet. Disappearing sea ice threatens the survival the species, and evidence shows that loss of sea ice is correlated with declines in a polar bear's body condition, reproductive success, and survival.

\section{Collaborative Conservation}

Saving polar bears requires innovative thinking and collaboration with partners around the globe. In 1997, San Diego Zoo was asked to provide sanctuary to the polar bears we care for by wildlife officials. The bears had been found orphaned, without a mother to guide, protect, or catch seals to feed them. 
Wildlife officials warned they would not survive even one winter. The bears came to our care with challenges, but the experienced wildlife care specialists at the Zoo provide opportunities to express natural polar bear behavior in an environment that frequently includes snow and ice. And perhaps most importantly, the bears participate in scientific and other conservation efforts that help us and our partners around the world work to save the species in the face of climate change.

"The polar bears we care for at the Zoo are contributing directly to our conservation efforts and helping us to understand what polar bears need to thrive in the wild," says Megan Owen, Ph.D., corporate director of wildlife conservation science at San Diego Zoo Wildlife Alliance.

For example, scientists have been working collaboratively in the Arctic for many years to assess the impact of human activity around key polar bear denning sites, where polar bear mothers go to give birth during winter and to provide a safe space for newborn cubs. Assessing what can be heard in the den is important to managing the impact of human activities.

Polar bears at the San Diego Zoo worked collaboratively with our science team and wildlife care professionals to signal when they could hear sounds-allowing us to determine the hearing ranges of polar bears and informing guidelines for protecting polar bears from sonic disturbances.

We are also working with partners on an energetics study: As sea ice shrinks, polar bears increasingly face a world where it is difficult for them to gather enough food to survive. Our science team and wildlife care professionals conducted studies to determine the amount of energy spent by polar bears in some activities, so that we can assess what they need to thrive in the wild.

\section{In the Field}

San Diego Zoo Wildlife Alliance also participates in research and conservation out in the field with a variety of partners.

Over the past three years, we have been helping to monitor the bears as they migrate around Canada's Hudson Bay. It's the largest inland sea in the world, covering nearly half a million square miles; and it is home to approximately 2,000 polar bears.

It is a collaborative effort with the University of Alberta, Environment and Climate Change Canada, and our long-time partners, Polar Bears International. We use a combination of trackers embedded into collars and ear tags-which upload multiple locations each day-to trace the movements of the bears in near real time, via satellites.

"Each spring, I join a dedicated team to head out in a helicopter to locate polar bears on the sea ice," writes Nicholas Pilfold, Ph.D., a scientist at San Diego Zoo Wildlife Alliance. "I have worked with polar bears in their habitat for ten years - and every time I get close, I am flooded with wonderment and joy that we share the planet with such magnificent animals. I also feel deference: there is a respect that this mighty species commands."

\section{Become an Ally}

Your tax-deductible gift saves, protects, and cares for wildlife worldwide.

\section{Take Action}

Take Action for Polar Bears

\section{Our Team}

Contact a member of our conservation, research or wildlife care teams here.

\section{Our Partners}


Polar Bears International

U.S. Geological Survey

University of Alberta

\section{Discover More}

Learn more about polar bears

Read articles and blog posts from the SDZWA Journal

Watch polar bears at the San Diego Zoo, live on our Polar Cam

Download a polar bear Zoom background

For Kids of All Ages

Explore our scientific publications 
San Diego Zoo Wildlife Alliance. 2021j. "Press Release: Energetics Study Indicates that Shrinking Sea Ice Is Creating an Ecological Trap for Polar Bears." https://sandiegozoowildlifealliance.org/pressroom/news-releases/energetics-study-indicatesshrinking-sea-ice-creating-ecological-trap-polar

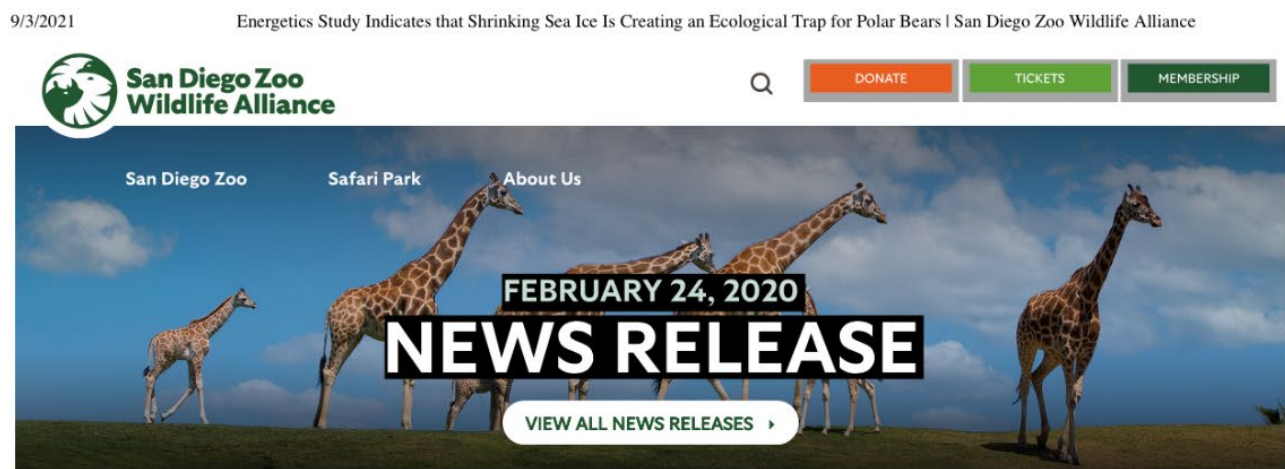

FOR IMMEDIATE RELEASE

Feb. 24, 2020

CONTACT:

San Diego Zoo Global

Public Relations

619-685-3291

WEBSITE:

SanDiegoZooGlobal.org

NEWS RELEASE

Energetics Study Indicates that Shrinking Sea Ice Is Creating an Ecological Trap for Polar Bears

San Diego Zoo Global researchers studying the effects of climate change on polar bears are using innovative technologies to understand why polar bears in the Southern Beaufort Sea are showing divergent movement patterns in the summer. In recent decades, about a quarter of this population of bears have chosen to come on land instead of staying on the shrinking summer sea ice platform. Historically, the polar bears in this region remained on the ice year-round. The decision of each individual bear to stay on the ice or to move to land appears to be linked to the energetic cost or benefit of either option, and the potential of having to swim to reach land.

"We found that bears who moved to land expended more energy on average during the summer than bears that remained on the receding sea ice," said Anthony Pagano, Ph.D., a postdoctoral research fellow co-mentored between San Diego Zoo Global, the U.S. Geological Survey and Polar Bears International. "And in the late summer, as the ice became even more restricted, a greater percentage of energy was expended by bears swimming to land. This means the immediate cost of moving to land exceeded the cost of remaining on the receding summer pack ice-even though bears are having to move greater distances to follow the retreating sea ice than they would have historically."

However, prior research has shown that bears on land in this region have access to whale carcasses in the summer, while bears on the sea ice appear to be fasting. Researchers are concerned that the decision by each individual bear to stay on the ice is creating an ecological trap that may be contributing to population decreases that have already been documented in this population.

The Southern Beaufort Sea subpopulation of polar bears has experienced increased sea ice retreat in recent decades. A basic understanding of polar bear energetics that can be applied to this research has come from studies that include polar bears at the San Diego Zoo and at the Oregon Zoo.

"The polar bear conservation program at the San Diego Zoo has supported research such as this by engaging in studies to measure the energetic costs of polar bear metabolism," said Megan Owen, Ph.D., director of Population Sustainability, San Diego Zoo Global. "These studies have enhanced the capacity of field researchers to interpret data collected on free-ranging bears, providing a better understanding of what it costs a polar bear to move about their rapidly changing habitat."

"The research underscores the importance of taking action to reduce the greenhouse gas emissions that are causing sea ice to melt," said Steven Amstrup, Ph.D., chief scientist at Polar Bears International. "It's yet another piece in the climate puzzle, showing the impacts of global climate warming on polar bears and how the bears are responding to sea ice retreat." 
About Polar Bears International

Polar Bears International is the only nonprofit with a sole focus on polar bears. Its mission is to conserve polar bears and the sea ice they depend on. Through media, science, and advocacy, Polar Bears International works to inspire people to care about the Arctic, the threats to its future, and the connection between this remote region and our global climate. To learn more, visit PolarBearsInternational.org or engage with Polar Bears International on Facebook, Twitter, or Instagram.

About San Diego Zoo Global

Bringing species back from the brink of extinction is the goal of San Diego Zoo Global. As a leader in conservation, the work of San Diego Zoo Global includes on-site wildlife conservation efforts (representing both plants and animals) at the San Diego Zoo, San Diego Zoo Safari Park, and San Diego Zoo Institute for Conservation Research, as well as international field programs on six continents. The work of these entities is made accessible to over 1 billion people annually, reaching 150 countries via social media, our websites and the San Diego Zoo Kids network, in children's hospitals in 12 countries. The work of San Diego Zoo Global is made possible with support from our incredible donors committed to saving species from the brink of extinction.To learn more, visit SanDiegoZooGlobal.org or connect with us on Facebook. 


\section{APPENDIX B: NEW ENGLAND AQUARIUM WEBSITE SOURCES}

New England Aquarium. 2021a. "Mission and Vision." https://www.neaq.org/about-us/mission-vision/

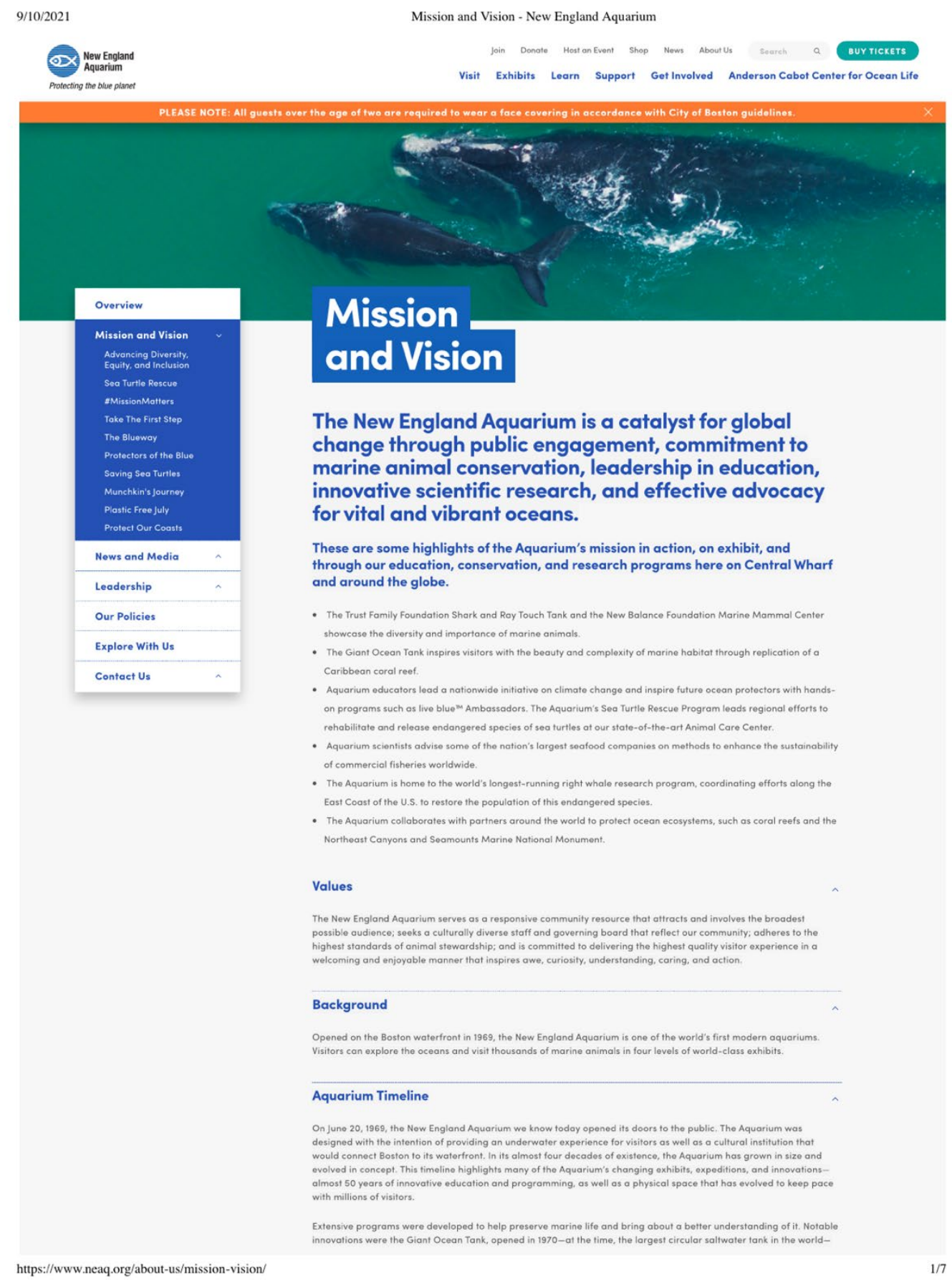


9/10/2021

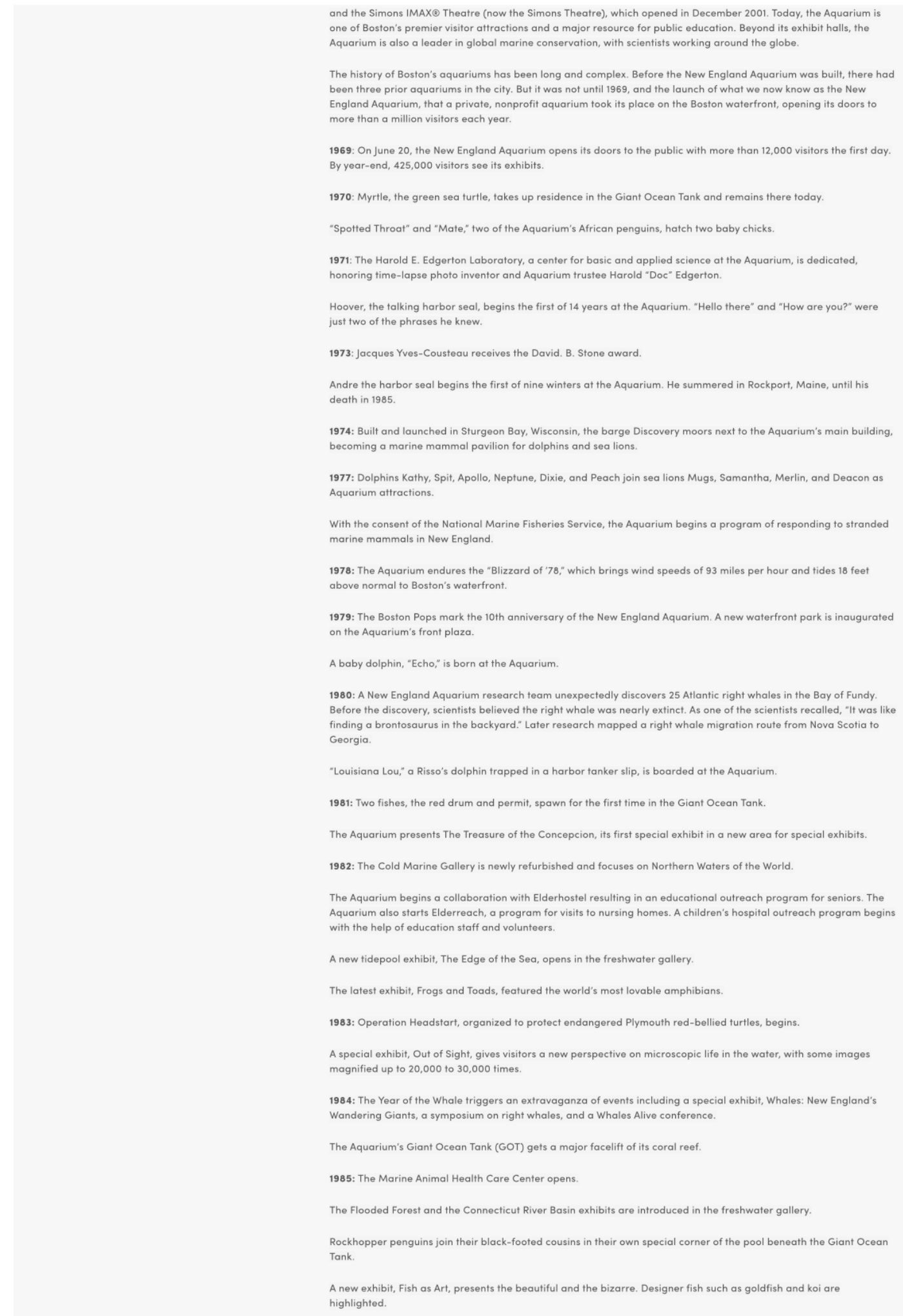


$9 / 10 / 2021$

(10/2010

Mission and Vision - New England Aquarium

The Aquarium begins "Nature of New England," a regular series of reports for WBZ-TV produced and written by staf member Paul Erickson.

A cookbook, A Feast of Fishes, joins a growing list of books published in association with the Aquarium.

1986: The exhibit Don't Blink Now uses live animals and video to capture animal behaviors that happen too fast or too infrequently for most of us to notice.

The Aquarium publishes Dive to the Coral Reefs and The Last Extinction, reflecting a growing commitment to conservation issues.

1987: Boston Harbor: The Place, the Problem, the Plan becomes a permanent exhibit in the Boston Harbor View Room. The Aquarium's research staff participates in a Boston Harbor Monitoring Program.

The Aquarium rescues three baby pilot whales from a mass stranding on Cape Cod.

A NOVA TV program and a children's book, Rescue of the Stranded Whales, celebrates the successful rehabilitation of these whales and their reintroduction to the wild.

1988: Stars of the Sea presents an exhibit of sea stars-from a Hollywood perspective.

The Aquarium introduces a new Thinking Gallery to educate its visitors on the world of fishes.

1989: Aquanaut Sylvia Earle receives the David B. Stone Award, saying that she looks forward to the next decade as "the greatest period of underwater discovery."

Stick Your Neck Out - A Closer Look At Turtles brings new drama to the life of turtles with a giant fiberglass sculpture over the entrance marquee and an eerie swamp-like setting as their habitat.

1991: Voyager II, a new state-of-the-art Whale Watch boat, is christened. The Aquarium's "Science at Sea" harbor cruises begin onboard the Doc Edgerton.

1992: The Boston Harbor Room is renovated.

"To present, promote and protect the world of water" is adopted as the mission of the Aquarium.

1993: The Aquarium names a new design team for a major expansion of the facility.

A new position of conservation officer is created; this person is charged with developing and implementing a strategic plan for aquatic conservation.

The Animal Heath Department at the Aquarium is started; it is designed to allow visitors to see veterinarians in action as they treated exhibit animals and animals recently rescued from the wild.

1994: The Aquarium unveils plans and exhibit concepts for an expanded facility.

More than 7,000 people attend Aquafest, a free public celebration of the Aquarium's 25 th birthday.

Jerry Schubel, an oceanographer from SUNY, Long Island, is named president and CEO of the Aquarium upon the retirement of Executive Director John Prescott. The Women in Science program launches, offering middle school girls the opportunity to learn about research, conservation, and animal care from female scientists at the Aquarium.

1995: The Aquarium launches its first website.

A new exhibit, Jellies, opens to foster awareness and appreciation of these beautiful but misunderstood animals.

The Aquarium's Education Center opens.

1996: In September, the Aquarium breaks ground for its new West Wing.

A new special exhibit, Ponds: the Earth's Eyes, opens.

1997: The new Aquarium Medical Center, which gives visitors an inside look at animal care, is opened to the public.

The first exhibit of the new Education Center focuses on Georges Bank and tells the story of this area fishery with live animals and hands-on exhibits.

A new seal and sea otter exhibit opens, providing an intimate view of California sea otters and harbor seals in a naturalistic setting

1998: With the completion of the West Wing, a larger space for changing exhibits is created. The expanded space includes a larger gift shop and the Harbor View Café, which overlooks Boston Harbor with views of the Boston skyline. The popular penguin exhibit is renovated with an improved habitat for the animals and new signage to educate visitors on the life and habitat of these amazing animals.

1999: An offsite exploration center opens in Newport, R.I, that encourages beachgoers to take a closer look at shore animals and their habitats, it offers hands-on educational and art activities, beach walks and talks by experts.

Sounds of the Sea, an exhibit funded by the National Science Foundation, opens in the Education Center.

Voyager III, a customized catamaran, joins the fleet making daily whale watching trips.

The little blue penguins join the African penguins in the always-popular penguin exhibit. 
9/10/2021

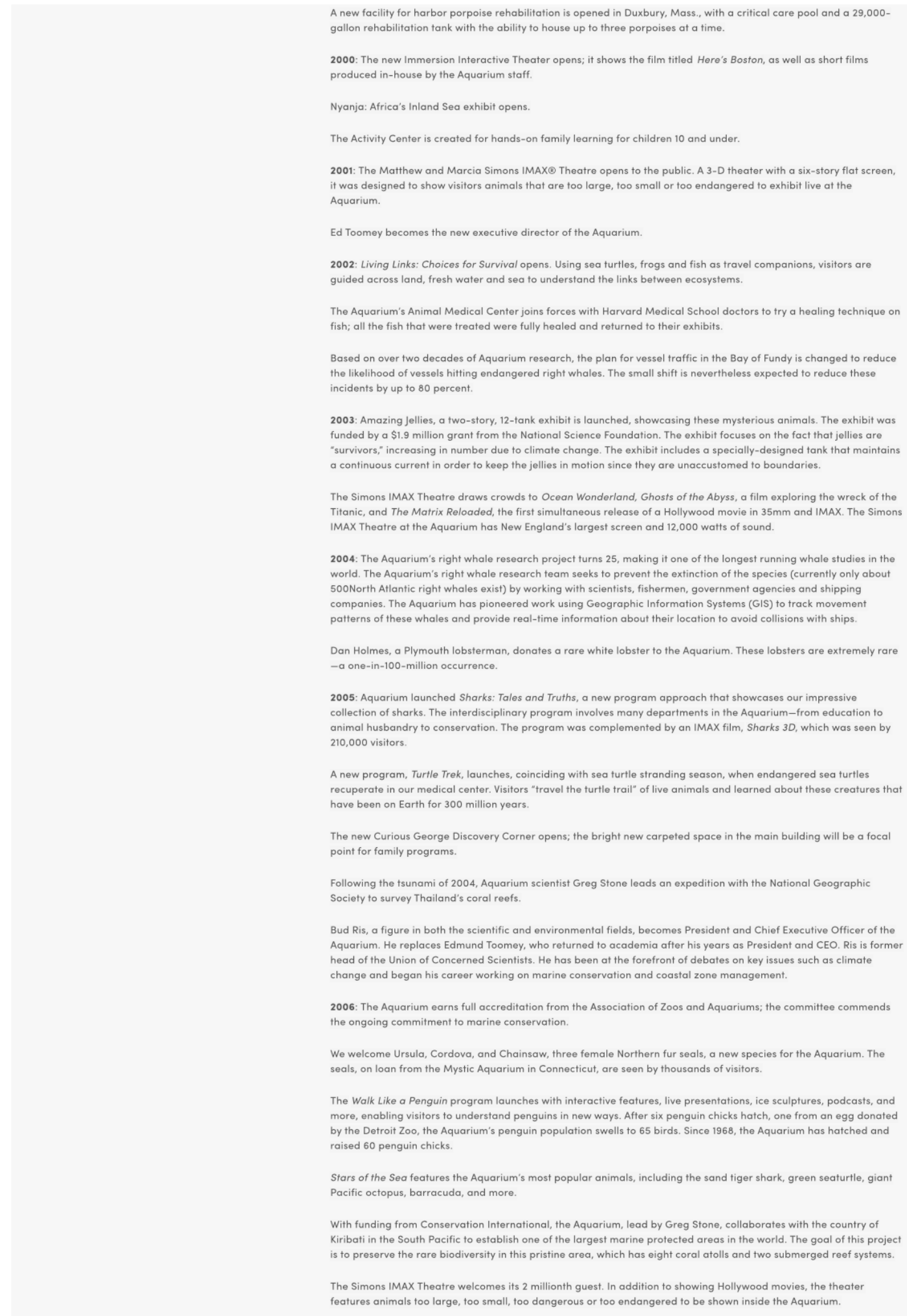


2007: The Aquarium's newest theme program, Killer Instincts, opens to the public. This exhibit helps visitors learn the truth about the animals we most fear-such as the sand tiger shark, anaconda, great barracuda, electric eel, lionfish. moray eel, giant Pacific octopus and southern stingray. The program includes a larger-than-life shark video and an IMAX film, Sea Monsters 3D: A Prehistoric Adventure.

After five years of planning, the Aquarium conducts a major expedition with National Geographic and Woods Hole Oceanographic Institution to the 10,000-foot deep Celebes Sea in the Indo-Pacific. The expedition is notable in that the relatively warm Celebes Sea harbors living fossils, prehistoric animals dating back tens or hundreds of millions of years. The team uses time-delayed video cameras, nets, scuba gear and a sub-like ROV (remotely operated vehicle) on the hunt for strange creatures and new habitats.

The Aquarium launches a new comprehensive five-year plan for upgrading exhibits and strengthening education and conservation programs.

1.3 million people visit the Aquarium in 2007 , including more than 100,000 schoolchildren.

The Aquarium completes a detailed review of the science pertaining to the impact of climate change, entitled Global Change and the Marine Environment.

The sustainable seafood initiative now includes the development of a new business model for Aquarium partners who buy seafood in quantity-Ahold, Gorton's and Dardens-in order to ensure sustainable stocks of seafood.

Researchers began a multi-year study to assess the impact of a major new offshore Liquid Natural Gas (LNG) terminal off Gloucester.

Spearheaded by Aquarium scientist Dr. Moira Brown, a team from the New England Aquarium and the Canadian Whale Institute convince the Canadian government to designate the Roseway Basin, where right whales congregate, as an area to be avoided by shipping traffic. (Collisions with ships are one of the leading causes of death of right whales, which are highly endangered.) In addition, Harvard University Press publishes The Urban Whale, edited by Scott Kraus and Rosalind Rolland, scientists at the Aquarium. The book presents current knowledge about the biology and plight of critically endangered right whales

2008: The Aquarium's Right Whale Research Team achieves a major policy victory when the federal government enacts a speed limit on commercial shipping traffic. The Phoenix Islands Protected Area (PIPA), the largest contiguous marine protected area at that time, doubles in size thanks to efforts by the New England Aquariun, Conservation International, and the Pacific island nation of Kiribati.

A temporary Shark and Ray Touch Tank exhibit generates excitement among visitors and paves the way for a permanent exhibit to be installed in the Aquarium's West Wing.

The Aquarium launches the live blue ${ }^{\text {TM }}$ concept and a redesigned website, making use of new technologies to reach a broader audience of about 1.8 million viewers annually.

2009: The Aquarium marks its 40 th anniversary.

The New Balance Foundation Marine Mammal Center opens. The open-air exhibit gives visitors an unforgettable look at Northern fur seals and stunning views of Boston Harbor, as well as presents a well-rounded vision of the Aquarium's global conservation efforts.

The Aquarium co-sponsors a major symposium on climate change's effects on oceans and coastlines with the Woods Hole Oceanographic Institution.

The Community Nights series launches with culturally sensitive translated materials to welcome new families to the Aquarium.

The Right Whale Research Team celebrates the birth of 39 right whales in the calving grounds off the Southeastern coast of the U.S. The Marine Animal Rescue Team rescues 83 cold-stunned sea turtles.

2010: Aquarium President Bud Ris makes a special plea for ocean conservation at the World Economic Forum's annual meeting in Davos, Switzerland.

Aquarium researchers collaborate with Roger Williams University to successfully rear queen triggerfish from eggs harvested from the Giant Ocean Tank, a first for any aquarium. The findings are the first steps toward sustainable ornamental fish trade.

A new education initiative called Sea Turtle introduces teens to marine biology and conservation issues during a semester-long scuba certification program.

Planning begins for renovations to the Giant Ocean Tank to transform the visitor experience. An off-site husbandry facility is secured to accommodate the needs of the growing Marine Animal Rescue Team.

The Aquarium's principal founder, David B. Stone, passes away.

2011: The Aquarium opens The Trust Family Foundation Shark and Ray Touch Tank, an exhibit that features sharks and rays in a mangrove-themed tank surrounded by shallow edges and viewing windows, allowing visitors to experience o close encounter with these animals.

Two rescued California sea lion pups, Zoe and Sierra, join the Aquarium's colony of Northern fur seals in the New Balance Foundation Marine Mammal Center.

The upgrade of the Aquarium's laboratory facilities, including the first fully equipped animal stress lab in the U.S., gets underway.

2012: The Aquarium receives a $\$ 5.5$ million grant from the National Science Foundation for leading a nationwide educational program on climate change. Construction commences on renovation of the Giant Ocean Tank and installation of the Blue Planet Action Center. Mission Blue Campaign concludes with $\$ 43.0$ million achieved. 
2013: The New Aquarium Experience featuring a fully renovated Giant Ocean Tank and a new Blue Planet Action Center opens July 1 , with record breaking attendance for the remainder of the year. The population of endangered North Atlantic right whales is counted at approximately 500 animals, demonstrating the success of various Aquarium initiatives to protect the animal from extinction

2014: The Aquarium completes a planned leadership transition, welcoming new CEO and President Dr. Nigella Hillgarth and CFO/COO P. Eric Krauss. In a major victory for North Atlantic right whale conservation, regulations recommended by Aquarium researchers that reduce the speed of boats in shipping lanes to prevent collisions with

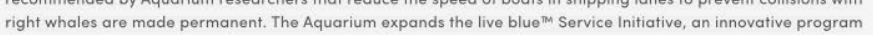
designed to bring together volunteers to work with the Aquarium and partner conservation organizations on projects that positively impact the environment.

2015: The Aquarium's Turtle Rescue Team program launches following an historic season in which the Aquarium's Animal Care Center in Quincy, in partnership with the Massachusetts Audubon Society, rescued and rehabilitated a record 733 cold-stunned sea turtles.

2016: The New England Aquarium launches the Anderson Cabot Center for Ocean Life, a groundbreaking initiative designed to expand the Aquarium's cutting-edge applied marine research and data-driven conservation solutions.

\section{A History of Boston Aquariums}

Boston has had four aquariums over the past 150 years: the Boston Aquarial Gardens (1859), the Boston Aquaria Gardens and Zoological Gardens (1861), the South Boston Aquarium (1912), and the present-day New England Aquarium (1969).

\section{The Forgotten Aquariums of Boston}

By Jerry Ryan

Download this PDF book for a full, illustrated history of the aquariums summarized on this page. The book covers Boston aquarial history from 1859 and features artist's renderings, diagrams, playbills and newspaper advertisements.

The path to opening the New England Aquarium, a private non-profit aquarium, in 1969 in Boston was a long and circuitous one, and the idea of what an aquarium should be has evolved over the years.

The Boston Aquarial Gardens $(1859$ - 1860)

Perhaps due to its turbulent history, the significance of the first aquarium in Boston, the Boston Aquarial Gardens, has been overlooked. It can however lay claim to being the first public aquarium in the world that was exclusively dedicated to the exhibition of marine life - even though this period was short-lived.

The Boston Aquarial Gardens and Zoological Gardens (1860 - 1863)

After eighteen months in existence, the Boston Aquarial Gardens were re-baptized the Boston Aquarial and Zoological Gardens, and moved to Central Court, a street off Washington Street.

The South Boston Aquarium (1912 - 1954)

Boston was without a true aquarium for nearly fifty years after the closing of the Boston Aquarial Gardens and Zoological Gardens and it was not until 1912 that the City of Boston undertook the construction of a new aquarium.

The New England Aquarium (1969 - present)

The demise of the South Boston Aquarium left a void in Boston. Through the South Boston Aquarium, generations of Bostonians had learned to appreciate the wonders of marine life. The seed had been sown for something larger and more ambitious.

The failures of both the Boston Aquarial Gardens and the South Boston Aquarium were instructive. The first was a purely mercantile venture that measured its success by its profits. The second was a civic institution with very limite goals, severe budget restrictions, and political pressures. Even prior to the closing of the South Boston Aquarium, a replacement was envisaged as a private, non-profit organization that would incorporate the best elements of the previous aquariums, while avoiding their piffalls.

At first, a small, modern aquarium was projected as part of the Museum of Science and preliminary studies were undertaken in this direction. In 1957, however, a group of local businesspeople formed what the New England Aquarium Corporation with the intent of founding an aquarium that would be independent. The directors of the new organization chose the then-rundown Boston waterfront as the site for their project.

The New England Aquarium was an immediate success, serving as a model for similar ventures the world over; it also helped to resurrect the Boston waterfront, changing a neglected part of the city into a civic treasure.

\section{How We Make a Difference}

At the New England Aquarium, we are committed to engaging and educating the public through our exhibits in Boston -but also in taking an active role in the world. Today, we see many threats facing the oceans-including overfishing, climate change, pollution and habitat loss. Our commitment is to build awareness and find innovative solutions through our marine conservation and research. Some of our signature programs include:

Discovering the Blue Planet: Creating the Next Generation of Ocean Protectors

Aquarium visitors, including thousands of schoolchildren, delight in seeing marine animals in beautiful and interesting habitats. More than ever, we are working to expand this sense of wonder to a level of interest that can last a lifetime. Our goal is to turn visitors into explorers, and explorers into stewards of the oceans. 
Today, our more than 1.3 million annual visitors include over 100,000 schoolchildren, as well as 30,000 New England students who are served by outreach programs and thousands more reached through our Teen Internship program, Virtual Programming, and Teacher Resource Center. Going forward, our outreach efforts will also focus on adult learners and the growing population of new immigrants to the city.

\section{Protecting Endangered Species and Habitats: North Atlantic Right Whales}

There are less than 400 critically endangered North Atlantic right whales remaining alive today, making this one of the most endangered of all large whales. Once heavily hunted by whalers for their oil, right whales now suffer from fatal ship strikes and fishing gear entanglements. Approximately half of right whale deaths can be attributed to human actions.

In 2003, the Aquarium, in cooperation with the Canadian government and several conservation organizations, spearheaded an particularly important conservation effort. The shipping lanes that run through the Bay of Fundy, O right whale breeding ground, were shifted by approximately 4 nautical miles. This small change has reduced the probability of whale-ship collisions by 80 percent.

The Aquarium's right whale team-the longest running marine mammal research project in the U.S.-also observes, counts and collects data on right whales and maintains a photographic record of every known North Atlantic right whale. Our team continues to forge government, shipping and fishing industry partnerships to help save these critically endangered whales.

Creating the Largest Marine Protected Area in the World: Phoenix Islands

The Aquarium was central to one of the most important global conservation efforts in the last several years: the creation of the Phoenix Islands Protected Area (PIPA). With eight coral atolls and two submerged reef systems, this is now the largest marine protected area in the world. At 158,453 square miles, this area includes some of the world's most pristine and primal ocean.

Aquarium Vice President for Global Marine Programs Greg Stone was at the center of negotiations, acting as scientist and conservationist, diplomat and fundraiser. The Aquarium is committed to working with key partners Conservation International, National Geographic and the government of Kiribati, the nation of which the Phoenix Islands are a part.

\section{Changing How Fish is Bought and Sold: Sustainable Seafood Programs}

Today, many species have been fished to near extinction and some seafood is caught or produced in ways that harm the environment. Through our Sustainable Seafood Programs the Aquarium's conservation department is working to help maintain healthy fish populations while supporting the fishing industry.

The Aquarium works directly with seafood buyers and sellers (such as Stop a Shop parent company Ahold USA and Gorton's) to help them make environmentally responsible seafood choices for their stores. We also educate consumers on which fish provide the best seafood choices and sponsor events, such as the Celebrate Seafood Dinner Series, to highlight sustainable seafood.

\section{Protecting New England's Resources: Pioneering Research on Lobster Shell Disease}

Over the past decade, fisherman and scientists have noticed an increase in the prevalence and severity of lobster shell disease, when bacteria eat away at their shells. In 1999, scientists became alarmed when a 30 percent increase in the disease was noted among Rhode Island lobsters. Today, Michael Tlusty, the Aquarium's director of research, is

focusing his work on the potential causes of the diseases, such as whether the result of rising water temperatures or a change in lobster diet is the likely cause.

\section{Sea Turtle Rescue Program}

The New England Aquarium has treated and released hundreds of Kemp's ridley sea turtles as well as many green and loggerhead sea furtles. These numbers are especially significant since the Kemp's ridley is the most endangered seo turtle in the world.

Learn More About Sea Turtle Rescue

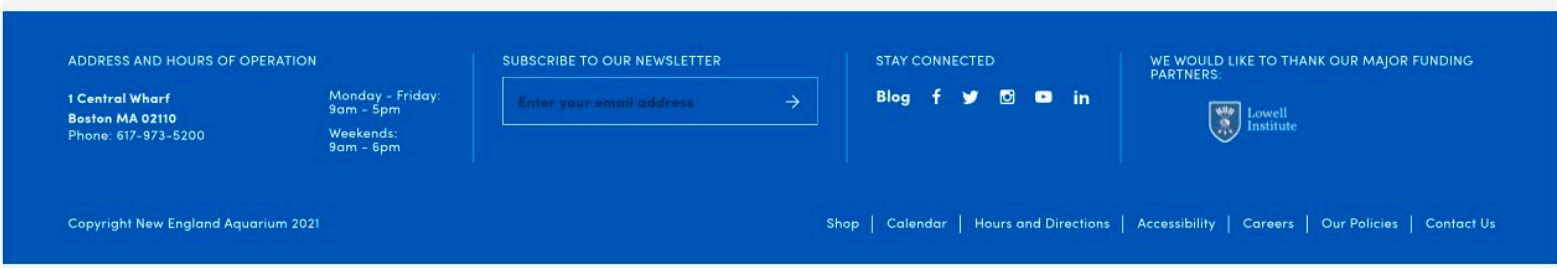


New England Aquarium. 2021b. "New England Aquarium Whale Watch." https://www.neaq.org/exhibits/whale-watch/

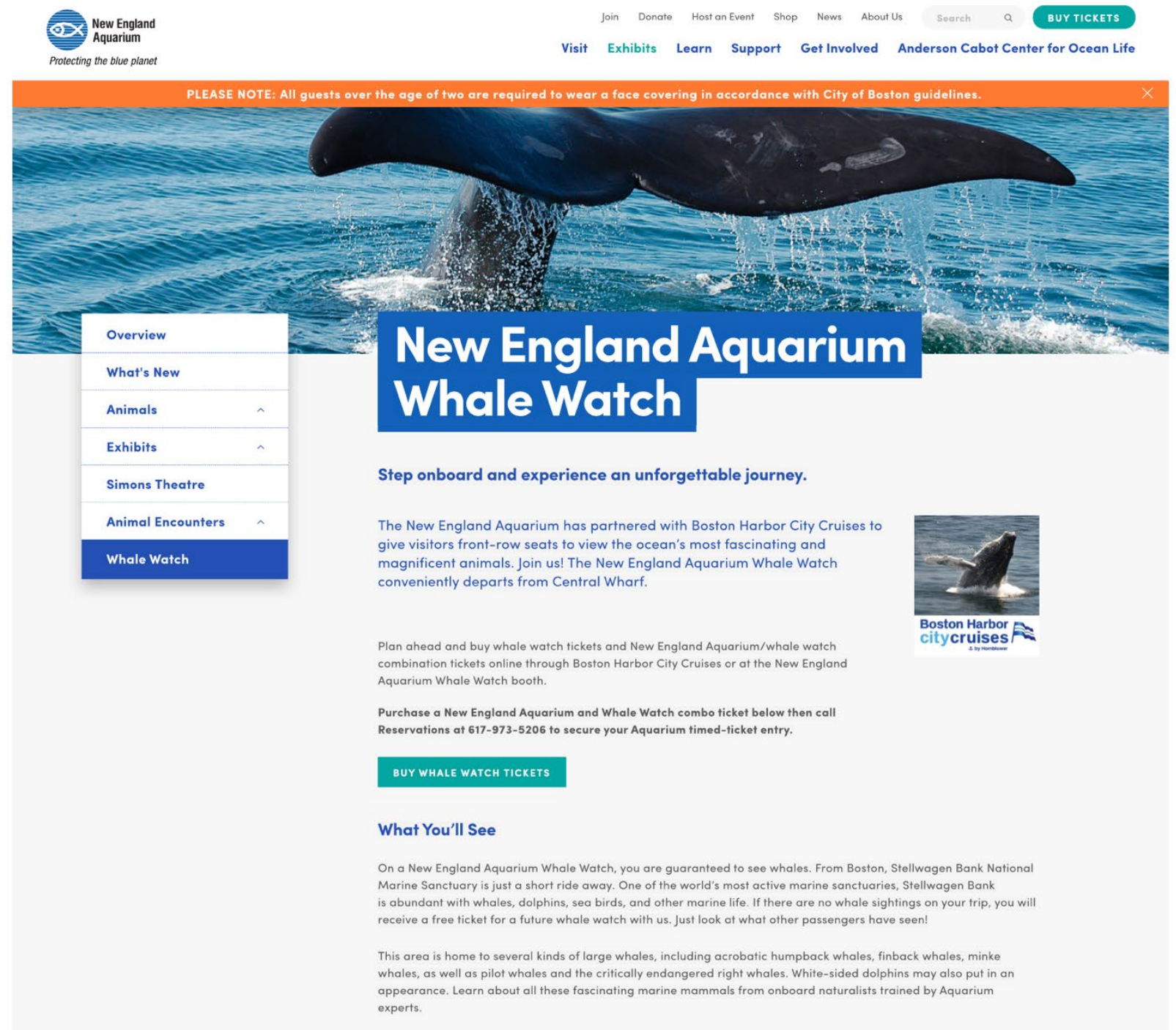


New England Aquarium. 2021c. "Anderson Cabot Center for Ocean Life at the New England Aquarium: Priorities." https://www.andersoncabotcenterforoceanlife.org/priorities/

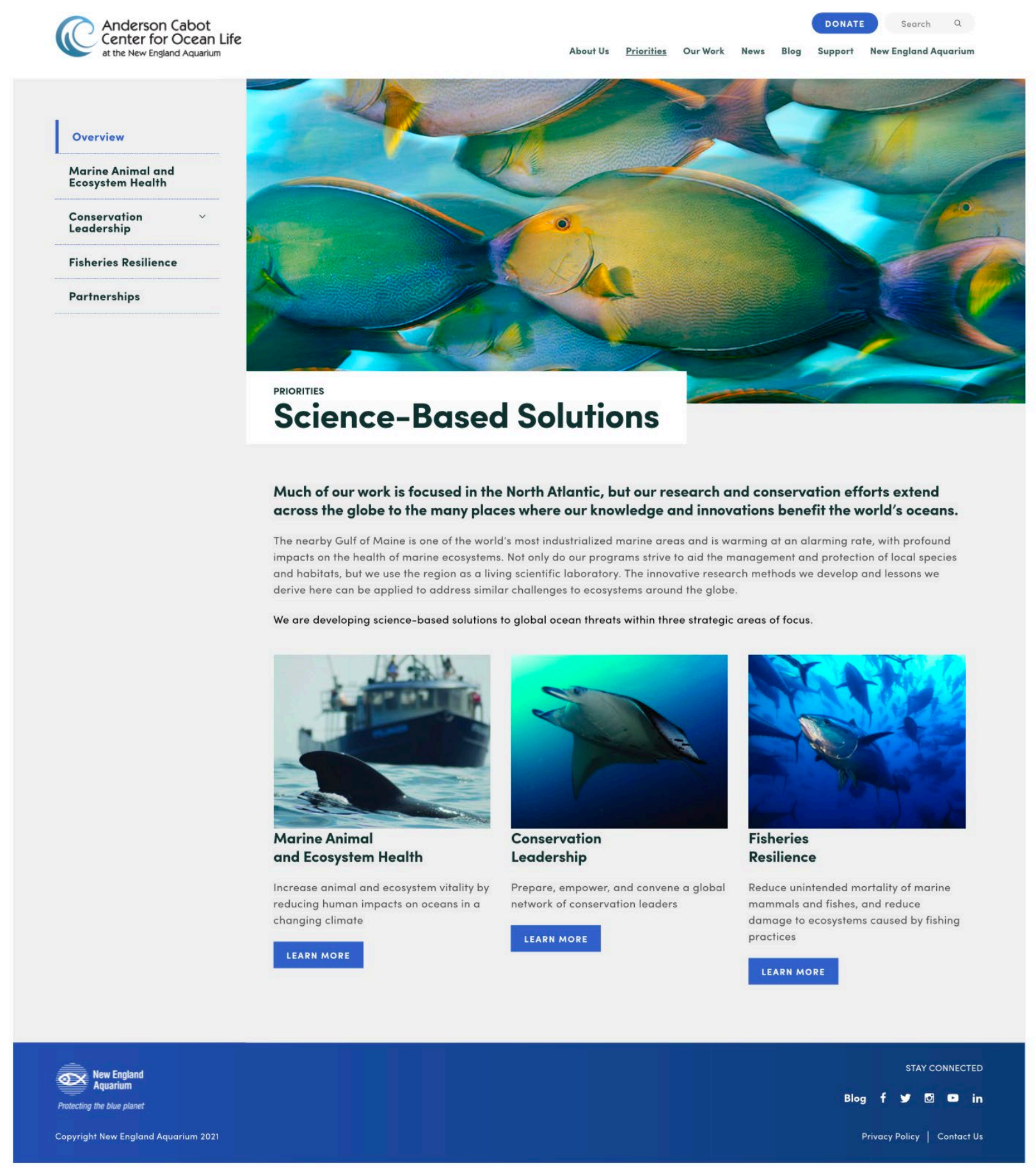


New England Aquarium. 2021d. "Species."

https://www.andersoncabotcenterforoceanlife.org/our-work/species/

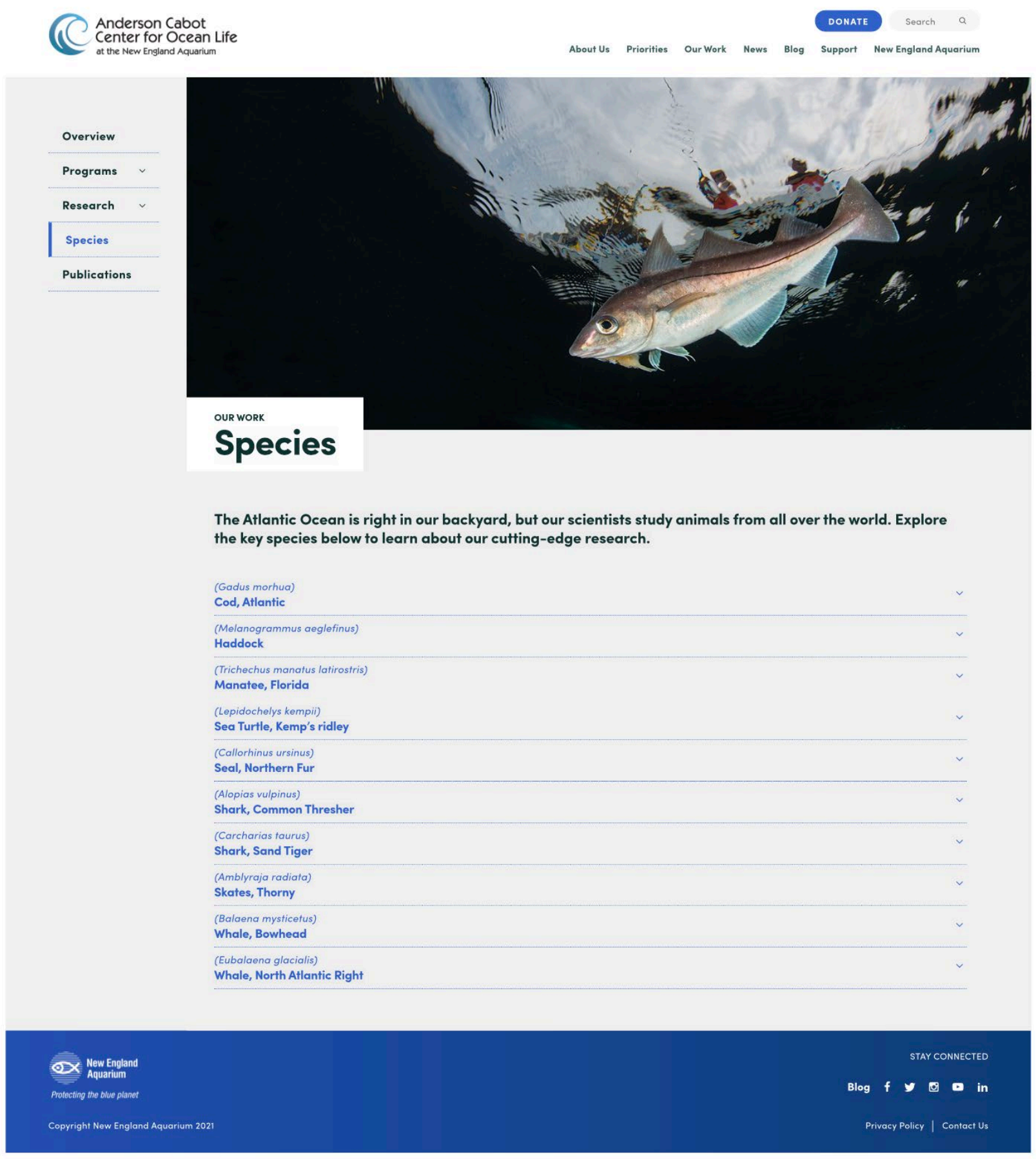


New England Aquarium. 2021e. "Lecture Series."

https://www.neaq.org/learn/lectures/

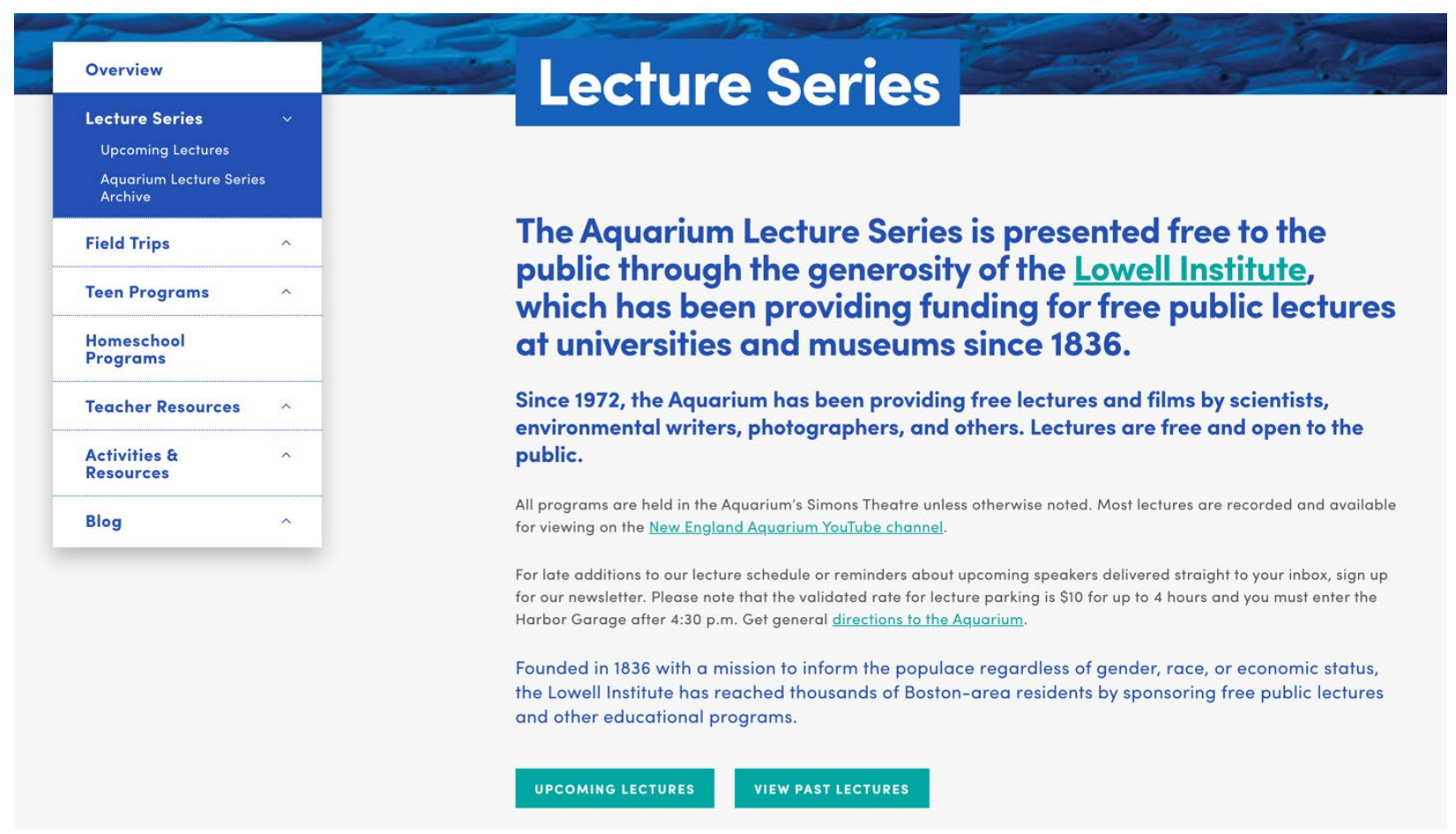


New England Aquarium. 2021f. "Teen Programs."

https://www.neaq.org/learn/teen-programs/

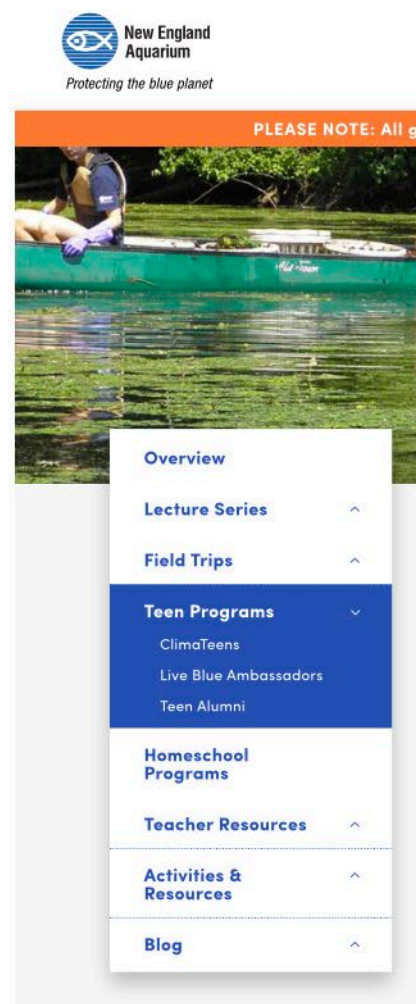
Join Donate Hostan Event Shop News About Us Search a
Visit Exhibits Learn Support Get Involved Anderson Cabot Center for Ocean Life

Do you love animals? Do you enjoy nature and being near water? Do you want to know more about our blue planet?

The Office of Teens Programs is the place to start if you want to get involved at the Aquarium. We offer a variety of volunteer and paid opportunities for teens ages 13 through 19.

Different programs happen throughout the year and have different application deadlines. Get a handy overview on our Youth Programs information Sheet (PDF 3.7MB). We do not currently offer job shadows.

\section{Our Teen Programs}

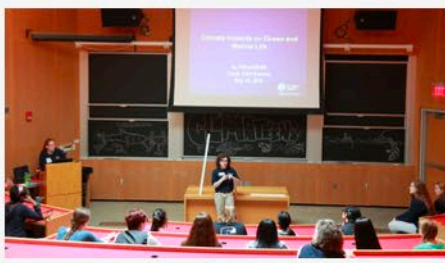

\section{ClimaTeens}

Climateens is a group of dedicated to youth 14 to 18 years old who care about the ocean and want to contribute to healthy future. Teens in the program arrive with various levels of knowledge about climate change, but they are united by a desire to learn more about it as an issue of concern and are committed to learning ways to engage public audiences, particularly their peers.

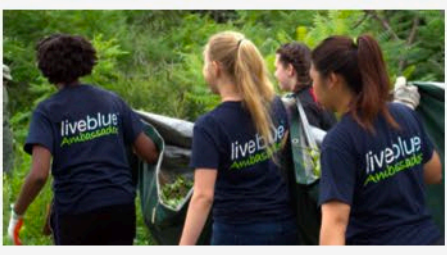

Learn More about Climateens :

live blue ${ }^{\mathrm{TM}}$ Ambassadors

The live blue "Ambassador program is a service learning program for teens ages 14 to 18 who are interested in serving the Aquarium's mission beyond the walls of the Aquarium. Participants will take part in different types of service-learning opportunities, which may include habita cleanup and restoration, public education and outreach, and citizen science. There is no limit to how many or how few events participants can attend.

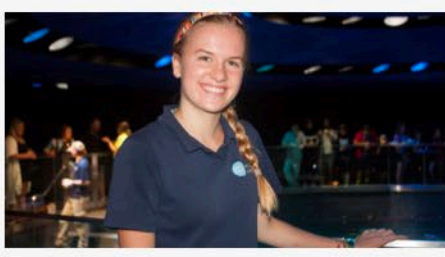

Teen Internships

The Summer Teen Internship Program is a great opportunity for teens age 14 and older to challenge themselves and learn useful skills while having fun and meeting new friends. The Aquarium offers paid and volunteer summer internships for Boston, Cambridge, and suburban youth for one week of training and six weeks of work in July and August. 
New England Aquarium. 2021g. "live blue ${ }^{\mathrm{TM}}$ Ambassadors."

https://www.neaq.org/learn/teen-programs/live-blue-ambassadors/

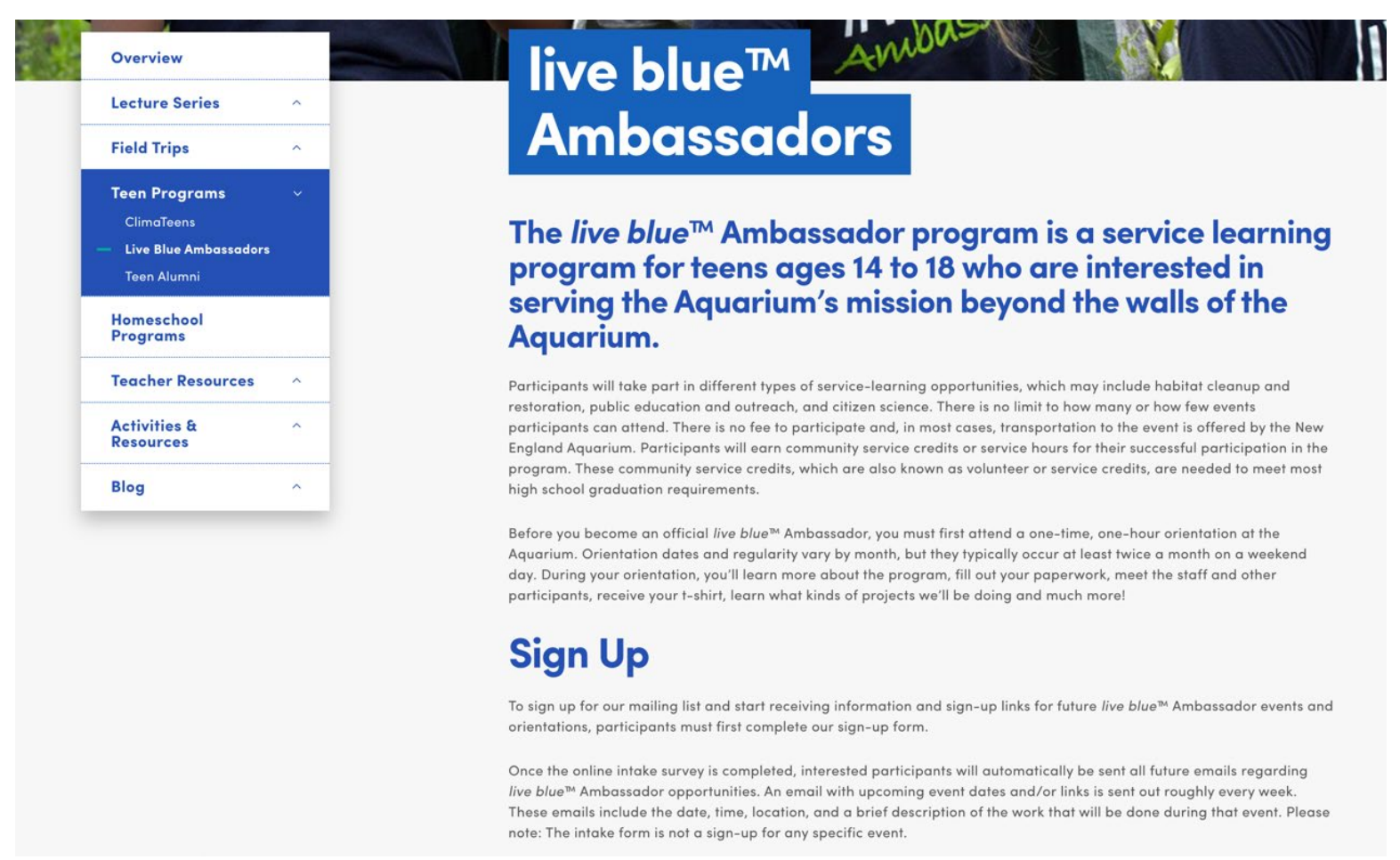


New England Aquarium. 2021h. "Summer Teen Internships."

https://www.neaq.org/get-involved/internship-programs/teen-internships/

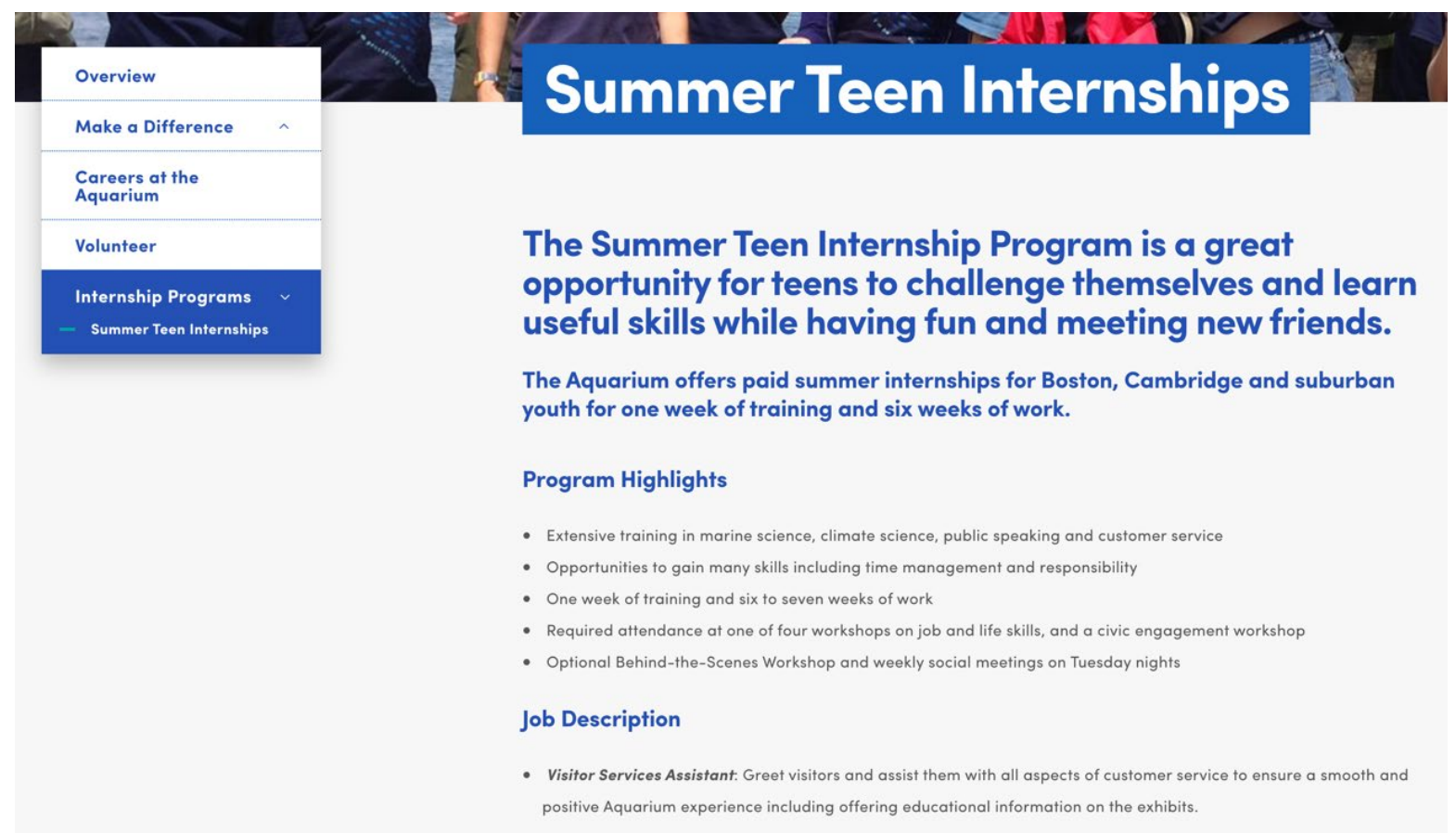


New England Aquarium. 2021i. "ClimaTeens."

https://www.neaq.org/learn/teen-programs/climateens/

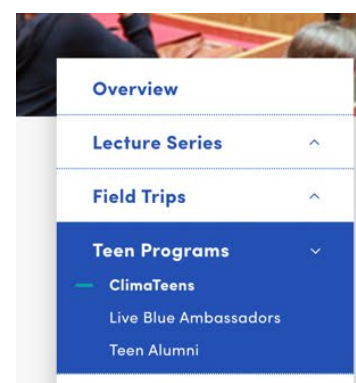

Homeschool

Homeschool

Teacher Resources

Activities \&
Resources

Blog
Climateens is a group of dedicated teens 14 to 18 year olds who care about the oceans and want to contribute to a healthy future. Teens in the program arrive with various levels of knowledge about climate change, but they are united by a desire to learn more about it as an issue of concern and are committed to learning ways to engage public audiences, particularly their peers.

\section{Who should become a ClimaTeen?}

This program is offered to teens already involved in our programs; there is no fee for accepted applicants.

Successful ClimaTeens are:

- concerned about ocean and climate issues and want to help develop solutions to prevent harmful impacts

- excited about learning and want to contribute toward a group learning process

- motivated and will work independently when asked

- ready to read about oceans and climate issues

- will support goals developed by the group and act as an active participant looking forward to connecting with other teens who are passionate about protecting the ocean familiar with the Aquarium's teen programming

Twice-monthly meetings run from October through June. There are occasional meetings and activities during summertime months. You must be able to attend 75 percent of the meetings to remain in the group.

\section{Contact Us}

Feel free to email teens@neaq,org with questions or comments about ClimaTeens. We especially welcome your thoughts and feedback on ClimaTeens presentations! 
New England Aquarium. 2021j. "Blue Planet Action Center." https://www.neaq.org/exhibit/blue-planet-action-center/

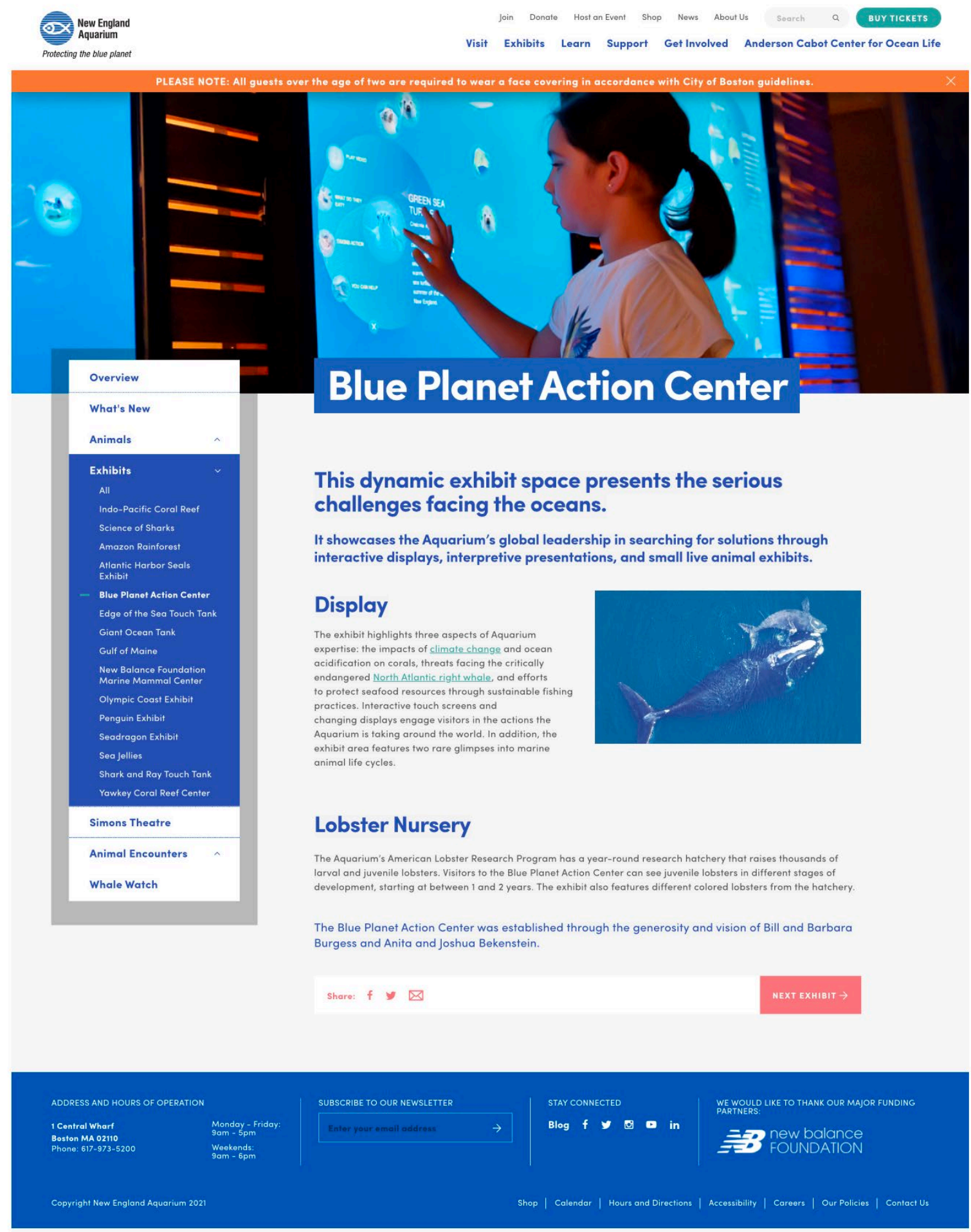


New England Aquarium. 2021k. "NNOCCI."

https://www.neaq.org/climate-change-education-resources/nnocci/

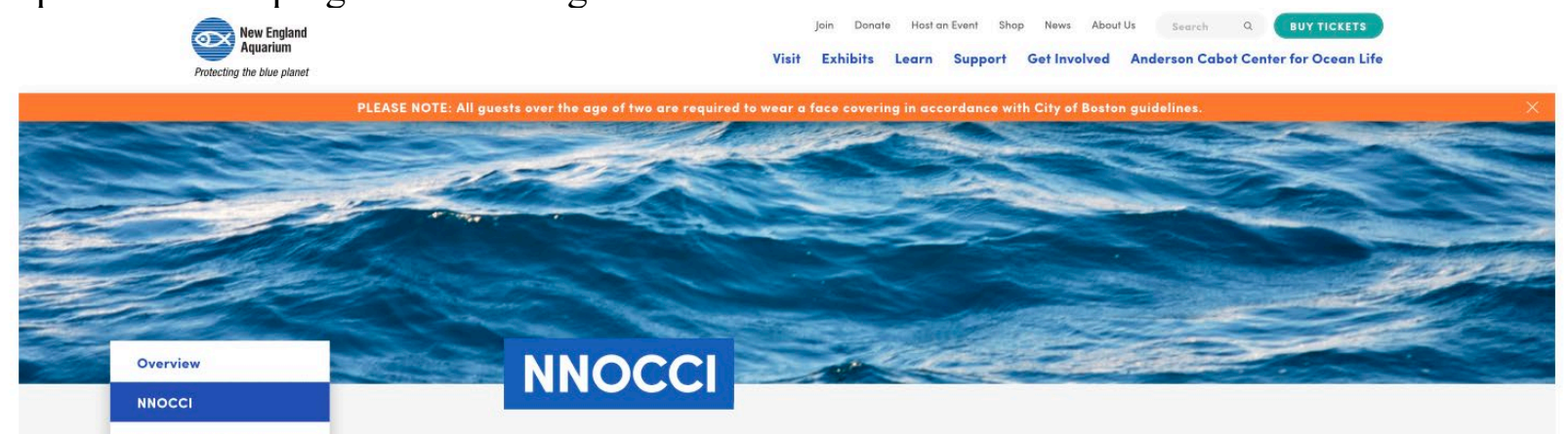

Visualizing Change

Millions of Americans visit informal science centers each year, eager to learn about our natural environment.

To make the most of the capacity of zoos, aquariums, and nature centers to engage the public in one of the most important scientific issues of our time, the National Network for Ocean and Climate Change Interpretation (NNOCCI) equips the science educators at these institutions to engage their visitors in constructive conversations about climate change.

Since 2010, NNOCCI has offered a rigorous training program that includes lectures from renowned climate scientists, grounding in evidence-based science translation techniques, and a supportive community of other educators who also want to make a difference on the issues facing our environment. This training effort has engaged informal science
education institutions nationwide. NNOCCI has facilitated 15 "Study Circles" with 440 members from 184 institutions across

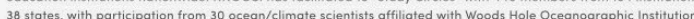

Together, we are working to change the public conversation about climate change to be inviting, interesting, empowering. and solutions-focused. External and internal evaluations show that NNOCCl is having a positive impact on climate interpretation in informal science centers-and on visitors. You can learn more about this exciting initiative by watching this 2.5-minute video and by exploring more at nnocciorg.

(n)

NNOCCl is supported by a grant from the National Science Foundation.

Our partners:

- Frameworks

- New Knowledge Organization

Woods Hole Oceanographic Institute

Association of Zoos and Aquorium

- National Aquarium in Baltimore

- $\cos$

- Penn State University 
New England Aquarium. 20211. "Teacher Resources: Climate Change and the Oceans." https:/www.neaq.org/learn/activities-resources/climate-change-ocean/

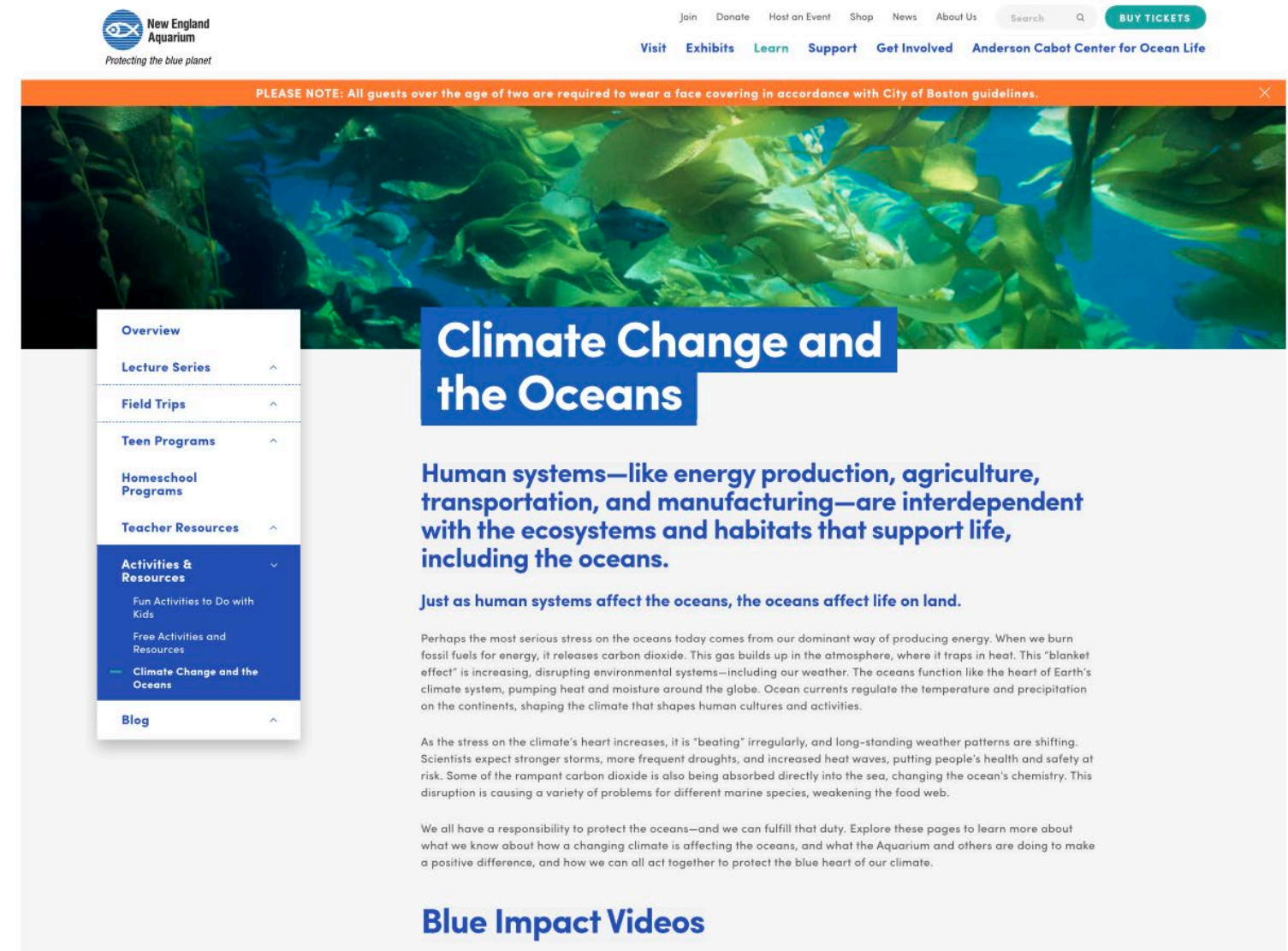

Expand your students' knowledge of climate change and draw connections between climate change and changes in the oceans. Orighally developed as a tour for visitors tho now England Aquarium, this video series prosents the challenges blue planet

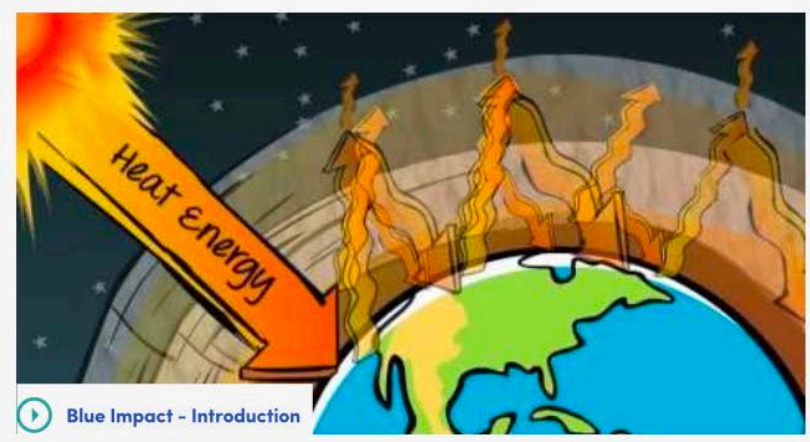

Introduction

Learn about the science of

Teacher answer key (PDEF16MB

Watch with closed captioning [link goes to YouTube ]

Length: 5:06 


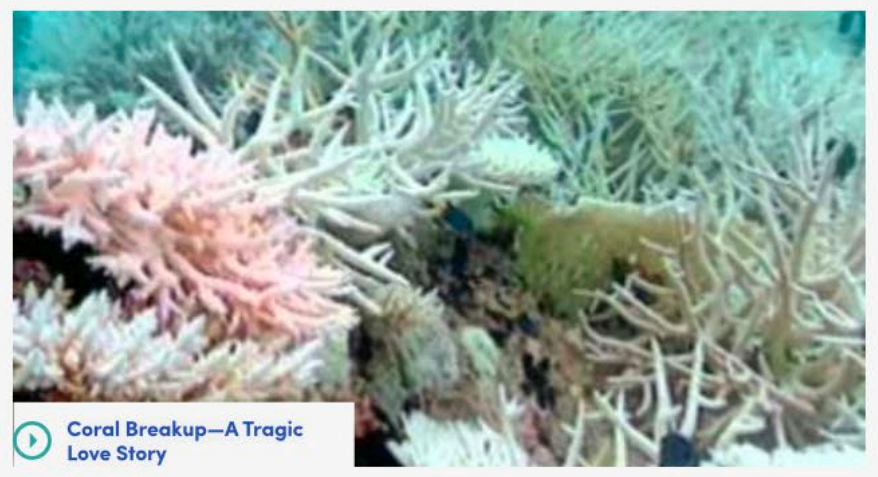

Coral Breakup-A Tragic Love Story

See how rising ocean temperatures affect corals.
Student sheet (PDF 177KB)
Teacher answer key (PDF 85KB)
Photesynthesis extension questions with key (6IKB)
Watch with closed captioning
Length: $4: 19$

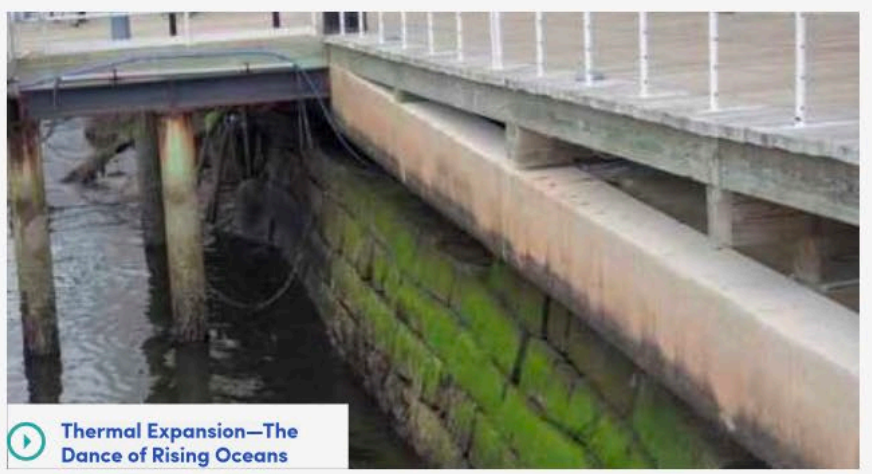

Thermal Expansion-Rising Oceans

Learn how sea levels rise

Student sheet (PDF 39KB)

Watch with closed captioning

length: 2.51

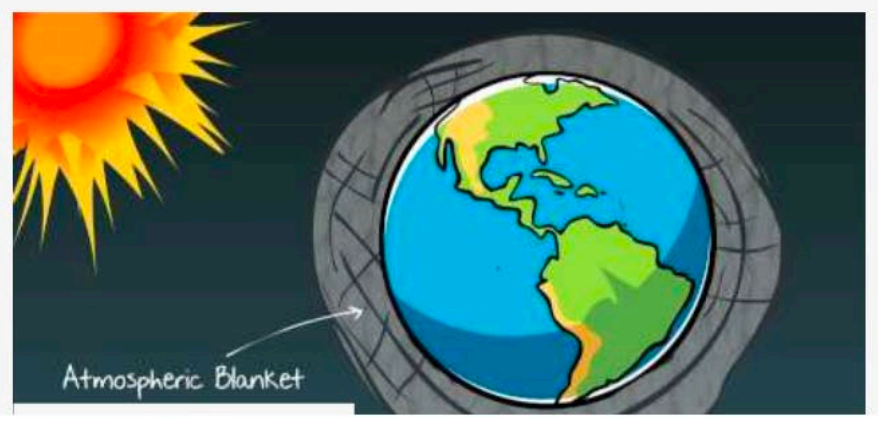


(D) Sea Jellies Take Over the Ocean Maze

Discover the science of booming jelly populations.

Student sheet (PDF 53KB)

Teacher answer key (PDF 50K

Watch with closed captioning

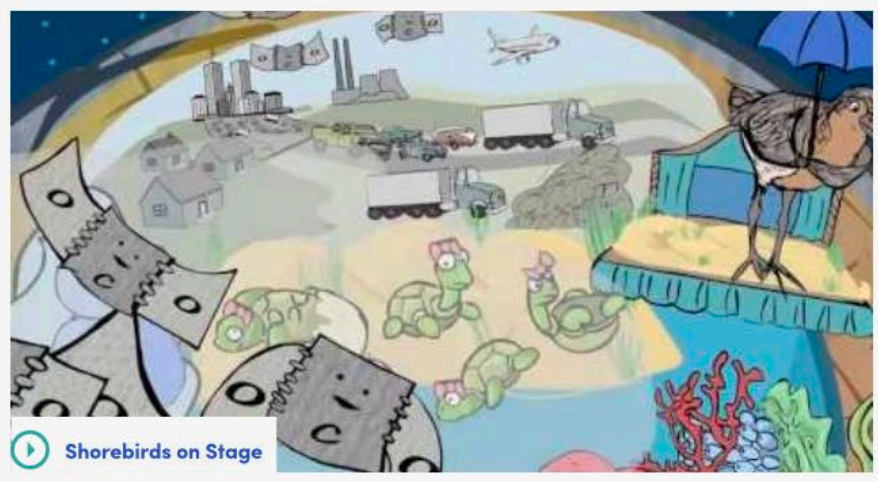

See how changes in weather affect shorebirds.

Student sheet (PDF 75KB)

Teacher answer key (PDF 77KB)

Watch with closed captioning

Longth: 5:19

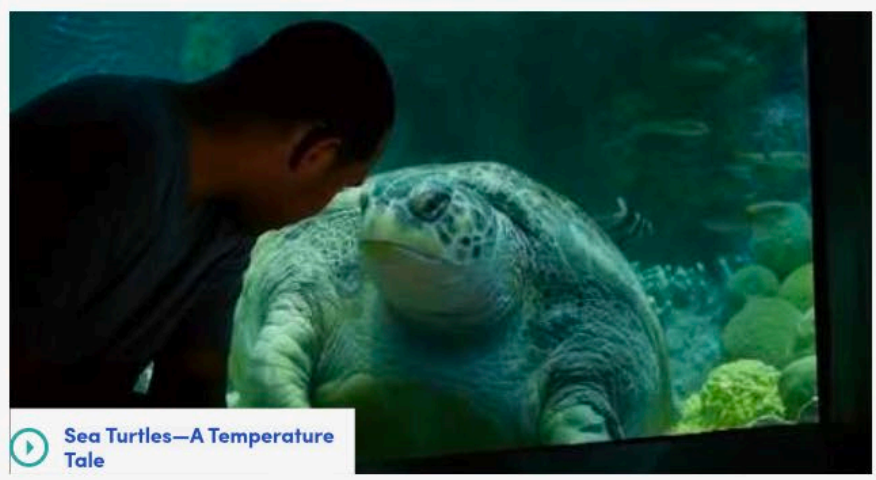

Learn how rising temperatures threaten sea turtles.

Student sheet (PDF 105KB

Teacher answer key (PDF $1.1 \mathrm{M}$ )

Watch with closed captioning

Length: $5: 21$ 


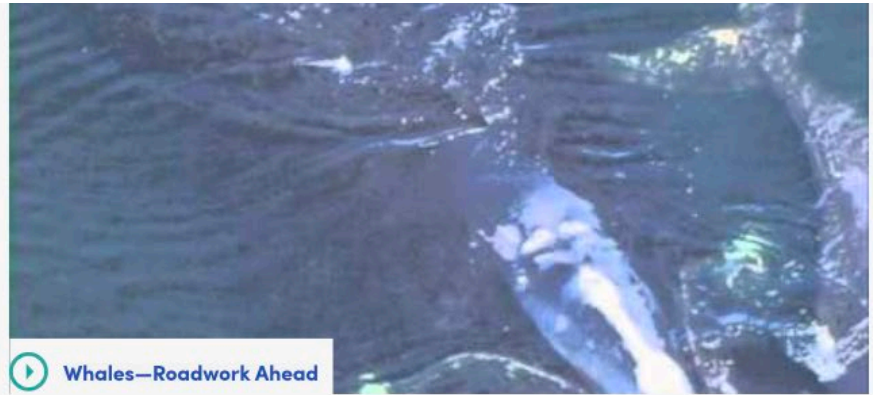

\section{Whales-Roadwork Ahead}

Understand how whales' food sources are changing

Student sheet (PDF 42KB)

Teacher answer key (PDF 47K

Watch with closed captioning

Length: $4: 40$

\section{Additional Resources}

Student sheets and teacher answer keys can be found to the right of each video.

Teacher answer key_(PDF 47KB)

Glossary.(PDF 56KB)

Take action! videos

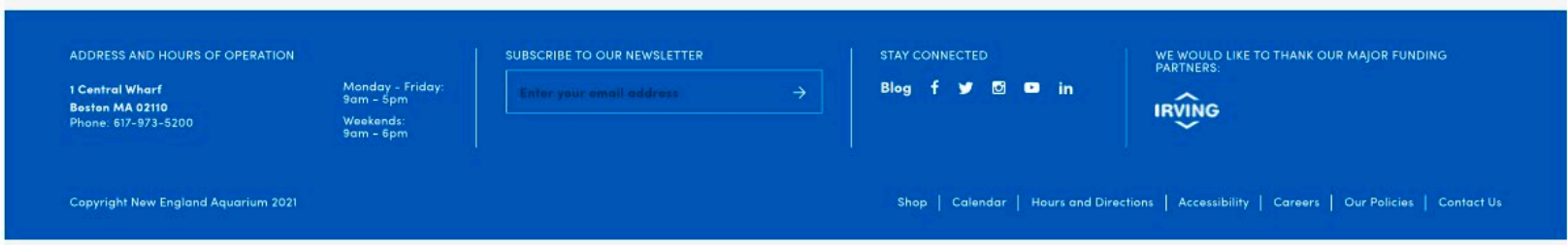


New England Aquarium. 2021m. "Blue Impact Series: Teacher Guide." http://www.neaq.org/wp-content/uploads/2016/06/LEARN_3-5_bluimpact_teacherguide.pdf

\section{Blue Impact Series Teacher Guide}

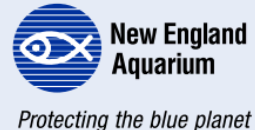

Protecting the blue planet

\author{
Learning Level \\ Intermediate - Advanced \\ Subject Areas \\ Science; English \\ Language Arts \\ Duration of Lesson \\ 45 minutes \\ Lesson Standards \\ Common Core (ELA) \\ - Writing \\ - Speaking and Listening \\ - Language \\ - Science and \\ Technical Subjects \\ MA Frameworks and \\ Next Generation Science \\ Standards (NGSS) \\ - Life Science \\ - Physical Science \\ - Earth and Space Science \\ - Technology and \\ Engineering / Engineering, \\ Technology and \\ Applications of Science
}

\section{Blue Impact Series Overview}

These videos were originally developed as a tour for visitors to the New England Aquarium to point out impacts of climate change. This new Blue Impact series will allow people near and far to understand some impacts of climate change on the oceans. The focus of the series is mainly on how our planet is warming and how this affects ocean life and the physical makeup of the ocean. We provide resources at the end on how to further your knowledge on climate change and how to draw connections between climate change and changes in the ocean. Most importantly we provide ideas for you, your family and school on how to take positive actions to maintain a healthy ocean and planet.

\section{Classroom Use}

The Blue Impact series features seven short science videos as well as three short videos describing certain steps that you can take to help reduce your carbon footprint.

Teachers can use these videos individually or as a series to enhance the following topics:

- Classification

- Global Change

- Density/Current

- Life Cycles

- Earth and Environmental Science - Migration

- Engineering Solutions

- Natural Selection

- Food Webs

- Symbiosis

Students can use the guided viewing sheets below during and after the video. These sheets can enhance classroom discussion and serve as a starting point forgroup projects and community action to reduce the impacts of global climate change while supplementing your curriculum.

\section{Objectives}

Students will be able to explain how human actions, specifically our use of fossil fuels, can impact the planet with an emphasis on the ocean. They will also be able to explain solutions that can alleviate these impacts.

Skills

- Communication

- Group work

- Literacy

- Observation

- Problem solving

Vocabulary

Glossary provided

Materials

- Computer with audio

- Projector

- Internet connection (to watch or download videos)

- Student sheets

- Student access to Internet (optional) 


\section{APPENDIX C: MONTEREY BAY AQUARIUM WEBSITE SOURCES}

Monterey Bay Aquarium. 2021a. "Our mission \& leadership."

https://www.montereybayaquarium.org/about-us/our-mission-and-leadership

\section{Q․|. Monterey Bay Aquarium}

VISIT

ANIMALS

JOIN \& GIVE

ACT FOR THE OCEAN

FOR EDUCATORS

$<$ About us

\section{Our mission \& leadership}

The mission of the nonprofit Monterey Bay Aquarium is to inspire conservation of the ocean

A leader in ocean conservation and education, the Monterey Bay Aquarium is considered by many to be the best in the world. Behind that reputation is a fantastic staff with remarkably diverse skills, all dedicated to earning and keeping that honor. Here are just a few.

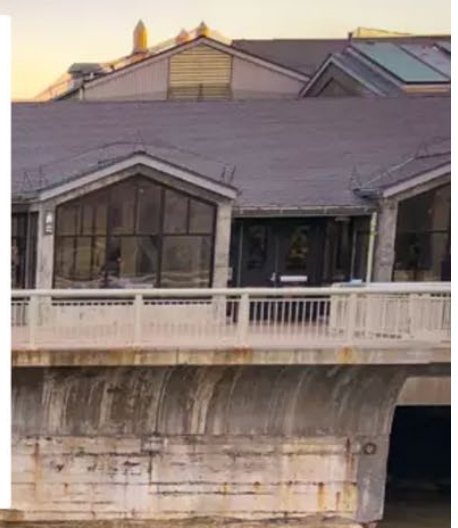


Monterey Bay Aquarium. 2021b. "About us."

https://www.montereybayaquarium.org/about-us

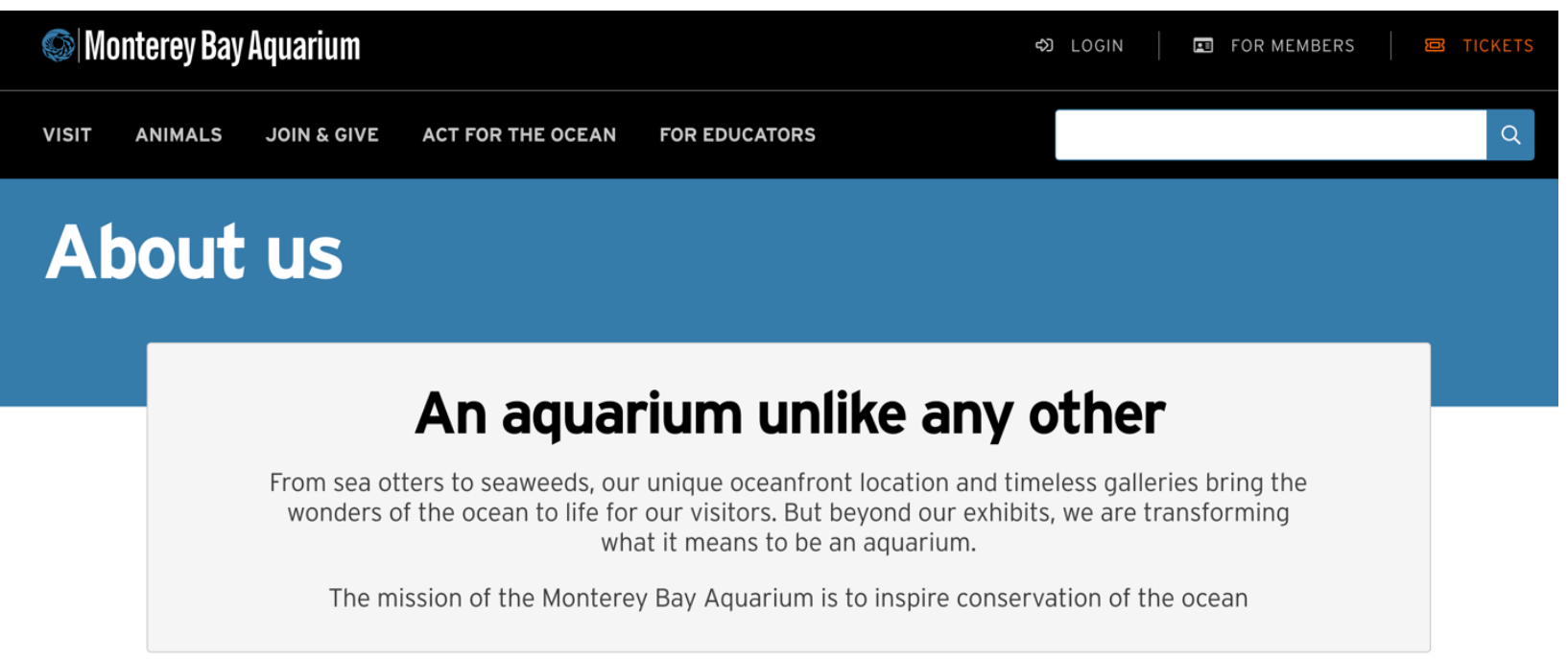

\section{We inspire}

Frolicking sea otters, fast-swimming sharks, pulsating jellies and waddling penguins - our world-class exhibits and breathtaking scenery instill a love of the ocean in our visitors. With over 200 exhibits and 80,000 plants and animals, the Aquarium is a window to the wonders of the ocean.

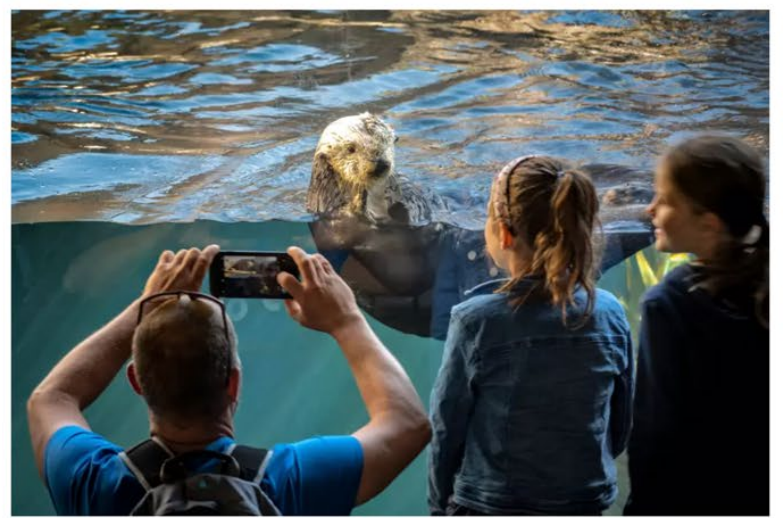




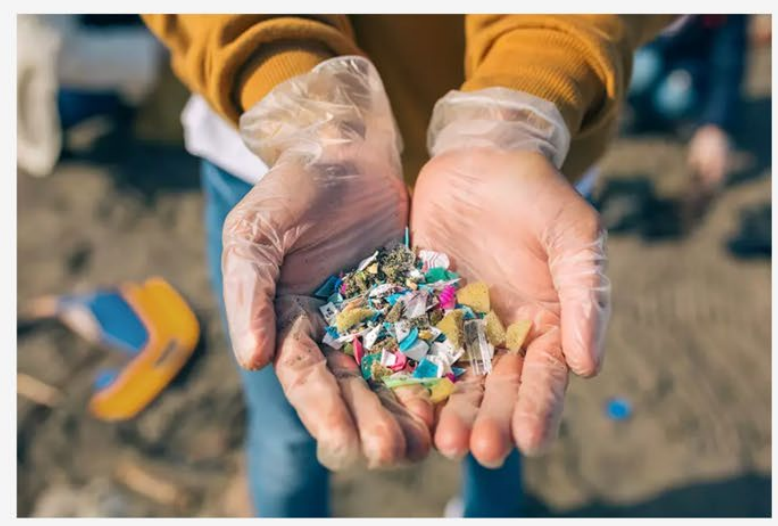

\section{We act for the ocean}

Our exhibits are just one part of what we do. Our scientists are rebuilding sea otter populations, transforming fisheries and aquaculture around the world, and working to protect California's ocean. Our policy experts are mong whe deam is shifting the global match sustainable.

Together we inspire people - from the public to politicians - to take action on some of the biggest threats to ocean health.

\section{We empower young ocean leaders}

Education is a top priority. Since 1984, more than 2.5 million students have visited the Aquarium for free. Our life-changing teacher and youth development programs are helping young people find their vouth development programs are helping young people find their for the ocean.

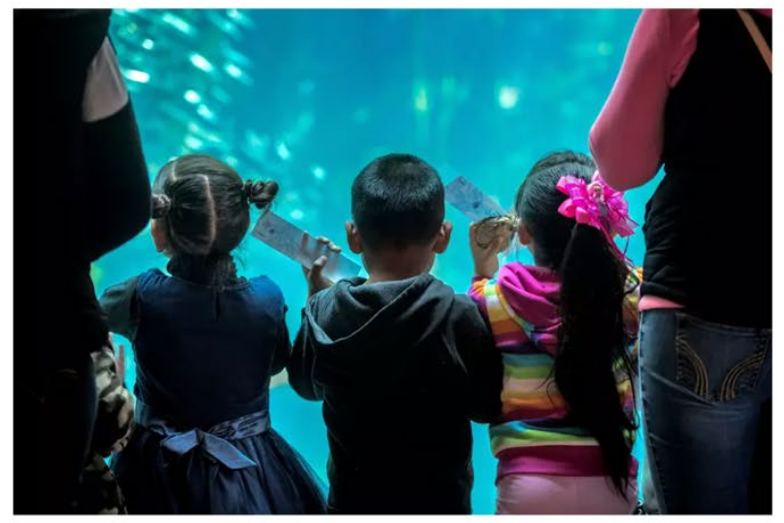

\section{Get to know us}

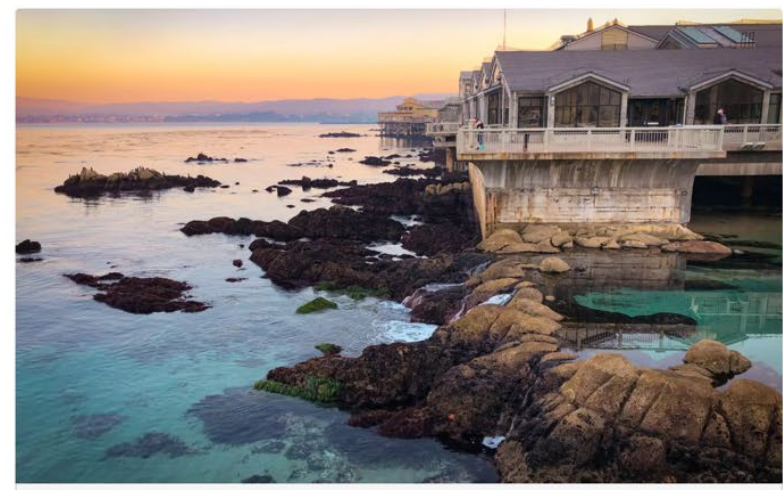

ABOUT US

Our mission \& leadership

Meet the team dedicated to making the Monterey Bay Aquarium a leader in ocean conservation and

$\oplus$ Meet our leadership team

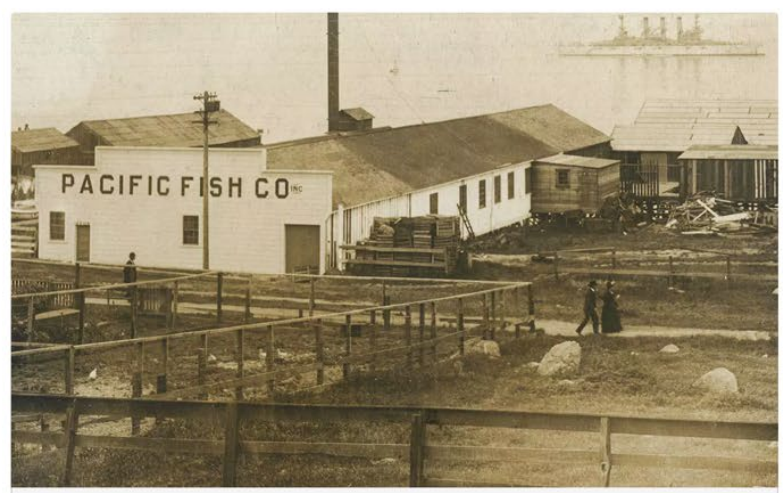

ABOUT US

\section{Our history}

Since opening our doors in 1984, the Aquarium has inspired millions of visitors and become a leader

$\oplus$ See the Aquarium's timeline 


\section{We share the love}

Our staff members are at the heart of the Aquarium. It takes hundreds of people to fulfill the mission of the Aquarium.

While our staff and volunteers are diverse in their skillset and roles, we all have one thing in common - a fierce love of the ocean and the critters that live there.

\section{Our staff includes:}

- Exhibit designers whose vision brings the depths of the ocean into the Aquarium,

- Aquarists and facilities operators that care for our animals 365 days a year,

- Researchers and policy experts working to protect our ocean,

- Teachers educating the next generation of ocean advocates,

- Science communicators sharing the Aquarium's stories with millions of people worldwide,

- Guides that provide visitors with once-in-a-lifetime experiences, and

- Volunteers that connect with our visitors, support our animal care team, assist our educators and even dive into exhibits to clean windows. 
Monterey Bay Aquarium. 2021c. "The challenge."

https://www.montereybayaquarium.org/act-for-the-ocean/california-ecosystems/the-challenge

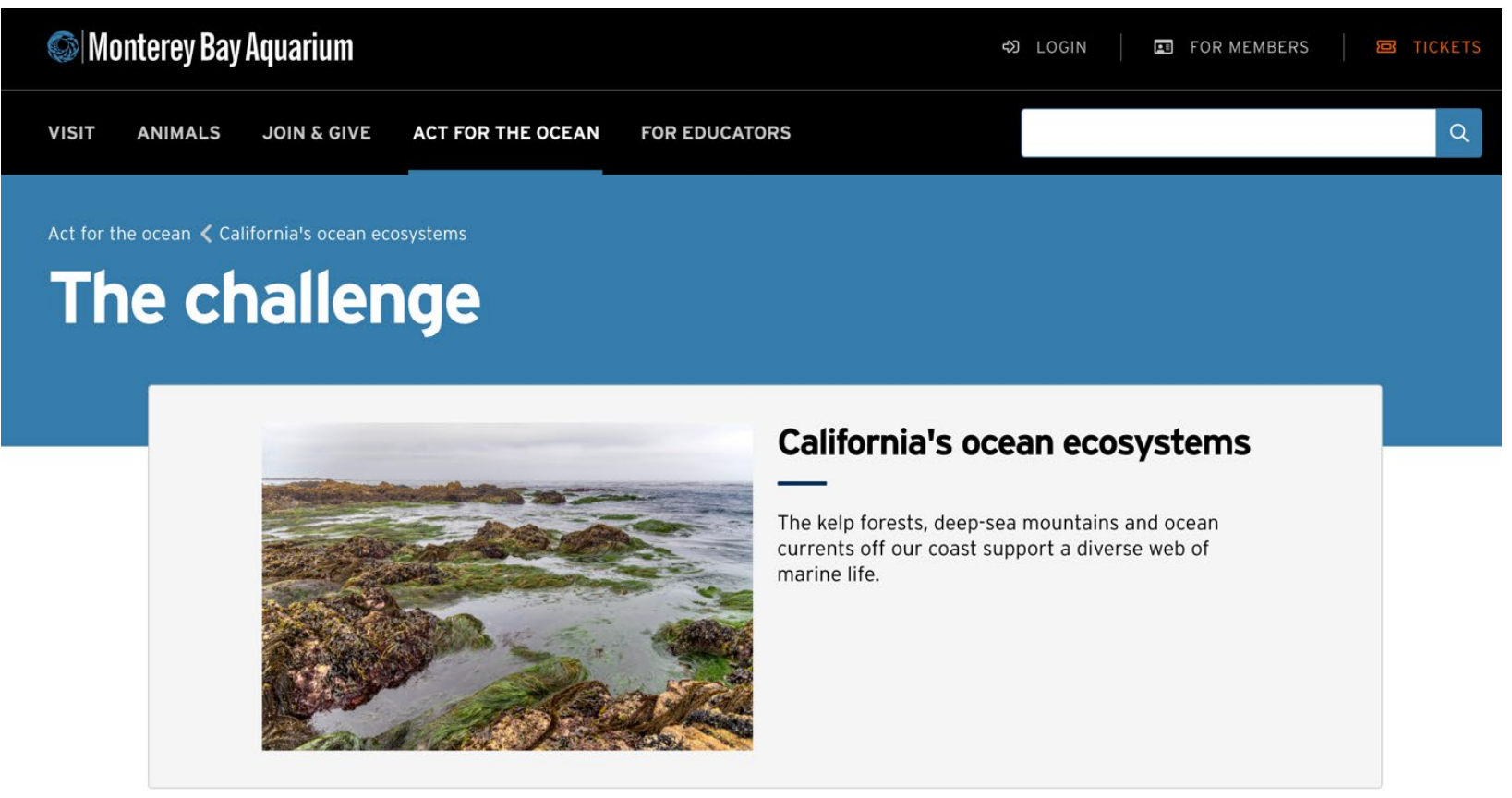

\section{On this page}

What makes California's coast so special?

5 challenges facing California's ocean ecosystems

How California is protecting its iconic coastline and ocean

\section{What makes California's coast so special?}

If you've spent any time along the California coast, you understand why our state's scenic shoreline is admired around the world. But beyond the water's edge, there lies a blue realm that's less well known and every bit as magnificent, vibrant with lush kelp forests, underwater mountains, submarine canyons and complex ocean currents.

California borders the Pacific Ocean, which makes up almost half of the world's ocean area and is home to much of the planet's biodiversity. Just offshore, the California Current is the feeding grounds for billions of fish, mammals and birds. These consistently cool waters help create our state's mild, welcoming climate and support a thriving economy within the Golden State.

On California's central coast, the waters of Monterey Bay include a two-mile-deep submarine canyon, kelp forests and coastal estuaries. These productive ecosystems support abundant wildlife, from territorial sea otters to migratory whales.

The Monterey Bay area is home to more than a dozen leading marine research institutions, including the Monterey Bay Aquarium Research Institute (MBARI). The region is a global capital for ocean science and technology and Monterey Bay is among the most studied areas of the ocean. It's also a natural setting for science-based policy solutions, thanks to a cluster of ocean conservation organizations and government agencies bordering a network of marine protected areas. 


\section{California's unique ocean habitats}

The iconic wildlife of Monterey Bay depend on healthy ocean habitats, including:

\section{Kelp forests}

Giant kelp plants form dense, sunlight-dappled forests that sway rhythmically in the cool waters of many of the world's oceans. These submarine forests grow along the Pacific coast of North America, towering up to 175 feet over the ocean floor. Beautiful and biologically complex, kelp forests provide food and shelter for a diverse community of plants and animals.

\section{Estuaries and wetlands}

Where California's rivers meet the ocean, estuaries and wetlands form critical habitats for wildlife and humans. They serve as nursery grounds for fish, many of which are commercial species vital to California's coastal economy. Migrating birds stop to rest, feed and breed. These swamp-like habitats filter the pollutants and nutrients that flow from land, sequester carbon in the underlying sediments, protect our shorelines from erosion and mitigate sea-level rise.

\section{Rocky reefs and seamounts}

California's rocky shoreline descends into the ocean, forming tide pools and underwater rocky reefs packed with sea life. Many animals rely on these stable, rough structures for shelter. Farther offshore, seamounts create beautiful islands of biodiversity in a vast ocean These underwater mountains attract sharks, whales, turtles and large pelagic fish. They are also home to unique and vulnerable deep-sea corals.

\section{Deep-sea canyon}

The largest ecosystem on Earth - the deep sea - lies between the ocean's sunlit upper layers and the midnight-black bottom miles deep. Here, species must adapt to a world with little to no light, near-freezing temperatures and enormous pressure. Little is known about deep-sea life because it's difficult and expensive to conduct research so far below the ocean's surface.

Here in Monterey Bay, a nearshore deep-sea canyon gives scientists rare access to study this remarkable habitat. As a result, we're rapidly increasing our understanding of the animals that swim or hover in the midwater "twilight zone," and those living on the deep-sea bottom.

\section{California's ocean wildlife}

Along California's coast, seasonal winds shear off surface waters, making room for cooler, deeper waters to fill in rapidly - a complex phenomenon called upwelling. These waters are rich in nutrients, which fuel the growth of phytoplankton, the basis of a robust marine food web. The productive waters of California attract migratory animals from all corners of the Pacific Ocean.

All told, 34 species of marine mammals and more than 180 species of seabirds and shorebirds come to the table. Many migratory animals stop along California's coast, and Monterey Bay in particular, on their long journeys. These traveling animals also include fishes, sharks and turtles.

Whales cruise the California coast as they migrate between breeding grounds in Baja California and their summer feeding grounds in Alaska. Sea turtles travel from Japan all the way to the U.S. West Coast to forage for jellies. Land animals such as monarch butterflies and some songbirds also spend time near Monterey Bay each year.

\section{Economic benefits of a healthy ocean}

California's more than 1,100 miles of coastline, and the waters offshore, directly support our state's robust economy. Coastal tourism and recreation, agriculture and fisheries all depend on healthy ocean and coastal ecosystems.

\section{Tourism and recreation}

Each year, millions of visitors from around the world visit California beaches to surf, kayak, fish, dive or just enjoy the scenery. This ocean-dependent tourism generates billions of dollars every year.

\section{Agriculture}

California's mild climate and weather patterns - influenced by the ocean - support some of the most productive agricultural areas in the United States. California's agriculture industry is worth more than $\$ 50$ billion a year.

\section{Fisheries}

On average, commercial fishing in California generates more than $\$ 150$ million a year for fishermen. California's top fisheries include sardines, anchovies, crab, lobster, squid, groundfish and salmon. 
Monterey Bay Aquarium. 2021d. "MBARI: About MBARI."

https://www.mbari.org/about-mbari/

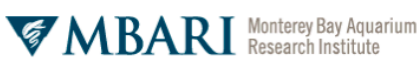

A nonprofit oceanographic research center

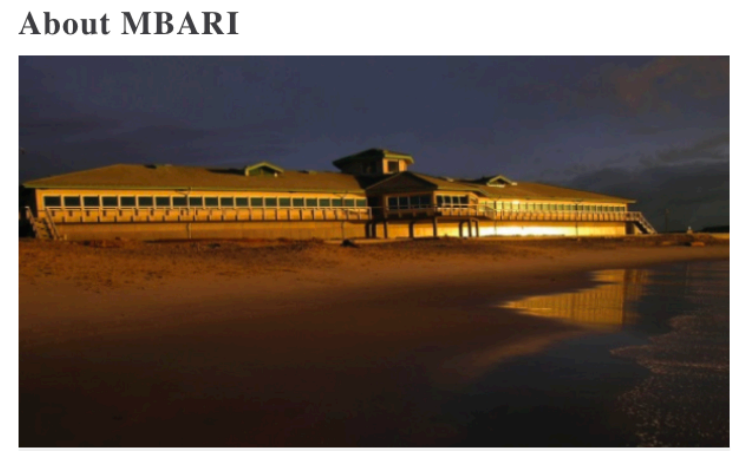

The MBARI offices, labs, and marine facilities are located in Moss Landing, California.

The mission of MBARI is to achieve and maintain a position as a world center for advanced research and education in ocean science and technology, and to do so through the development of better instruments, systems, and methods for scientific research in the deep waters of the ocean. MBARI emphasizes the peer relationship between engineers and scientists as a basic principle of its operation. All of the activities of MBARI must be characterized by excellence, innovation, and vision.

MBARI Founder David Packard

The Monterey Bay Aquarium Research Institute (MBARI) was founded in 1987 by David Packard.

Science and technology goals

To carry out its mission, the institute has defined six main goals:

- Identify important areas of marine science where research progress is limited by lack of appropriate technology.

- Develop sophisticated systems for investigating aspects of the marine environment and its inhabitants where high scientific potential exists.

- Meet the highest possible performance standards for the operation of its equipment and technological systems.

- Conduct high-quality, innovative research that maximizes effective management and use of all MBARI assets.

- Develop, in collaboration with the Monterey Bay Aquarium, creative programs that maximize the educational value of MBARI's research results.

- Transfer research results, technology, and operational techniques to the marine science community worldwide.

Location, personnel, and funding

MBARI is located in Moss Landing, California, where its three research ships and two remotely operated vehicles are berthed, giving them immediate access to Monterey Bay. MBARI also operates several autonomous underwater vehicles and maintains moorings offshore, equipped with ocean-monitoring instruments.

As a private, nonprofit research center, MBARI is funded by The David and Lucile Packard Foundation. Christopher Scholin serves as the institute's president and chief executive officer, managing a work force of approximately 220 scientists, engineers, and operations and administrative staff. MBARI scientists propose and execute innovative studies, both experimental and theoretical, in the ocean sciences. Engineers and operations staff, in partnership with the scientists, develop or adapt supporting technology.

\section{Deep-sea research}

Monterey Bay is one of the most biologically diverse bodies of waters in the world, and the underlying submarine canyon-part of the complex geology of the continental plate margin-is one of the deepest underwater canyons along the continental United States. With a "laboratory" up to 4,000 meters deep only a few ship-hours from their base of operations, institute scientists conduct research relevant to much of Earth's water-covered realm.

MBARI's current efforts span eight research themes, including: benthic processes, midwater research, upper ocean biogeochemistry, ocean observatories, remotely operated vehicle enhancements and upgrades, new in situ instruments, infrastructure support, and information dissemination and outreach.

Brochure about MBARI (PDF)

MBARI

7700 Sandholdt Road 
Monterey Bay Aquarium. 2021e. "Our history."

https://www.montereybayaquarium.org/about-us/our-history

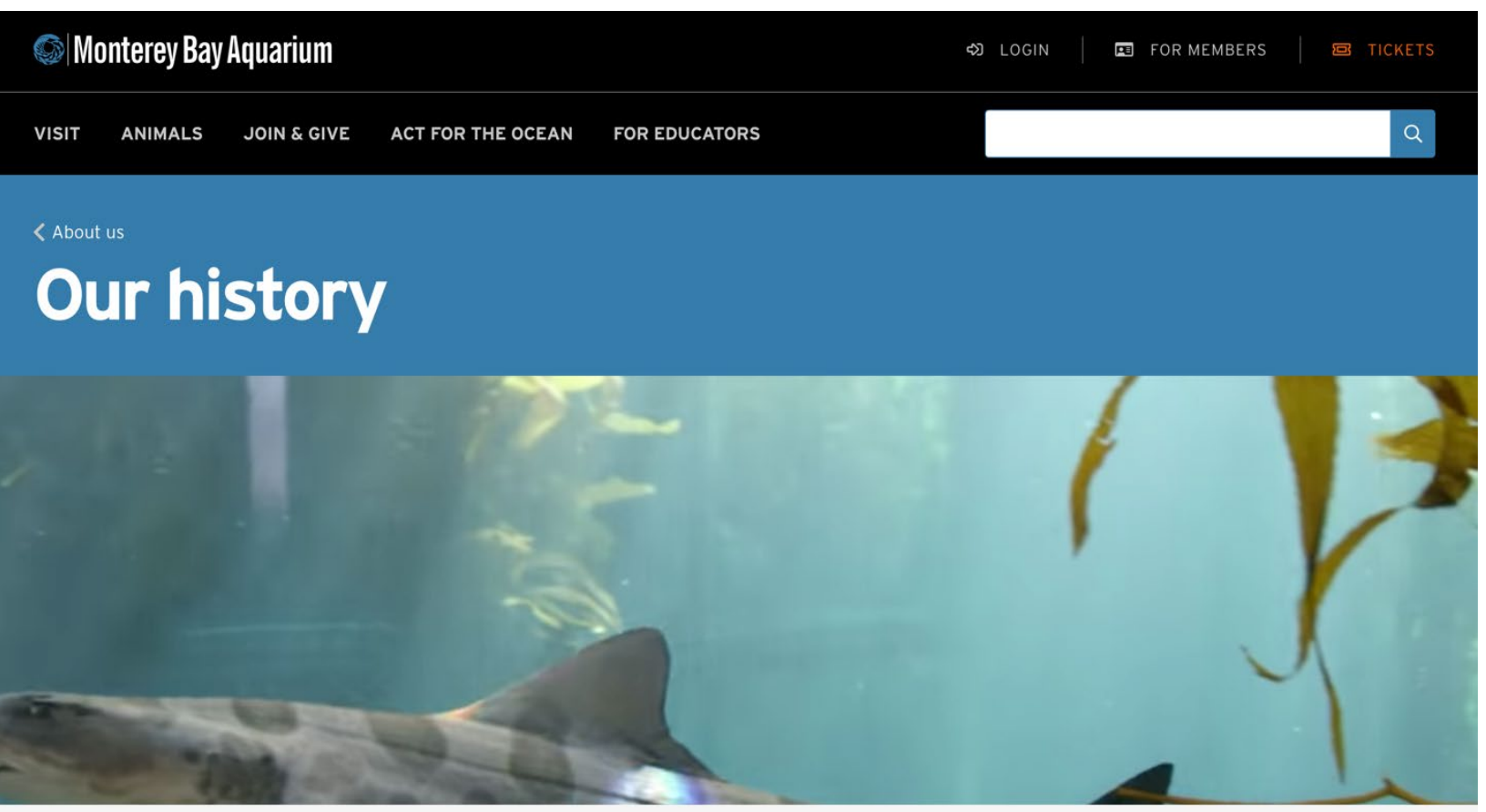

Today, more than 35 years after opening, the Monterey Bay Aquarium is a showcase for the habitats and sea life of one of the world's richest marine regions.

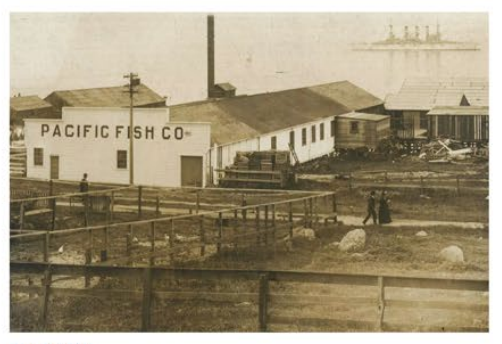

July 7, 1916:

Knut Hovden opened his cannery on the current site of the Aquarium

thery

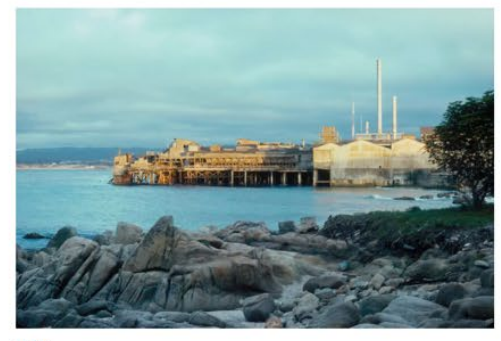

1973:
Following the collapse of the sardine fishery in the early 1950's, the Following the collapse of the sardine fishery in the early 1950 's,
Hovden Cannery began canning squid instead. Unable to market enough, the Hovden cannery closed its doors in 1973.

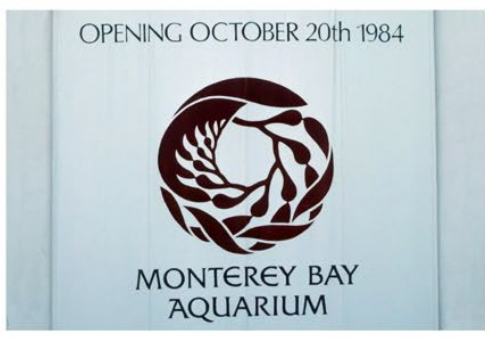

November 1977:

Plans began to take shape for a world-class aquarium showcasing the 


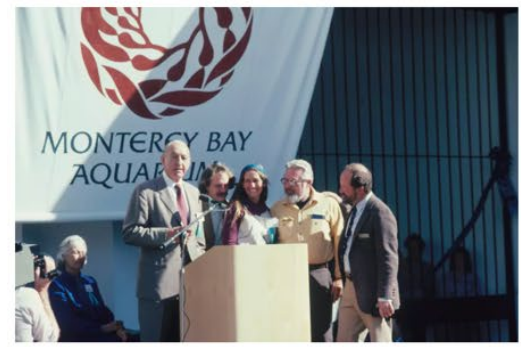

April 1978: David and Lucile Packard Foundation of Los Altos, California, formed the Monterey Bay Aquarium Foundation. A one-time personal gift
from David and Lucile Packard provided initial construction costs for the Aquarium, which ultimately totaled $\$ 55$ million.

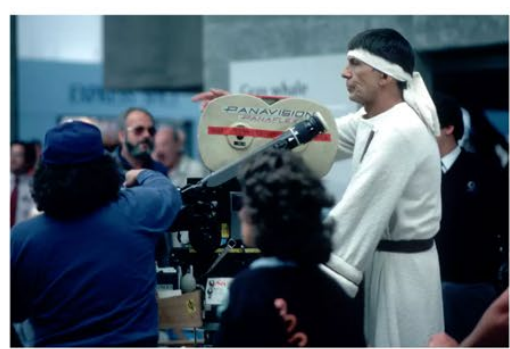

April 1986:

The Aquarium qained movie-star status appearing in Star Trek IV: The Voyage Home.

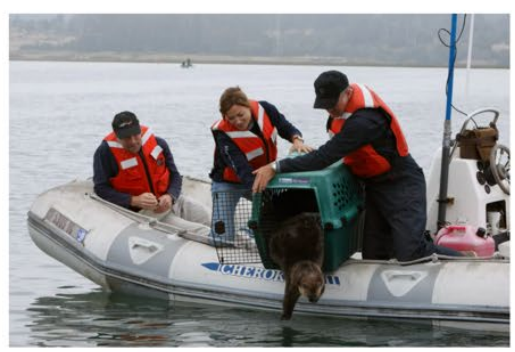

1989:

We succeeded in raising and returning a stranded sea otter pup to the ve been pioneers in sea otter rescue, rehabilitation and the vital coastal habitats they call home.

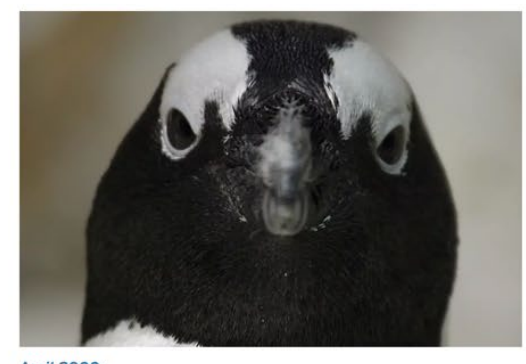

April 2000

Our Splash Zone family galleries open - the first-ever children's museum inside an aquarium.

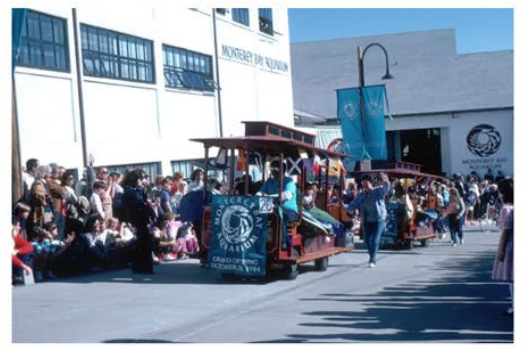

October 20, 1984:

Opening day! The Aquarium opened its doors to 10,681 visitors on its first day

ACCREDITED BY THE ASSOCIATION AQUARIUMSOS

October 1986:

was awarded accreditation from the American Zoo and Aquarium Association (AZA).

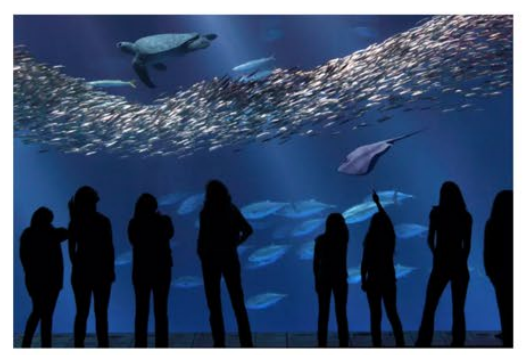

March 1996:

The million-gallon Open Sea exhibit - the largest exhibit at the opens to showcase a community of tunas, hammerhead sharks, sea turtles, sunfish and more.

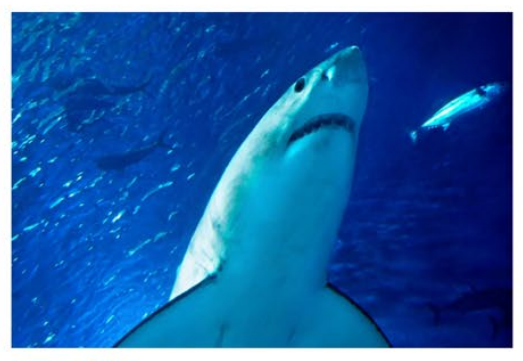

September 2004:

Our first young white shark went on exhibit. Over the next decade, we
successfully displayed several Exhibit - the only aquarium to ever do so. Having young white sharks on exhibit contributed to the scientific understanding of this iconic species. After a few months, we tagged and released the sharks back surprising information about the lives of young white sharks.

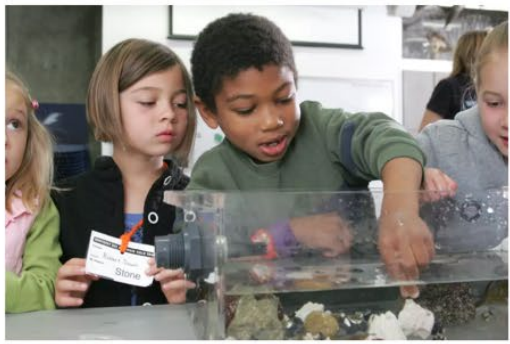

March 1985 to date.

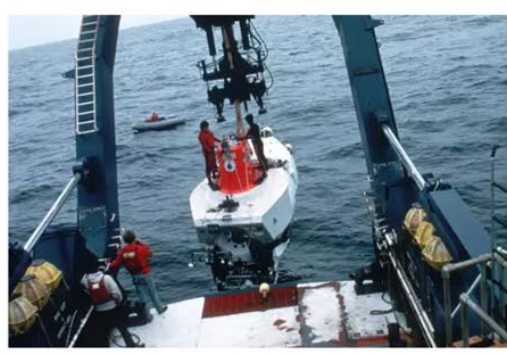

Summer 1987:

The Monterey Bay Aquarium Research Institute (MBARI) was founde with the vision of explore the ocean.
.

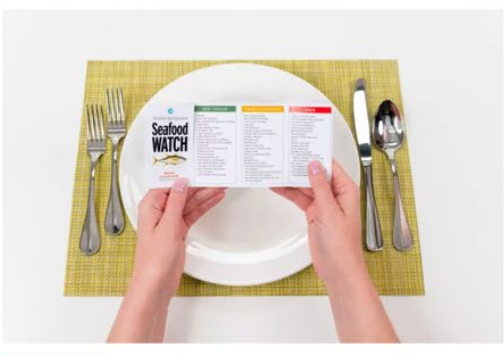

October 1999: Seafood Watch debuts an online program and consumer pocket quide
to help consumers and businesses make sustainable seafood choices.

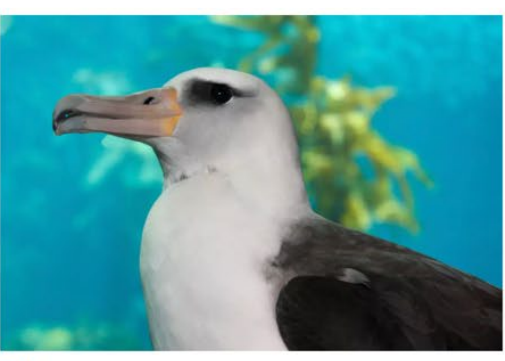

2006:

We welcome Makana, a Laysan albatross rescued from the Hawailan slands to the Aquarium. We are the only accredited institution in us raise public awareness about threats from ocean plastic pollution. 


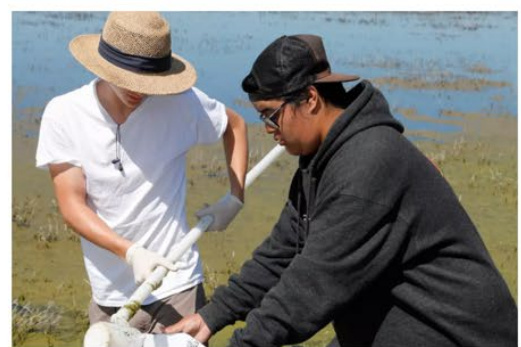

2006:

We launched our Watsonville Area Teens Conserving Habitats program, a long-term education
conservation as a cultural norm.

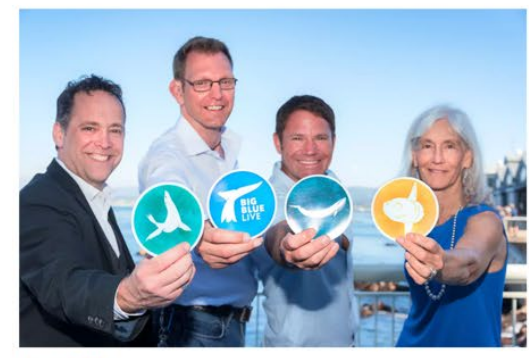

Auqust 2015:
We host "Big Blue Live," a live television event that celebrates Monterey Bay as an ocean conservation success story of global significance.

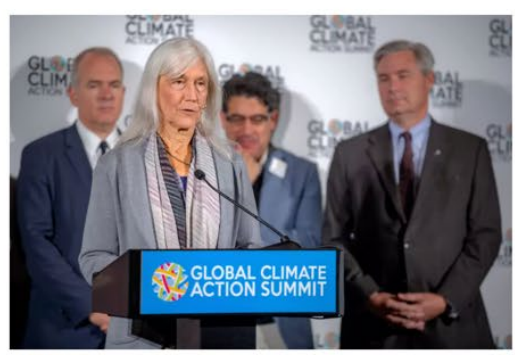

September 2018:

We help put the ocean on the agenda at the Global Climate Action Summit when Executive Director Julie Packard introduces an ocean-

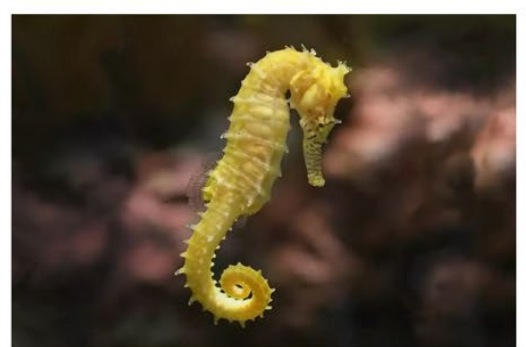

April 2009:

The Secret Lives of Seahorses special exhibition opened, becomin the Aquarium's most popular temporary exhibit ever.

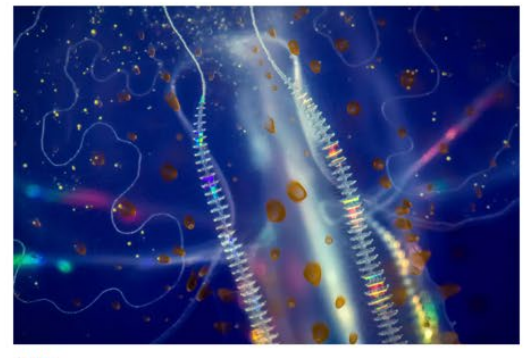

2017:

We become the first institution in the world to culture the stunning to hatch and raise chambered nautilus.

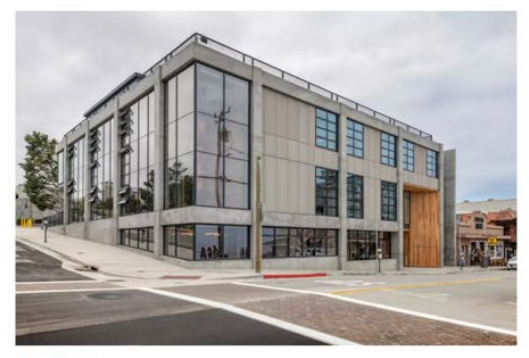

June 2019:

Our new Bechtel Education Center welcomes its first students. The ecosystem-based education and youth development programs of any aquarium in the nation.

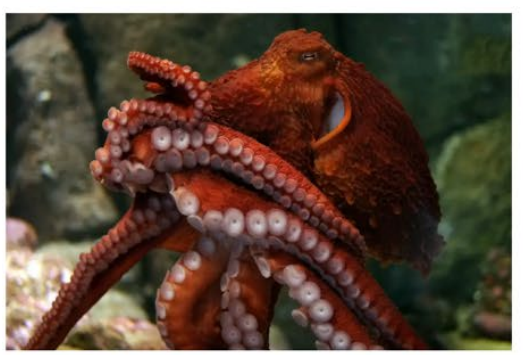

April 2014:

The Tentacles: The Astounding Lives of Octopuses, Squid and tion opened, presenting some of the ocean's most engaging animals.

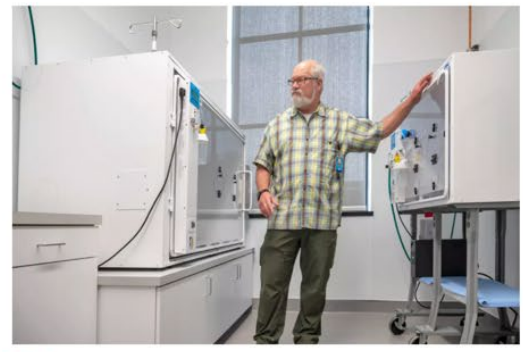

2018:
Our Jull Plant Grainger Animal Care Center opens, allowing us to
expand ocean animal health care and provide training opportunities expand ocean animal health care and provide training opportunities for aspiring veterinarians in conservation medicine.

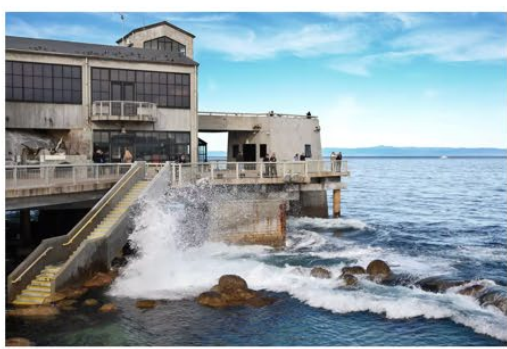

October 20, 2019:

The Acuarium celebrated 35 years of inspiring ocean conservation through its exhibits, education, research and conservation programs and much more.

"Reflecting on our first 35 years, our original vision stands: The Aquarium will continue to amaze and delight families from all over the world, spark a love of science and nature in young people, offer a sanctuary for wonder and reflection, and become an experience infused in the lifetime memories of millions of people." 
Monterey Bay Aquarium. 2021f. "Introduction \& history."

https://www.montereybayaquarium.org/newsroom/media-kits/introduction

\section{Introduction \& history}

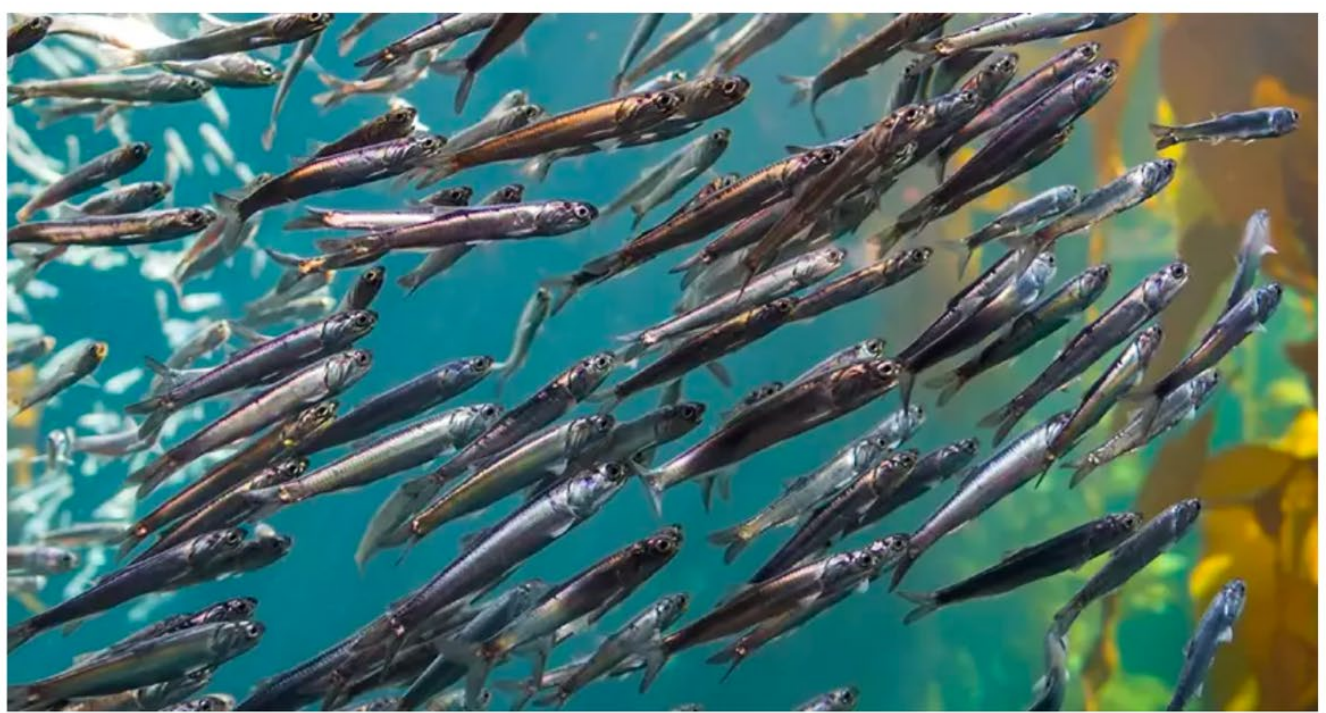

\section{Introduction}

The Monterey Bay Aquarium is the most admired Aquarium in the United States, a leader in science education and a global voice for ocean conservation through active programs in marine science and public policy. Everything we do works in concert to protect the future of our ocean.

\section{Mission}

The mission of the Monterey Bay Aquarium is to inspire conservation of the ocean.

\section{Vision: inspiration and action}

Our mission is more urgent than ever before. Worldwide, the ocean is in peril, its wildlife and habitats threatened by an ever-increasing pace of human activity. We risk losing vita natural systems that sustain us all and are a source or hu. Whood and inspiration for humanity. We believe shat humankind can turn this tide. We envision a world in which the sustaining natur systems. To make this vision a reatity we help peop kan more, core more and do more on behalf of the ocens. Our exhibits and programs introduce, pepie from all walks of life to the wonders of the marine world from Monterey Bay to the vast oceans beyond As a bader in ocean conservation, we extend our impact by to thing bevond our walls to inspire the public and policymaters to act on behalf of the ocean. 


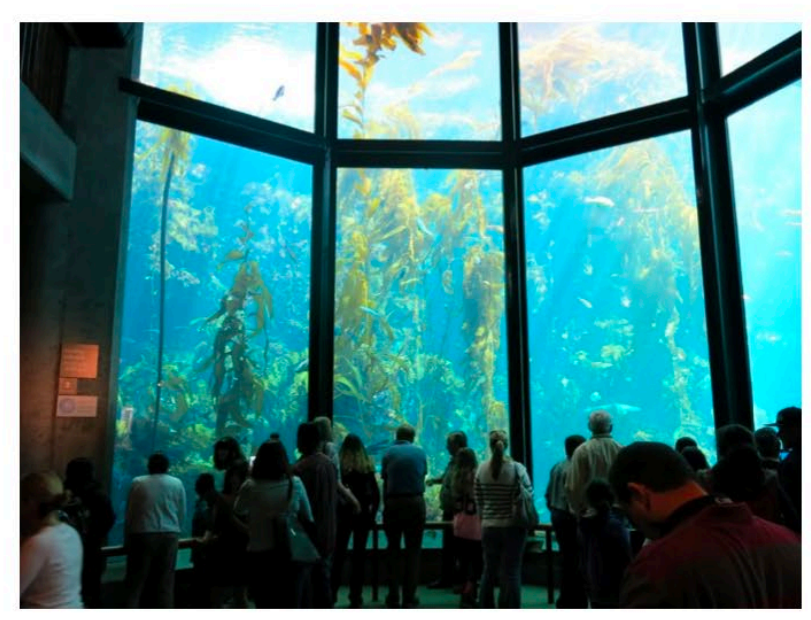

\section{History}

In the late 1970s, a group of marine scientists affiliated with Stanford University and Silicon Valley crafted a vision for what was to become the world-class Monterey Bay Aquarium. They imagined a small Aquarium devoted to the diversity and beauty of life in the waters just offshore, built inside a derelict cannery from the industrial heyday of the sardine packing era immortalized by author John Steinbeck.

After six years of planning and funded by a $\$ 55$ million personal gift from David and Lucile Packard, their vision became reality on October 20,1984. The Aquarium opened its doors in a state-of-the-art building on the ocean's edge, on Monterey's historic Cannery Row.

Ours was a different mission - not one of commerce, but a commitment: to inspire conservation of the ocean.

We were the first major public Aquarium in the world with permanent exhibits devoted to the marine life of our home region: the waters of Monterey Bay and California's Central Coast. The exhibits we created helped spark public interest that led to designation of the Monterey Bay National Marine Sanctuary - the largest in the continental United States.

We were also the first Aquarium with a living kelp forest; the first to create large-scale jellyfish exhibits; the first to successfully exhibit young great white sharks and return them successfully to the wild; the only Aquarium outside Japan to exhibit ocean sunfish, yellowfin and bluefin tuna; and a pioneer in the creation of changing special exhibitions that are now common in the Aquarium world.
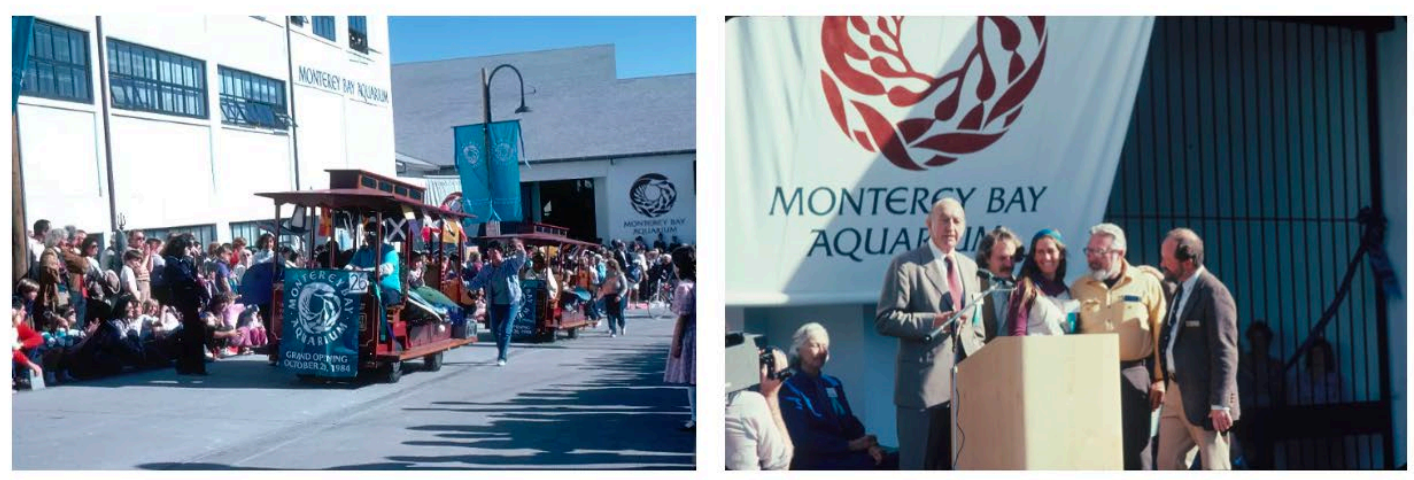


\section{Today}

We are working more effectively than ever on behalf of ocean health by integrating science-based conservation research with policy initiatives and partnerships that are making a difference. In the face of growing threats to ocean health, we have adopted a new strategic approach that focuses our conservation and science efforts on critical

issues affecting the future of the ocean, including steps to reduce plastic pollution, promote sustainable seafood globally, address climate change, and protect key species such as sea otters, sharks and Pacific bluefin tuna.

From our exhibits to our global research and policy initiatives to education programs designed for teachers, students and underserved communities, we are working to turn the tide for ocean conservation.
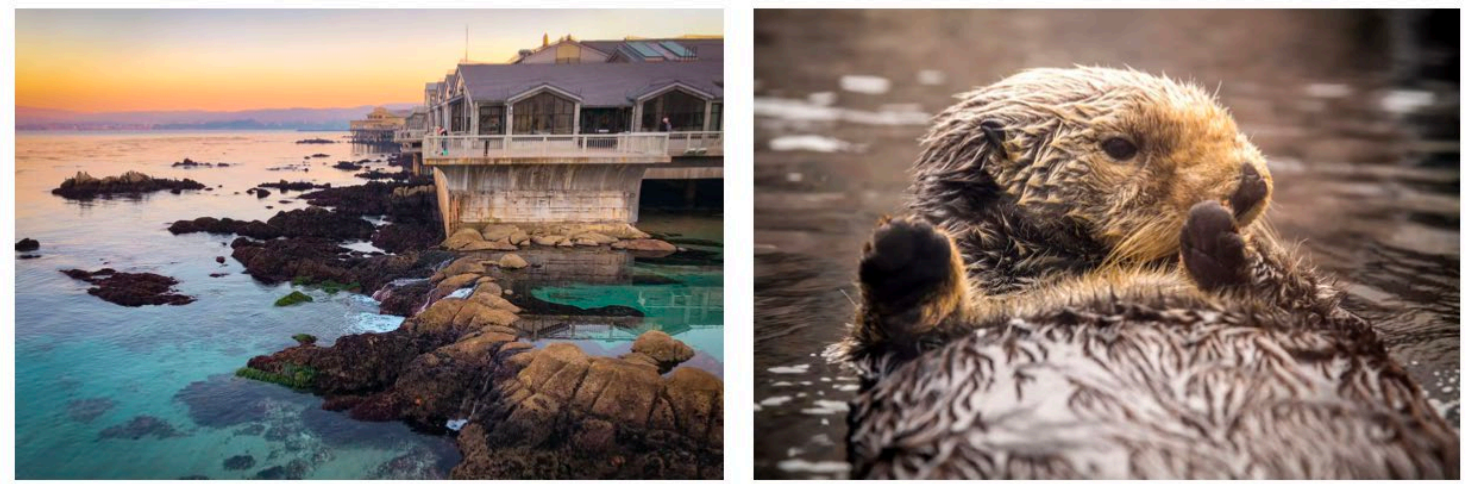

\begin{tabular}{|c|c|}
\hline \multicolumn{2}{|c|}{ Monterey Bay Aquarium media kit } \\
\hline Introduction \& history & $\begin{array}{l}\text { Conservation \& science } \\
\text { programs }\end{array}$ \\
\hline \multirow{2}{*}{ Exhibit descriptions } & Education programs \\
\hline & Honors \& awards \\
\hline
\end{tabular}


Monterey Bay Aquarium. 2021g. "Act for the ocean."

https://www.montereybayaquarium.org/act-for-the-ocean

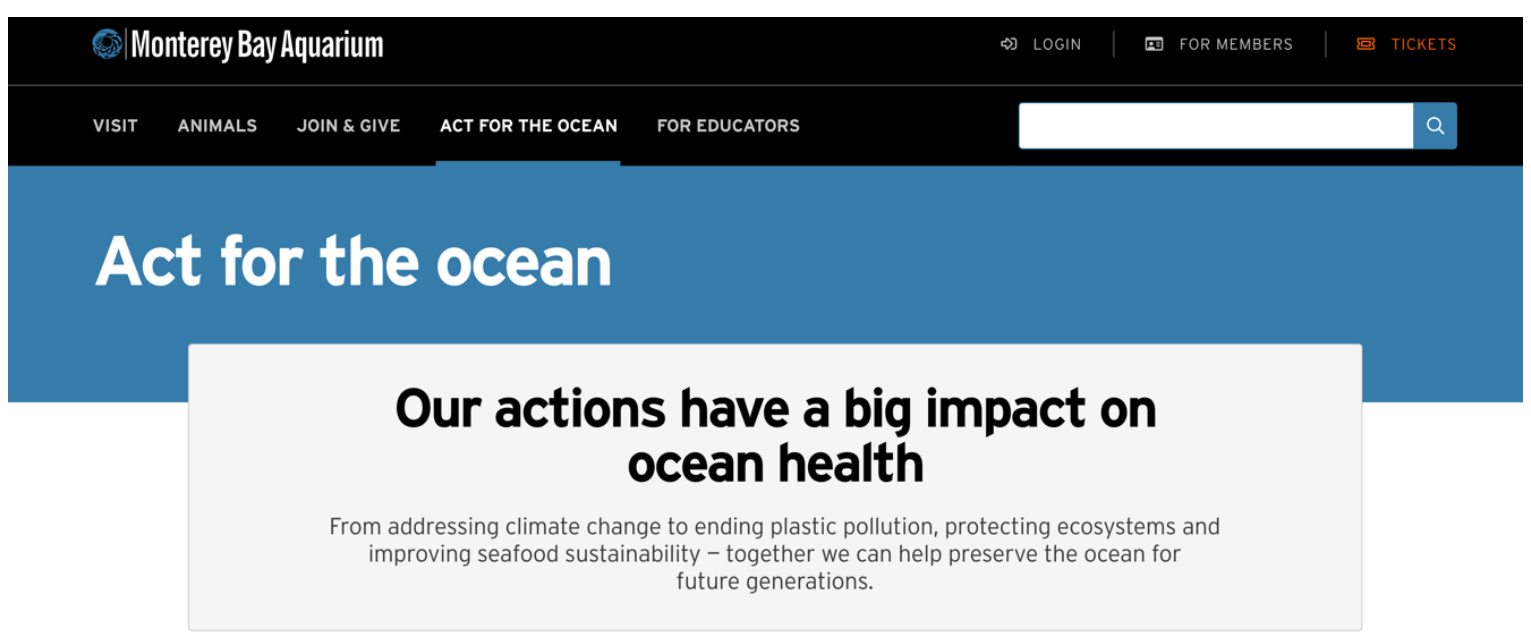

\section{Help turn the tide}

Explore the biggest threats facing the ocean today - and how together we can take action to protect the ocean for future generations.

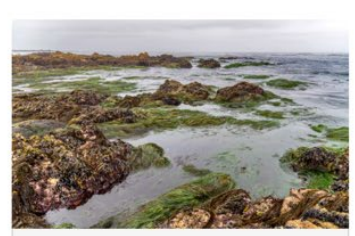

ACT FOR THE OCEAN

California's ocean ecosystems

California's well being depends on keepin our world-famous coastal waters healthy
and resilient in a rapidly changing world.

$\Theta$ Protect our ocean

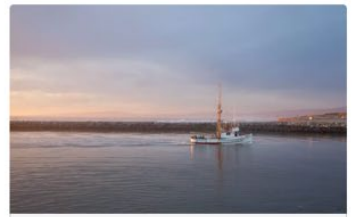

ACT FOR THE OCEAN

Sustainable seafood

Choosing sustainable seafood items can protect our ocean and ensure a hes
supply of seafood into the future.

$\bigoplus$ Speak up for sustainable seafood

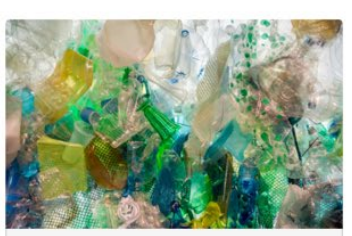

ACT FOR THE OCEAN

Plastic pollution

Ocean plastic pollution is a problem we can
solve. Dive deeper into the major causes, impacts and solutions for ocean plastic pollution.

$\oplus$ Help end plastic pollution

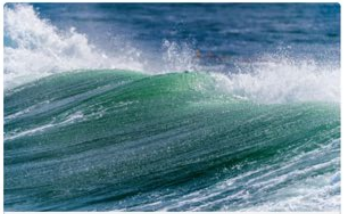

ACT FOR THE OCEAN

Climate change

Understand the ocean's role in
climate change and how we can all take action to protect the ocean.

() Take on climate change 
$\checkmark$ Curious how you can protect the ocean?

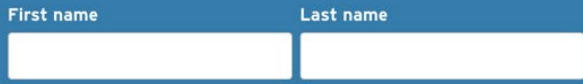

Sign up for our ocean action emails and get the scoop on issues affecting the ocean, research updates and simple tips on how you can lead an ocean-friendly life delivered to your inbox.

\section{See how we're stepping up for the ocean}

We are committed to solving the problems that face our ocean. Explore how

we are giving the ocean a voice - and making a difference every day.

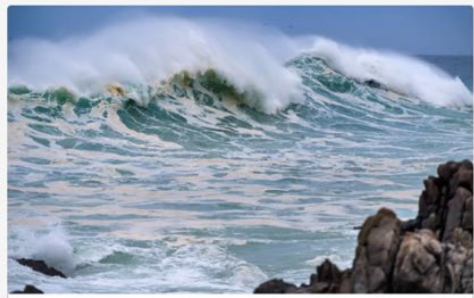

STORY

Aquarium science puts the disparities of climate change on the map

A landmark study published by Science Advances charts the most comprehensive accounting of global greenhouse
emissions resulting from the burning of fossil fuels.

$\oplus$ Read more

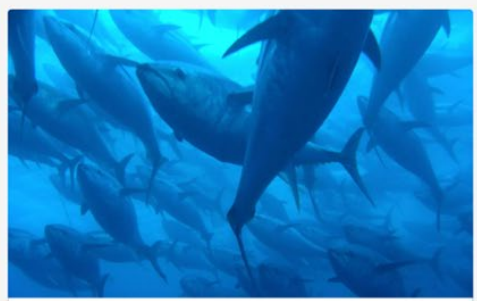

STORY

Tuna fisheries management is moving in the wrong direction

Tuna is king in kitchens and restaurants around the world, but nearly fifty percent of Seafood Watch's global tuna ratings are

$\Theta$ Learn why

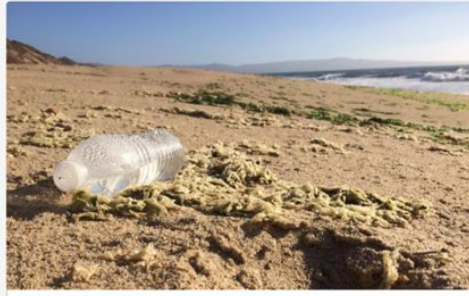

STORY

Consumers deserve the truth about plastic

Several forward-thinking bills aimed at reducing plastic waste are in front of California's Legislature. Learn about the your representative know you want these bills to be passed

(๑) Read the story

\section{Ways you can take action}

Each one of us can take simple actions every day to help protect the ocean wildlife and habitats that we love. Learn how you can act for the ocean today.

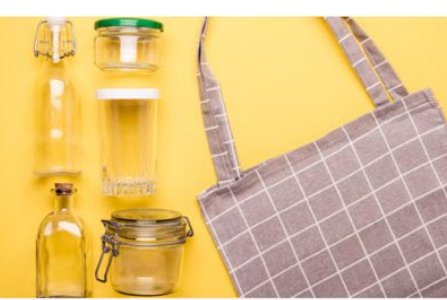

End plastic pollution

Much of the plastic items found in the landfill or in the ocean difference by cutting back on single-use plast

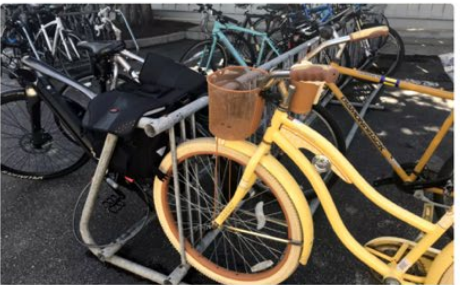

Support clean energy

Wondering what you can do for climate change? The number
one thing you can do is to support a clean energy future

(๑) Take climate action

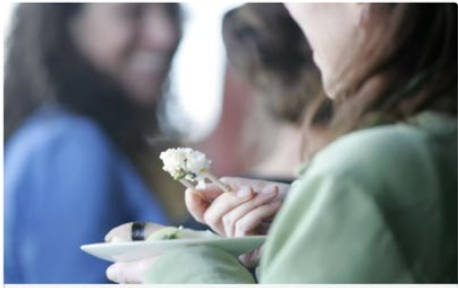

Speak up for sustainable seafood

Your choices matter - let your favorite businesses know that

$\oplus$ Choose sustainable seafood 
Monterey Bay Aquarium. 2021h. "Bechtel Family Center for Ocean Education \& Leadership." https://www.montereybayaquarium.org/for-educators/bechtel-education-center
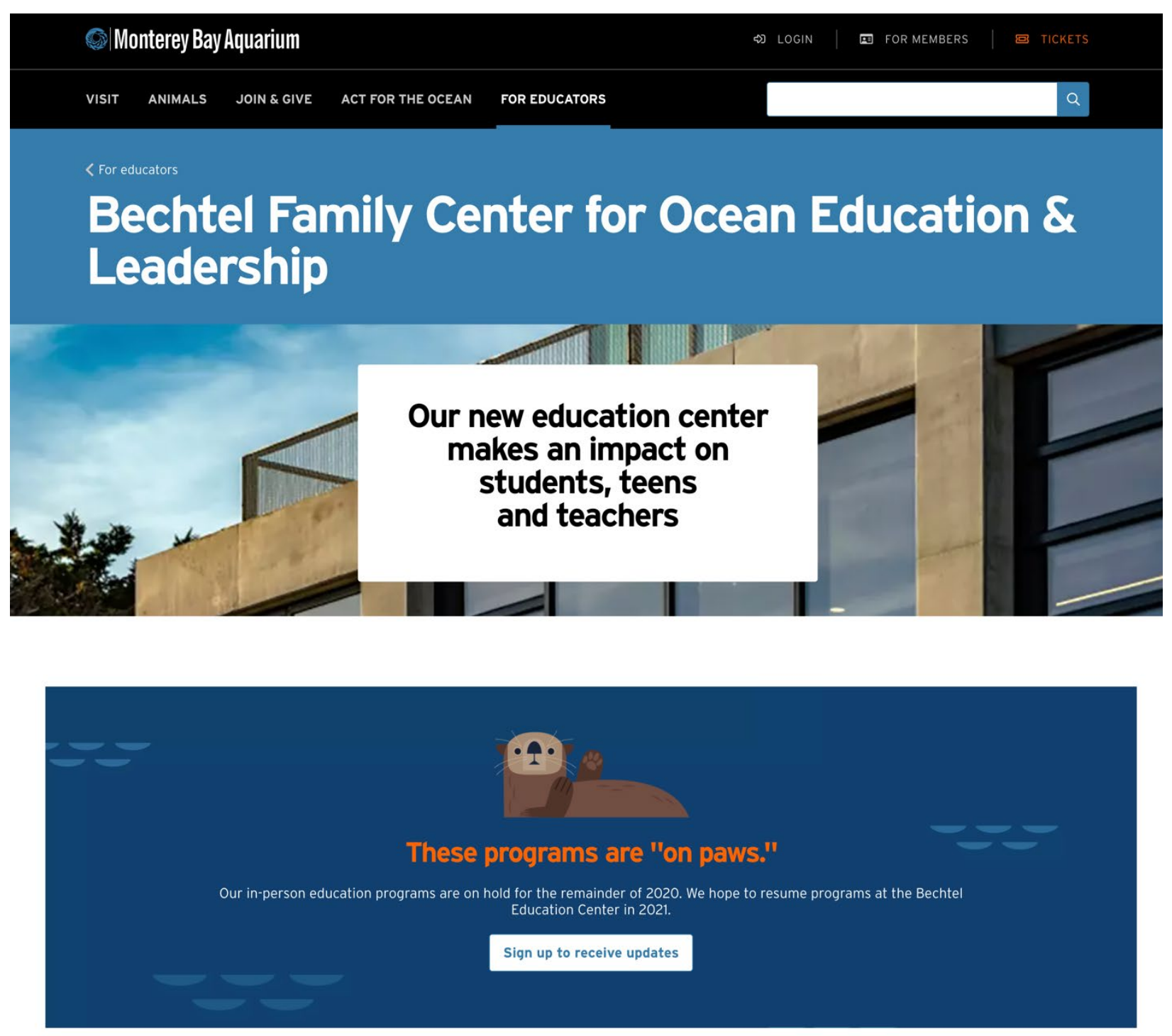
(2)

\section{Getting here}

$\frac{625 \text { Cannery Row }}{\text { Monterey, CA } 93940}$

Directions and instructions for bus drivers

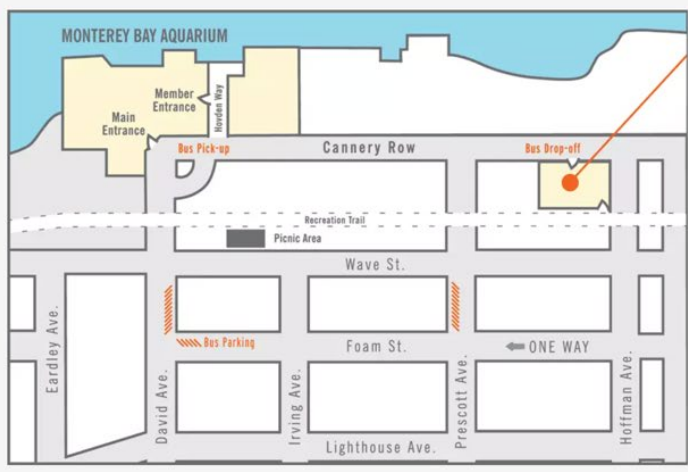

\section{Bechtel Education Center features}

- Located just a few blocks from the Aquarium on Cannery

- Four stories, 26,000 square feet

- Four learning labs with live animal displays
- Collaborative learning spaces

Multipurpose room for large gatherings and studen lunches

- Rooftop garden and meeting space
- Public exhibit space

Designed to meet U.S. Green Building Council's LEED gold standards for sustainability, including the use of solar panels, a living roof and water conservation features

\section{Inspiring the next wave of ocean leaders}

Our Bechtel Education Center is a historic investment in science education and youth development. Our exceptional education programs have made an important and lasting impact on children, teens and teachers. The new education center expands our ability to reach more than twice as many students and educators as we do now - and all still free of charge.

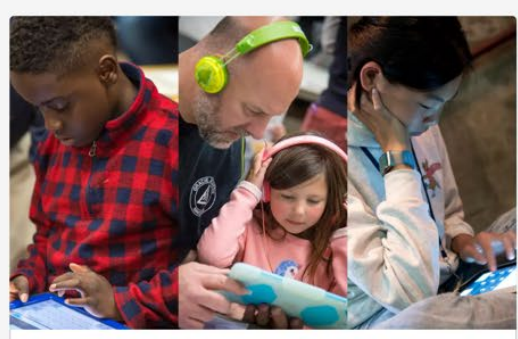

FIELD TRIPS

\section{Field trips}

Give your class a virtual Aquarium experience! With Online Discovery Labs, students get a 45 -minute live Zoom an Aquarium educator.

$\oplus$ Learn about Online Discovery Labs

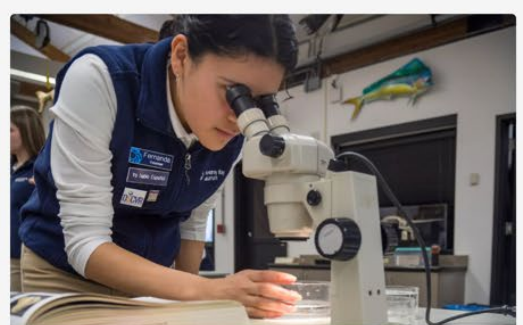

TEEN PROGRAMS

\section{Teen programs}

Teen programs are currently on hold. You can still browse and learn about our programs for teens.

$\Theta$ See our teen programs

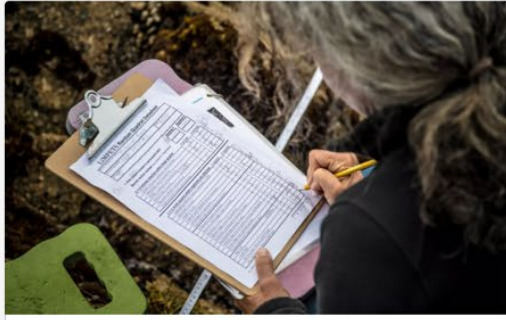

TEACHER DEVELOPMENT

Teacher programs

Explore our free teacher development institutes and workshops.

$\Theta$ See our teacher programs 
Monterey Bay Aquarium. 2021i. "Teen programs."

https://www.montereybayaquarium.org/for-educators/for-teens/teen-programs
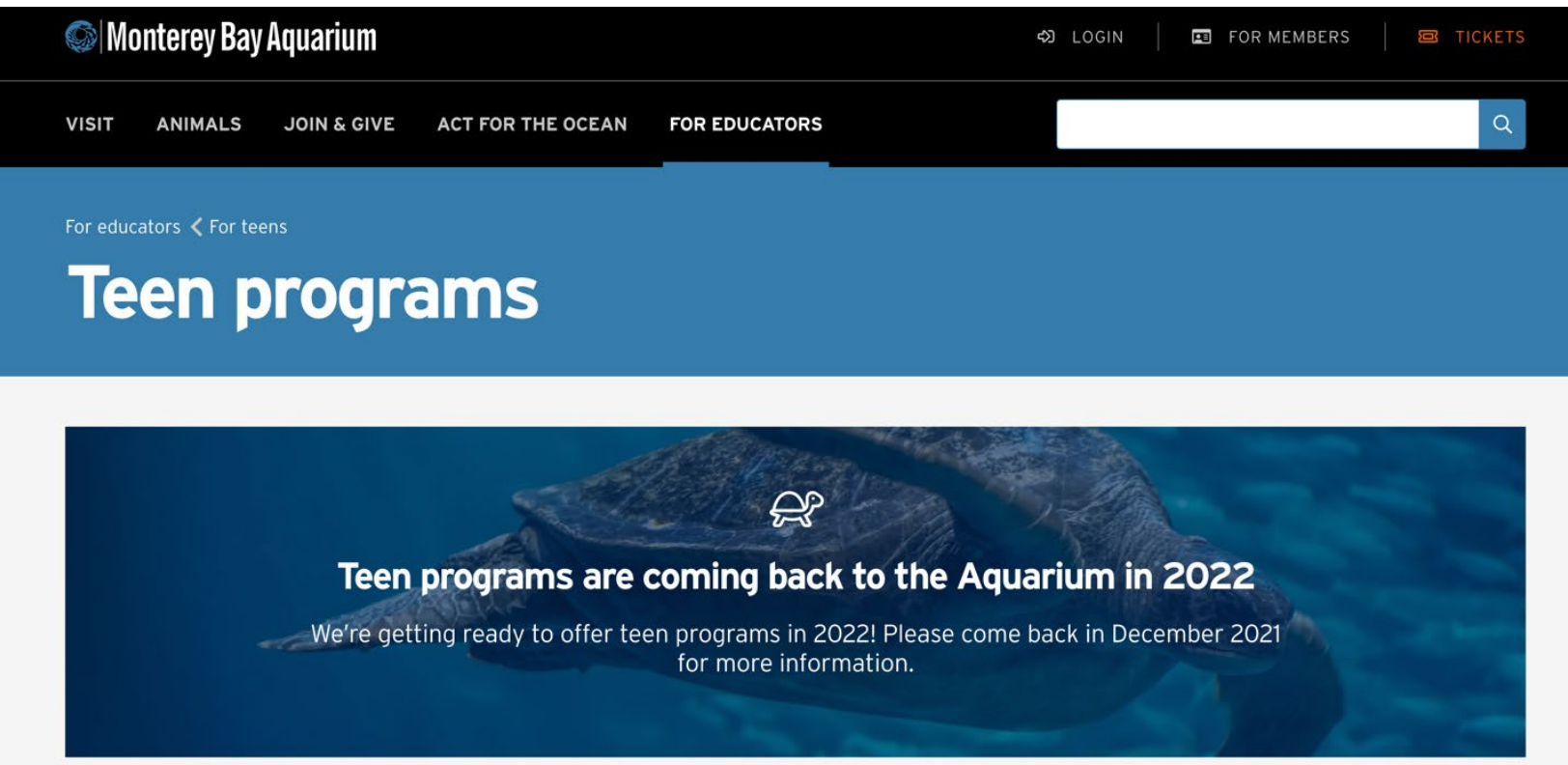

\section{Check out what our teens have been up to}

Though we've been closed, teens in our programs, and program alumni, continue to do great things. Explore our stories to see what teens have been doing and meet program alumni.

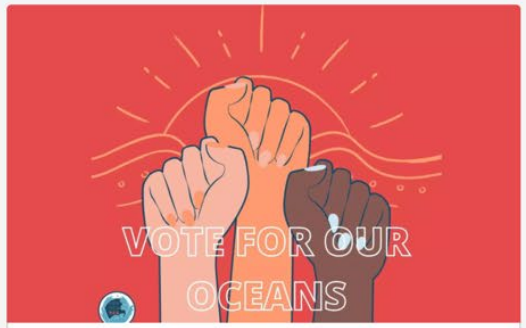

STORY

Getting out the vote from home

In the middle of a pandemic, these young people found an opportunity to make a difference.

$\Theta$ Read the story

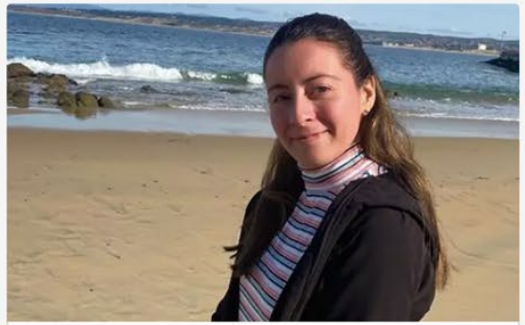

STORY

\section{Meet Mary Garcia}

Mary Garcia is building on her experience as an Aquarium WATCH program alum to help our Education Department transition in-person programs online.

$\oplus$ Meet Mary

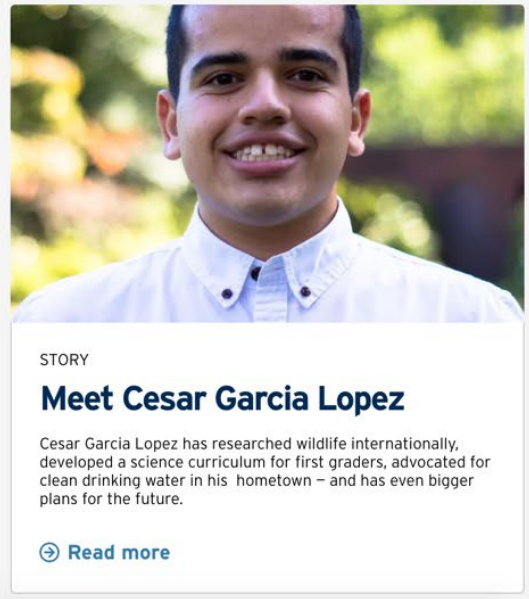




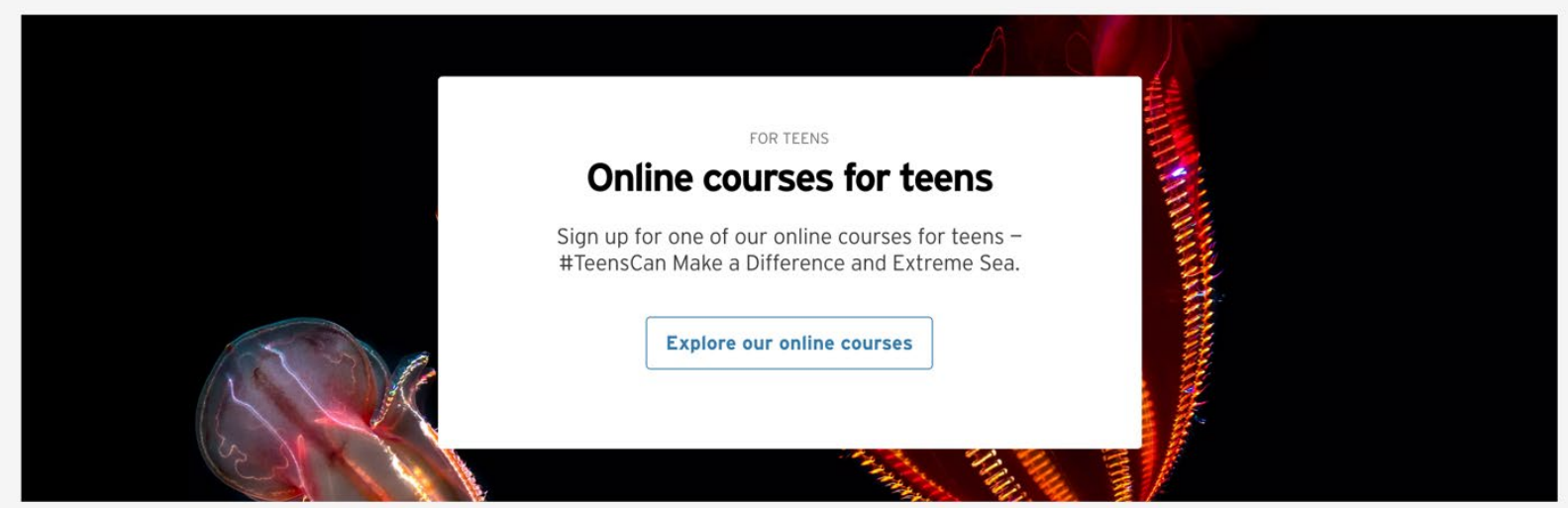

\section{Teen programs}

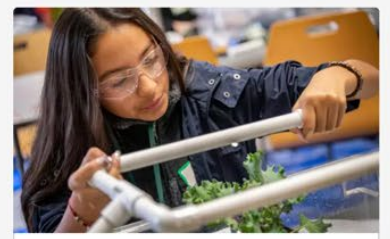

TEEN PROGRAMS

\section{Design for the Ocean}

This program is currently unavailable. This program offers students interested in designing solutions for ocean conservation
problems ways to use their engineering
skills.

$\Theta$ Learn about D40

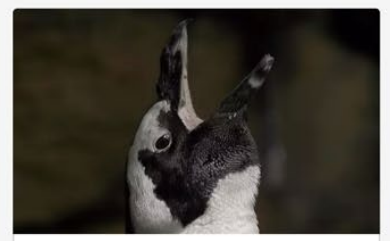

ABOUT US

Sign up for alumni updates

Have you participated in one of our teen programs? Sign up for alumni updates to get job opportunities, scholarships and more!

$\Theta$ Send us a message

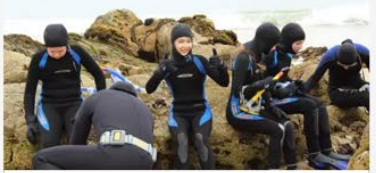

TEEN PRograms

Student Oceanography Club

This program is currently unavailable. The Student Oceanography Club is for middle marine science and making a difference in their communities.

$\oplus$ Learn about SOC

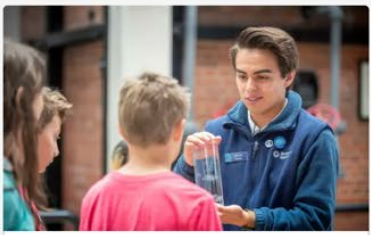

TEEN PROGRAMS

Teen Conservation Leaders

This program is currentily unavailable.
Teen Conservation Leaders develop important job and life skills while interacting with Aquarium guests.

$\oplus$ Learn about TCL

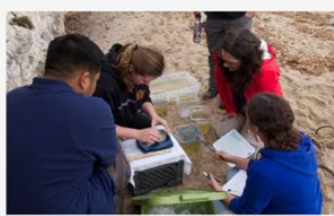

TEEN PROGRAM

Watsonville Area Teens Conserving Habitats

This program is currently unavailable. This students to explore empowers high school students to explore local environmenta
issues and participate in community

$\oplus$ Learn about WATCH

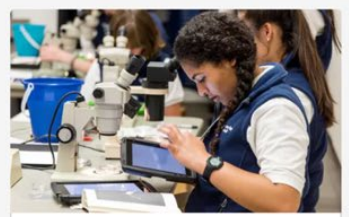

TEEN PROGRAMS

Young Women in Science

This program is currently unavailable designed to get middle school students excited about science, the ocean and conservation

$\Theta$ Learn about YWS 
Monterey Bay Aquarium. 2021j. "Teen Conservation Leaders."

https://www.montereybayaquarium.org/for-educators/for-teens/teen-programs/teen-conservationleaders

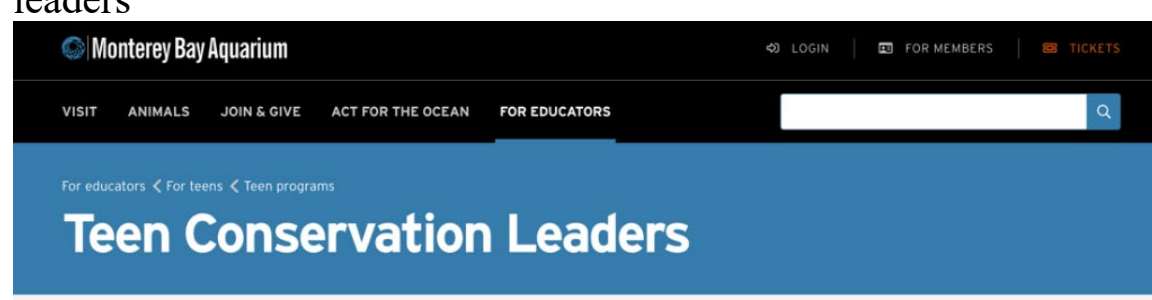

目 High school

Students develop important job and life skills as they interpret Aquarium exhibits for our guests.

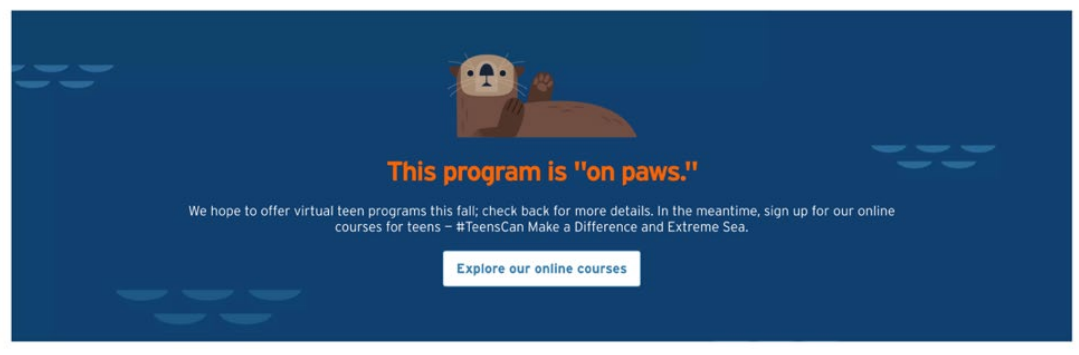

\section{Program details}

The Teen Conservation Leaders (TCL) program provides an important volunteer service to the Aquarium, our guests and our communities. During a fun and intensive two-week training at the beginning of the summer, students learn basic marine biology and ocean conservation. Upon completion of the training, students provide exhibit interpretation for our guests. As a Teen Conservation Leader, students develop important job and life skills, build self-confidence and earn community service hours.

During their first summer, TCL students participate in the Guest Track. Students hone their interpretation skills and provide enriching guest experiences. Students become familiar with Aquarium stories and animals while sharing their passion for conservation. Applicants should have an interest in actively communicating with visitors of all ages and backgrounds.

Additional volunteer opportunities are available only to TCL volunteers who have participated in the summer program. These opportunities include assisting in special events at the Aquarium, supporting a variety of education programs, or interpreting exhibits for guests.

\section{图 Requirements}

- Grade level: Entering 10th, 11th or 12th grade next fall

- Ages: At least 14 years old

- Demonstrate an eagerness to learn and to work with people of all ages and backgrounds

- Be proficient in English and comfortable with science vocabulary

- Volunteer for approximately eight-hour days as assigned

- Be available to attend all important program dates 
Monterey Bay Aquarium. 2021k. "Online courses."

https://www.montereybayaquarium.org/for-educators/learning-at-home/online-courses

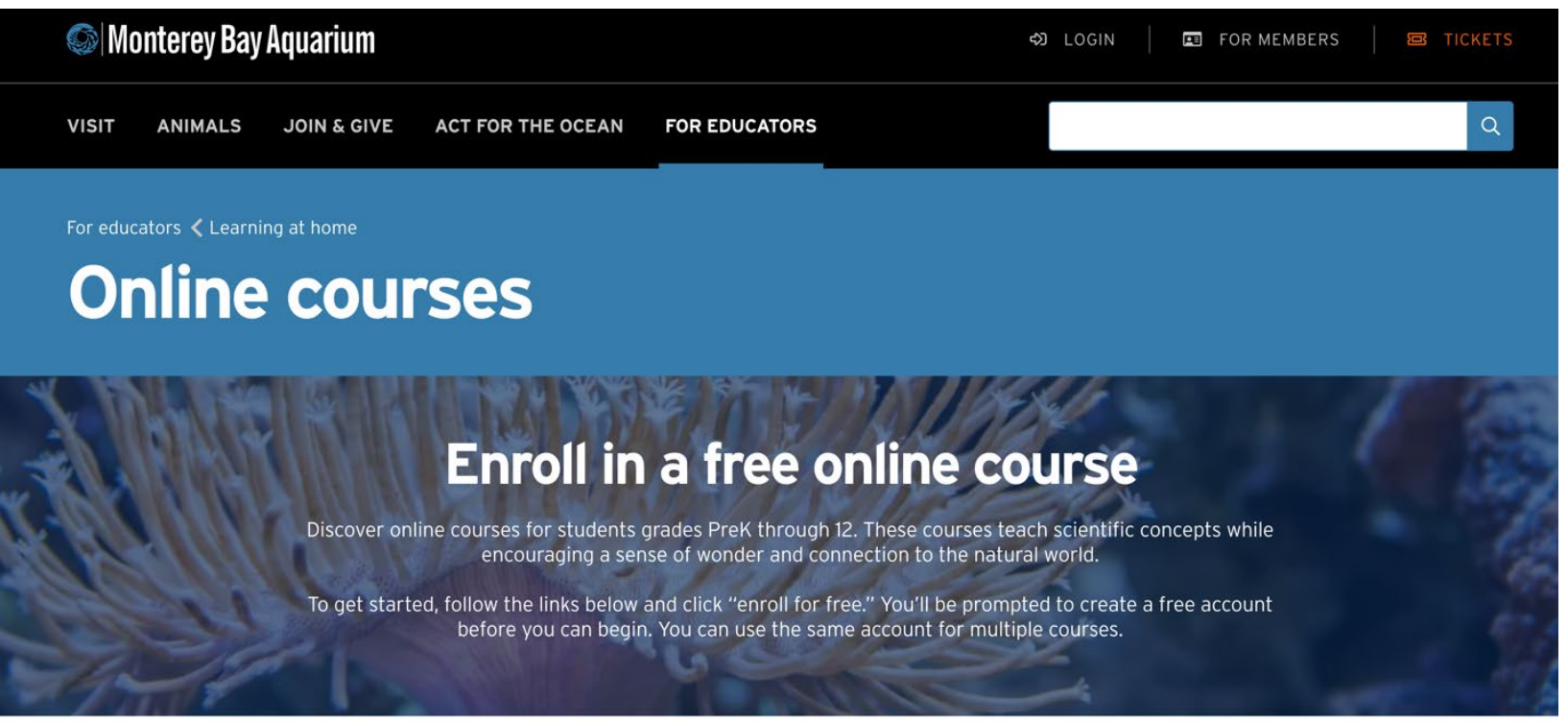

Grade level

Select

13 result(s)

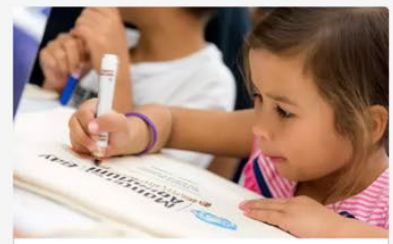

DNLINE COURS

Nurturing Naturalists

Parents and caregivers

This course provides tips for how you can
help your young child build trust in nature help your young child build trust in nat
and confidence as a learner. Specific

examples will support and inspire you to explore, wonder and learn alongside your curious child.

$\bigoplus$ Take the cours

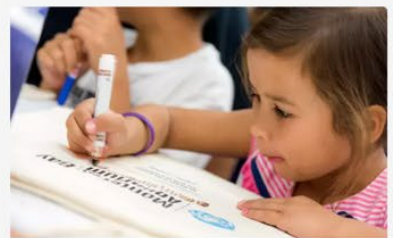

CURSO EN LINEA

\section{Inspirando Naturalistas}

\section{Padres y cuidadores}

Este curso contiene consejos de cómo

en la naturaleza y en sus habilidades de

aprendizaje. Ejemplos especificos te

ayudaran y te inspiraran a explorar, a sentir asombro y a aprender junto a tu curioso

$($ Toma el curso

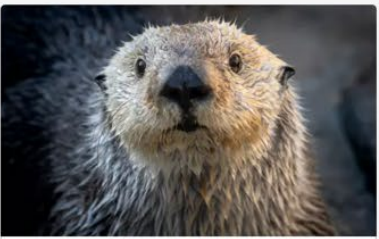

ONLINE COURSE

\section{Otter Spotters}

\section{Grades PreK-2}

Learn all about adorable sea otters and the kelp forest habitat they call home. Move like a sea otter and create your own sea olter observing otter behaviors just like a biologist would. This course is designed for students to do with the support of an adult or older sibling.

$\oplus$ Take the cours

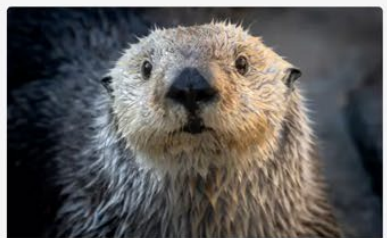

CURSO EN LINNEA

\section{Notando Nutrias}

Grados PreK-2

conoce todo acerca de las adorables nutrias ysobre ellugar que llaman hogar: el bosque marina y crea tu titere en forma de nutria marina usando materiales simples. Observ comportamiento de la nutria igual que lo haría un biólogo. Este curso está diseñado para que los estudiantes lo hagan con la

$๑$ Toma el curso 


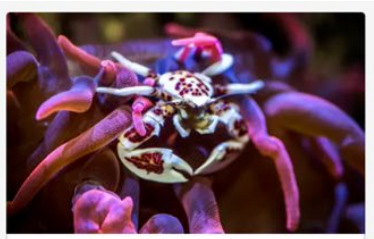

ONLINE COURSE

Tide Pool Scientist

Grades PreK-2

Learn about the rocky shore and some

the animals who live there. Create a tid

pool in your home, complete with anim

materials. Explore your tide pool with som

science tools and discuss how to care for

this ocean home with your loved ones. This

course is designed for students to do with

$(\oplus)$ Take the course

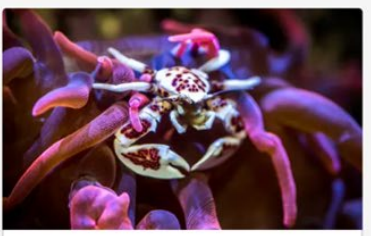

CURSO EN LINEA

Científic@ de Pozas de Marea

Grados PreK-2

Conoce acerca de la orilla rocosa y algunos de los animales que lo habitan. Crea una

podelos de animales que cognas con

materiales simples. Explora tu poza

marea usando algunas herramientas

cientificas y platica con tus seres queridos

curso esté diseñado parague los estudientes lo hagan con la ayuda de un adulto, herman o hermano mayor.

$(\oplus)$ Toma el curso

()) Take the course

Fin-tastic Sharks

Grades 3-5

Sharks are often misunderstood. Not al depicted he movies! in this course, you't

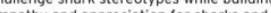
their diversity.

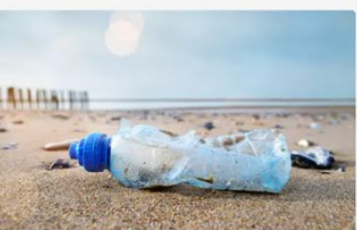

ONLINE COURSE

The Ocean, Plastic and $\mathrm{Me}$

Grades 6-8

Meet Makana and Alika - two Laysan animass Then reflect on how our cean can both positively and negatively affect these animals and marine ecosystems. Explore a faraway island, the ocean wat uncover how you're connected to the ocean we all share!

$(-$ Toma el curso $(\rightarrow$ Take the course

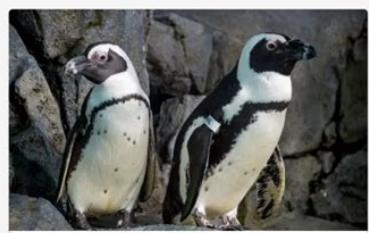

ONLINE COURSE

Birds on the Brain

Grades 3-5

Become a junior ornithologist by learning that make them unique. Learn how to set up your own science notebook, make careful through hands-on activities.

$(-)$ Take the course

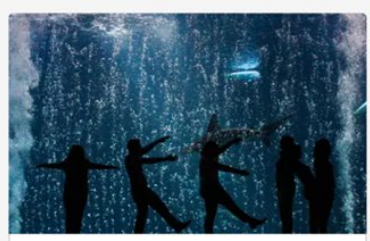

ONLINE COURSE

\#TeensCan Make a Difference

Grades 6-12

Are you ready to make a difference in this passions for our prent. interactive course influenced and inspired by teens to help you find your spark for conservation and take action.

$\Theta$ Take the course

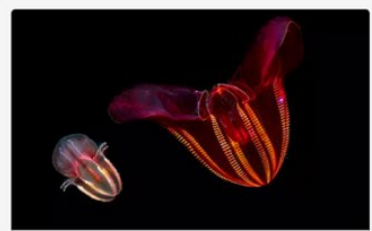

ONLINE COURSE

\section{Extreme Sea}

\section{Grades 7-12}

Explore the extreme depths of the ocean and how scientists have discovered the
animals that live there. Learn about the adaptations that help animals survive in the This course drew inspiration from The Extreme Life of the Sea by Anthony Palum and his father, Stanford professor Steve

$\Theta$ Take the course 
Monterey Bay Aquarium. 20211. “\#TeensCan Make a Difference (Grades 6-12).” https://montereybayaquarium.thinkific.com/courses/teenscan?_ga=2.244267525.1652520732.1632115848-487294886.1629255196

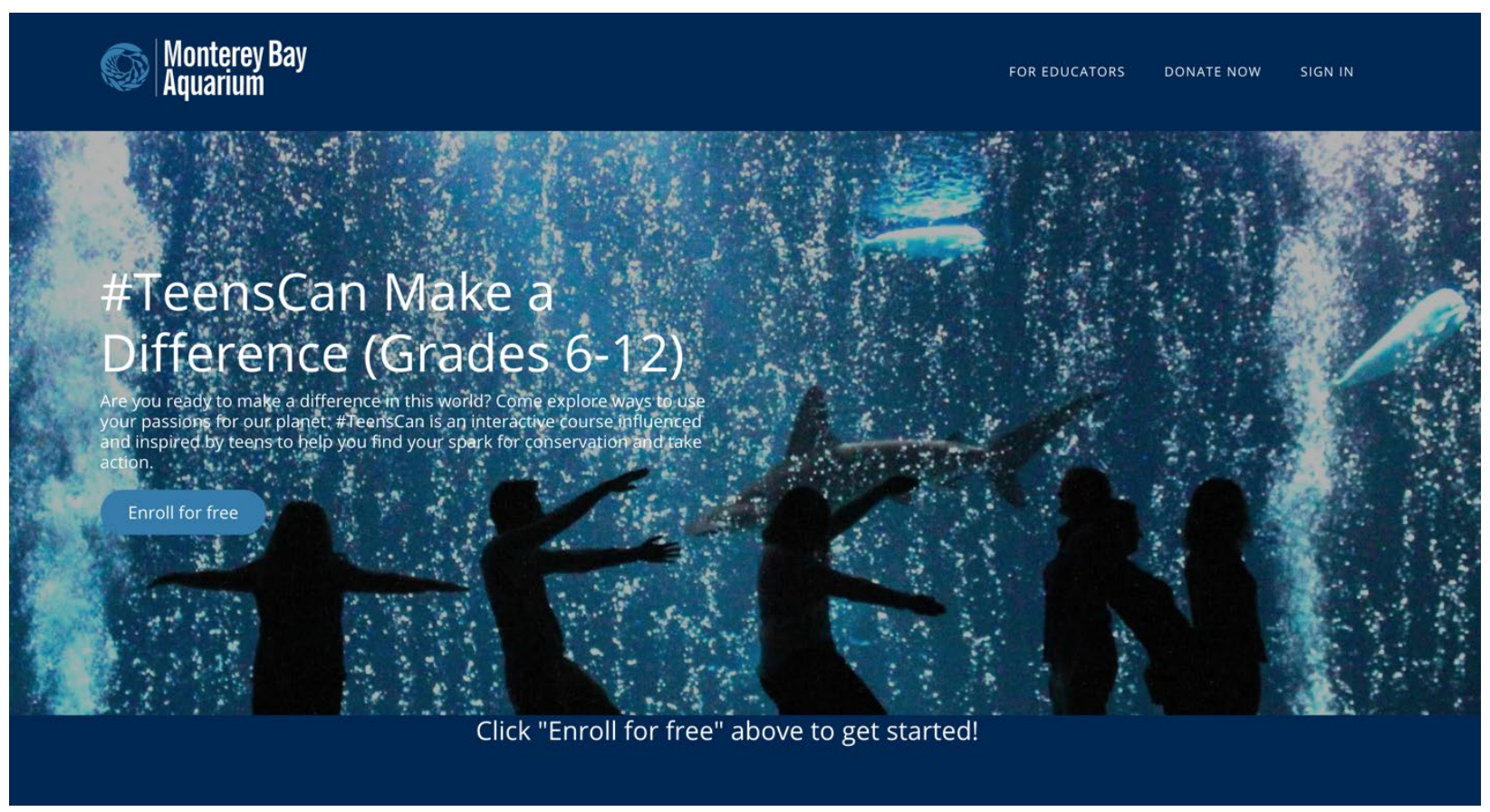

\section{Course curriculum}

\section{RETHINK}

How to use this course

Rethink, with Annarose

国 Welcome to \#TeensCan! 
2 RECREATE | RE-CREATE

From recreation to re-creation

$\square$ What's a spark?

正 Your spark!

$\square$ Eric's spark: recreate

The ocean connection

Are you an animal lover?

$\square$ Eric's Spark: re-create

Teen activists from around the globe

What sparks YOU?

西 My spark(s)

What system(s) do I want to impact?

$\square$ Make a systems map

Te-create your world

3 REPURPOSE

$\square$ Repurpose, with Tabitha

$\square$ How does this work?

플 Repurpose

$\square 0$ How to: Make your own t-shirt bag

Repurpose food waste

뜻 How to: Compost

Tx. Composting tips

How to: Make your own tie dye, with Andrea

Share your creation with \#TeensCan 


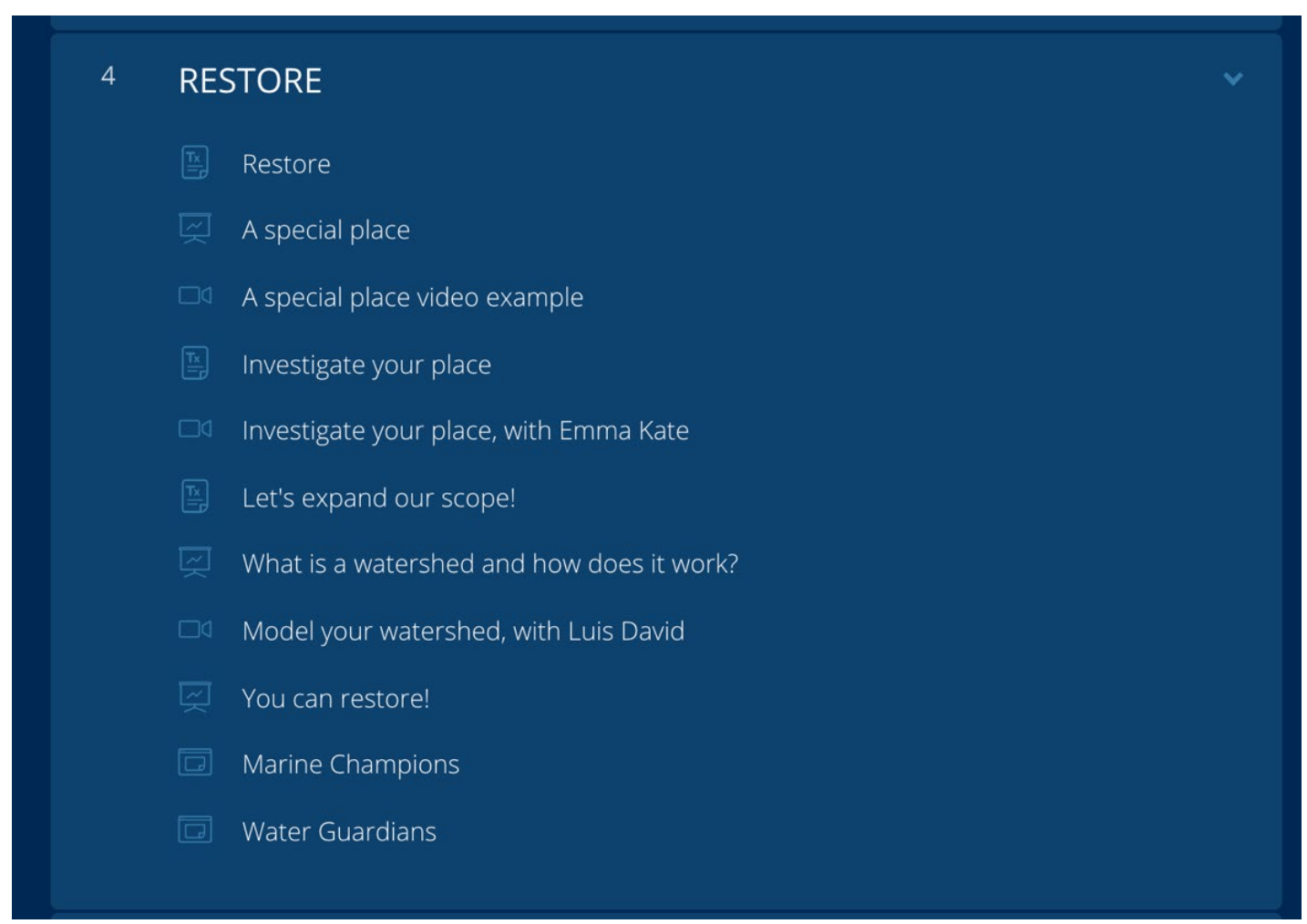

5 REACH
囷 Find your voice
즙 Social media activism
[ Reach others online, with Angelica
Instagram for action
Using blogs to convey your message
The punny side of social media
(들 Create your own brand, with Annarose

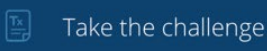

\section{REGISTER}
Your voice matters
Not 18? Pre-register
졸 Can't vote?
[0 Remember: \#TeensCan make a difference 
REFLECT

Reflection

Reflect with mindfulness

8 RESOURCES

Meet our collaborators

풀 Dig deeper 